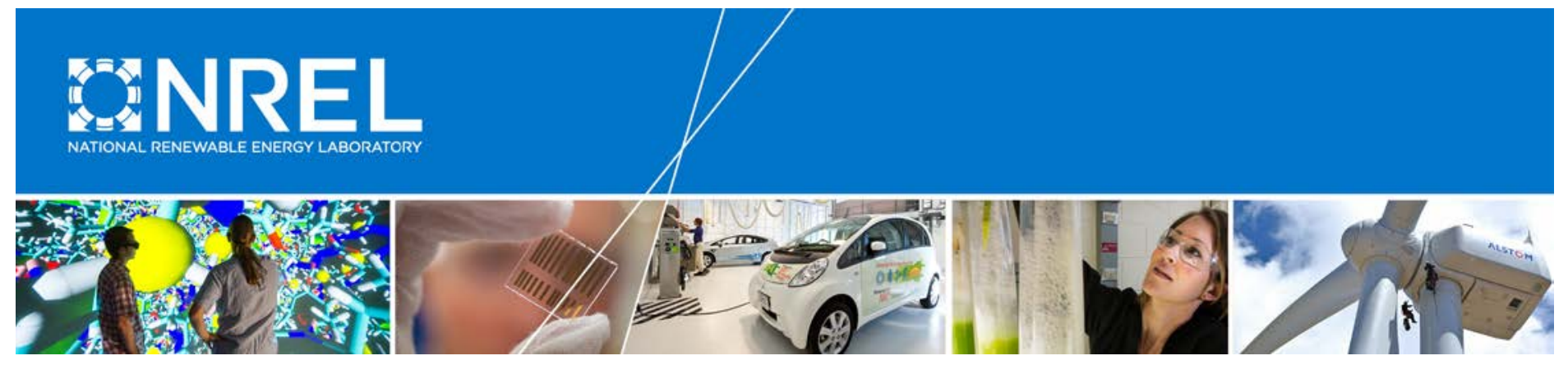

\title{
The Distributed Generation Market Demand Model (dGen): Documentation
}

Benjamin Sigrin, Michael Gleason, Robert Preus, lan Baring-Gould, and Robert Margolis National Renewable Energy Laboratory

NREL is a national laboratory of the U.S. Department of Energy Office of Energy Efficiency \& Renewable Energy Operated by the Alliance for Sustainable Energy, LLC

This report is available at no cost from the National Renewable Energy Laboratory (NREL) at www.nrel.gov/publications.

Technical Report

NREL/TP-6A20-65231

February 2016 


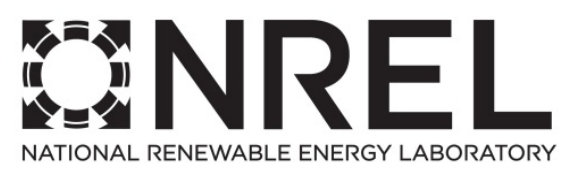

\title{
The Distributed Generation Market Demand Model (dGen): Documentation
}

\author{
Benjamin Sigrin, Michael Gleason, Robert Preus, \\ Ian Baring-Gould, and Robert Margolis \\ National Renewable Energy Laboratory
}

Prepared under Task Nos. WE14.2H01, SS13.1010

NREL is a national laboratory of the U.S. Department of Energy Office of Energy Efficiency \& Renewable Energy Operated by the Alliance for Sustainable Energy, LLC

This report is available at no cost from the National Renewable Energy Laboratory (NREL) at www.nrel.gov/publications.

National Renewable Energy Laboratory 15013 Denver West Parkway Golden, CO 80401 303-275-3000 • www.nrel.gov

\section{Technical Report}

NREL/TP-6A20-65231

February 2016

Contract No. DE-AC36-08GO28308 


\section{NOTICE}

This report was prepared as an account of work sponsored by an agency of the United States government. Neither the United States government nor any agency thereof, nor any of their employees, makes any warranty, express or implied, or assumes any legal liability or responsibility for the accuracy, completeness, or usefulness of any information, apparatus, product, or process disclosed, or represents that its use would not infringe privately owned rights. Reference herein to any specific commercial product, process, or service by trade name, trademark, manufacturer, or otherwise does not necessarily constitute or imply its endorsement, recommendation, or favoring by the United States government or any agency thereof. The views and opinions of authors expressed herein do not necessarily state or reflect those of the United States government or any agency thereof.

This report is available at no cost from the National Renewable Energy Laboratory (NREL) at www.nrel.gov/publications.

Available electronically at SciTech Connect http:/www.osti.gov/scitech

Available for a processing fee to U.S. Department of Energy and its contractors, in paper, from:

U.S. Department of Energy

Office of Scientific and Technical Information

P.O. Box 62

Oak Ridge, TN 37831-0062

OSTI http://www.osti.gov

Phone: 865.576.8401

Fax: 865.576.5728

Email: reports@osti.gov

Available for sale to the public, in paper, from:

U.S. Department of Commerce

National Technical Information Service

5301 Shawnee Road

Alexandria, VA 22312

NTIS http://www.ntis.gov

Phone: 800.553 .6847 or 703.605 .6000

Fax: 703.605.6900

Email: orders@ntis.gov 


\section{Acknowledgments}

The U.S. Department of Energy Solar Energy Technologies and Wind and Water Technologies Programs funded this project. We thank Wesley Cole, Easan Drury, Trudy Forsyth, Tony Jimenez, Eric Lantz, Trieu Mai, Christopher Mone, and Jarett Zuboy for input and assistance on this project. Opinions represented in this article are the authors' own and do not reflect the view of the U.S. Department of Energy or the U.S. Government. This work was supported by the U.S. Department of Energy under contract number DE-AC36-08GO28308. 


\section{List of Acronyms and Abbreviations}

$\begin{array}{ll}\text { CBECS } & \text { Commercial Building Energy Consumption Survey } \\ \text { CSP } & \text { concentrating solar power } \\ \text { DER } & \text { distributed energy resource } \\ \text { dGen } & \text { Distributed Generation Market Demand (model) } \\ \text { DHS } & \text { U.S. Department of Homeland Security } \\ \text { DOE } & \text { U.S. Department of Energy } \\ \text { DSIRE } & \text { Database of State Incentives for Renewables \& Efficiency } \\ \text { DSM } & \text { digital surface model } \\ \text { EIA } & \text { U.S. Energy Information Administration } \\ \text { GIS } & \text { geographic information system } \\ \text { HSIP } & \text { Homeland Security Infrastructure Program } \\ \text { kWh } & \text { kilowatt-hour } \\ \text { kW } & \text { kilowatts } \\ \text { LCOE } & \text { levelized cost of energy } \\ \text { LiDAR } & \text { light detection and ranging } \\ \text { NREL } & \text { National Renewable Energy Laboratory } \\ \text { NSRDB } & \text { National Solar Radiation Database } \\ \text { PV } & \text { photovoltaic(s) } \\ \text { R\&D } & \text { research and development } \\ \text { RECS } & \text { Residential Energy Consumption Survey } \\ \text { ReEDS } & \text { Regional Energy Deployment System (model) } \\ \text { SAM } & \text { System Advisor Model } \\ \text { SolarDS } & \text { Solar Deployment Systems (model) } \\ \text { TMY } & \text { typical meteorological year } \\ \text { TOU } & \text { time of use } \\ \text { TPO } & \text { third-party ownership } \\ \text { URDB } & \text { Utility Rate Database } \\ \text { VRRE } & \text { variable renewable resource energy } \\ & \end{array}$




\section{Executive Summary}

The Distributed Generation Market Demand (dGen) model is a geospatially rich, bottom-up, market-penetration model that simulates the potential adoption of distributed energy resources (DERs) for residential, commercial, and industrial entities in the continental United States through 2050. The National Renewable Energy Laboratory (NREL) developed dGen to analyze the key factors that will affect future market demand for distributed solar, wind, storage, and other DER technologies in the United States within a single modeling platform. The dGen model builds on, extends, and provides significant advances (Table ES-1) over NREL's SolarDS model (Denholm et al. 2009), which is now deprecated.

Currently, dGen simulates the adoption of distributed solar (the dSolar module) and distributed wind (the dWind module), as described in detail in Appendices A and B, respectively. The dGen team will add modules in FY16 for behind-the-meter storage (dStorage) as well as a module for evaluating distributed geothermal systems (dGeo), such as ground-source heat pumps and geothermal direct use. The model is also configured to link with utility scale capacity expansion models maintained and applied at NREL (see Appendix C). All technologies modeled within the dGen framework leverage a database of highly resolved geospatial information (Figure ES-1), along with algorithms for modeling DER economics, customer decision-making, and diffusion of technology over time.

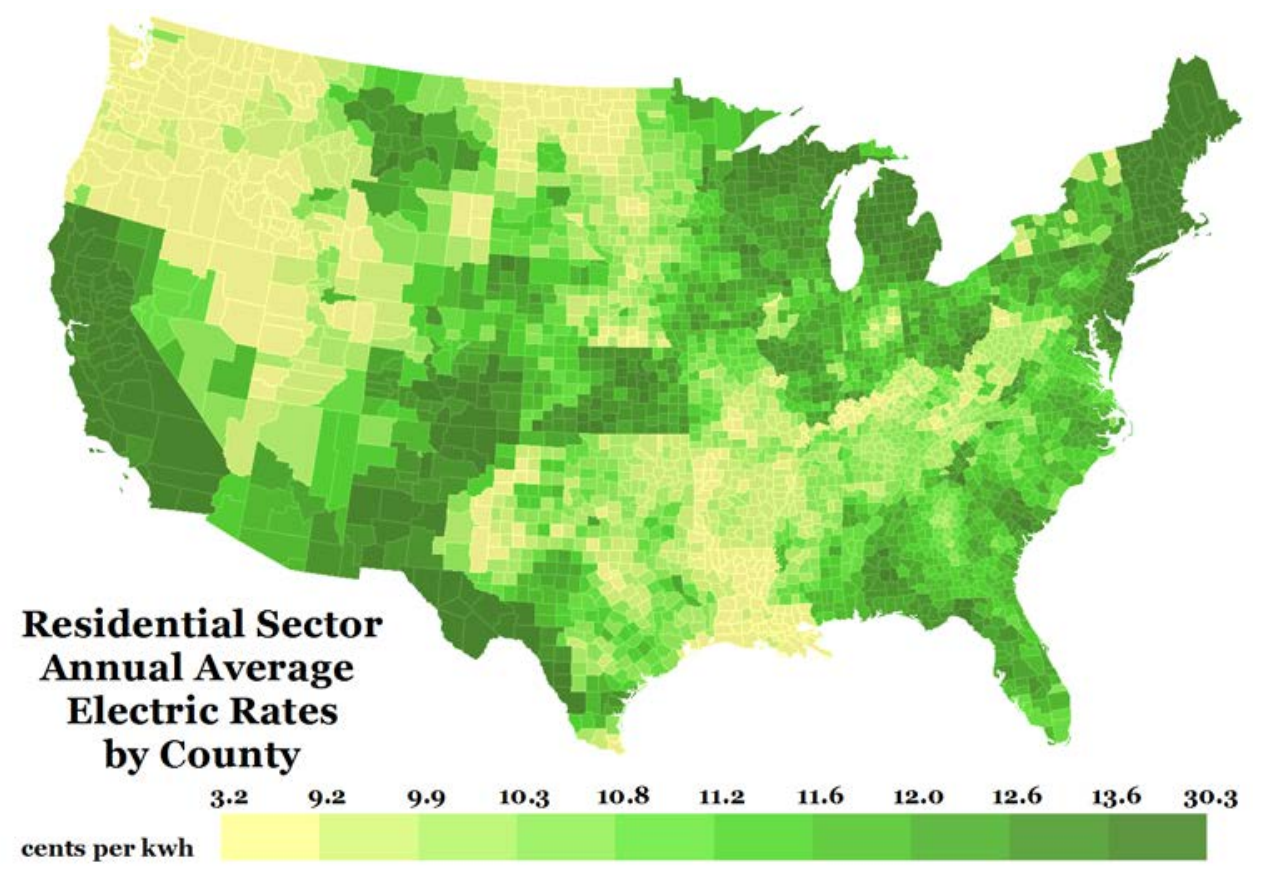

Figure ES-1. Residential sector annual average electric rates by county (2012)

dGen uses several high-resolution data sets, such as 2012 average electric rates by county. Examples of other high resolution data sets supporting the model include wind resource (200 m resolution), solar resource (10 km resolution), and local and state policy incentives. 
In dGen, market diffusion of DER technologies is simulated in two-year intervals from 2014 through 2050 based on various market factors for the residential, commercial, and industrial sectors within each county in the United States. The consumer demand is modeled through an agent-based approach that includes five steps (Figure ES-2):

1. Generating agents (i.e., potential customers) and assigning them attributes based on a probabilistic representation of individual customer types

2. Applying technical and siting restrictions, such as resource quality, rooftop availability (solar), and parcel size and canopy height (wind) to develop measures of resource availability and quality for each of those agents

3. Performing economic calculations using cash flow analysis incorporating project costs, prevailing retail rates, incentives, and net metering considerations

4. Calculating market share of each technology by simulating technology adoption based on Bass-style adoption and other considerations of consumer behavior

5. Generating automated output reports, including visualizations and tabular reporting of annual and cumulative capacity deployed, number of systems installed, system generation, and multiple other measures of technical and economic performance

Users of dGen can simulate the market potential for solar and wind independently, which assumes there is no competition between technologies. Ongoing model development, to be documented in future work, includes the addition of a module to facilitate customer choice between wind and solar, as competing technologies. Results are presented at the state and national levels for several key metrics, including adoption penetration, cumulative and annual installed capacity, generation, market value, and levelized cost of energy.

Table ES-1. Key Differences between the dGen and SolarDS (Deprecated) Models

\begin{tabular}{|l|l|l|}
\cline { 2 - 3 } \multicolumn{1}{l|}{} & dSolar & SolarDS \\
\hline Model scope & $\begin{array}{l}\text { U.S. national model over two-year time slices } \\
\text { for residential, commercial, and industrial } \\
\text { sectors. Considers multiple DER } \\
\text { technologies (solar, wind, storage, } \\
\text { geothermal) in isolation or in competition. } \\
\text { Easily scales to study state or local issues. }\end{array}$ & $\begin{array}{l}\text { U.S. national model over two-year } \\
\text { time slices for residential and } \\
\text { commercial, sectors. DGPV focus } \\
\text { only }\end{array}$ \\
\hline $\begin{array}{l}\text { Customer } \\
\text { resolution }\end{array}$ & $\begin{array}{l}\text { Reformatted as agent-based model (see } \\
\text { Section II). Customers defined as } \\
\text { statistically-representative entities that } \\
\text { sample from regional/local distributions for } \\
\text { attribution. }\end{array}$ & $\begin{array}{l}\text { Customers types generated based } \\
\text { on 'binned' approach; Bins are } \\
\text { created to represent variation in } \\
\text { scenario parameters using ad hoc } \\
\text { bin frequencies. }\end{array}$ \\
\hline
\end{tabular}




\begin{tabular}{|l|l|l|}
\cline { 2 - 3 } \multicolumn{1}{c|}{} & dSolar & SolarDS \\
\hline $\begin{array}{l}\text { Use of } \\
\text { geographic } \\
\text { information } \\
\text { systems (GIS) }\end{array}$ & $\begin{array}{l}\text { Extensive use of geospatial data; all agents } \\
\text { assigned point-location based on sector and } \\
\text { population-weighted sampling. GIS } \\
\text { framework permits integration and addition of } \\
\text { disparate data sets under common } \\
\text { framework. Default resolution at U.S. county } \\
\text { level (3,108) and 10 agents per county- } \\
\text { sector }\end{array}$ & $\begin{array}{l}\text { Limited use of geographic data. } \\
\text { Customers not assigned a point- } \\
\text { location. Default resolution at sub- } \\
\text { state (218) level. }\end{array}$ \\
\hline $\begin{array}{l}\text { Costs of } \\
\text { electricity }\end{array}$ & $\begin{array}{l}\text { Based on OpenEI Utility-Rate Database, } \\
\text { calculates bill savings "bottoms-up" using } \\
\text { hourly generation and consumption profiles, } \\
\text { incorporating demand charges TOU charges, } \\
\text { etc. }\end{array}$ & $\begin{array}{l}\text { Based on ElA 861 average costs of } \\
\text { electricity by state; time-of-use } \\
\text { charges pre-calculated using } \\
\text { multiplier on average rates }\end{array}$ \\
\hline
\end{tabular}

Model users can customize numerous parameters related to current and future DER performance improvements and cost reductions, customer financing structures, market projections (e.g., load and rate growth), siting criteria, and incentive and net metering policies. With these inputs, model users can investigate the effects of a diverse set of scenarios on market potential and identify the critical market factors that drive end-use demand. In this capacity, dGen can be a powerful tool for exploring pathways through which the U.S. DER market could develop and identifying the effects of various factors on DER market growth.

This report documents the dGen model framework, algorithms, and underlying assumptions. This report does not present results using the model, which will be released in separate follow-on documents. The primary intent of this document is to explain our methods in a way that will enable other modelers and analysts to build on our approach. 


\section{Table of Contents}

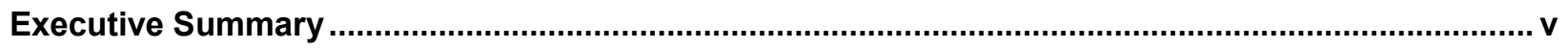

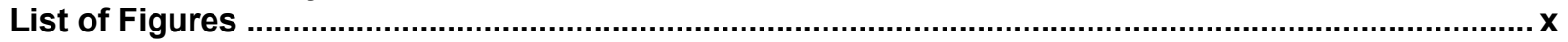

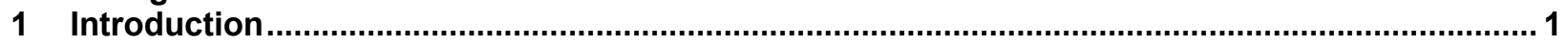

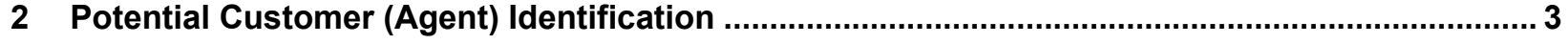

2.1 Methodology for Categorizing Agents ...................................................................... 3

2.1.1 Assigning Attributes to Agent Locations ............................................................ 3

2.1.2 Sampling Potential Locations......................................................................... 5

2.1.3 Sampling Agent Annual Electric Load .............................................................. 5

2.2 Advantages and Limitations of dGen Agent-Based Approach ..........................................6

2.2.1 Generation of Statistically Probable Representations of Agent Types.........................6 6

2.2.2 Decreased Model Bias and Quantified Model Uncertainty....................................... 7

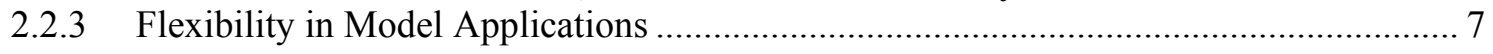

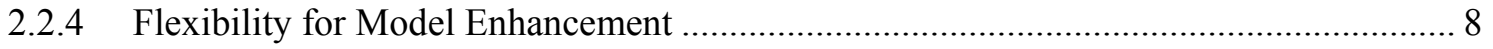

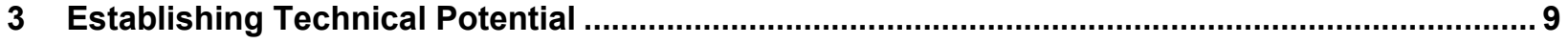

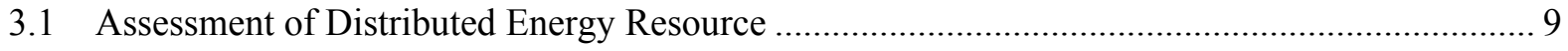

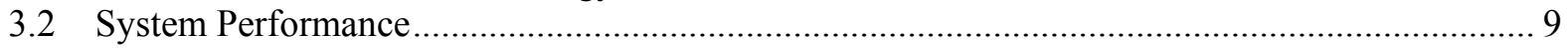

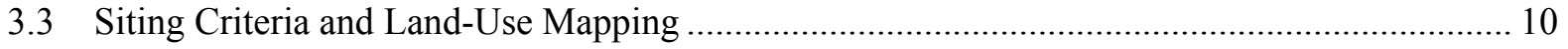

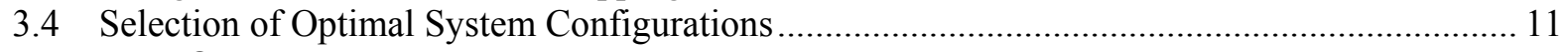

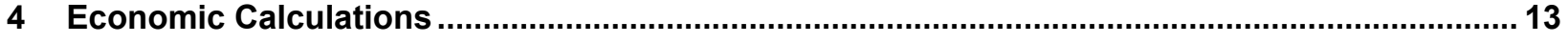

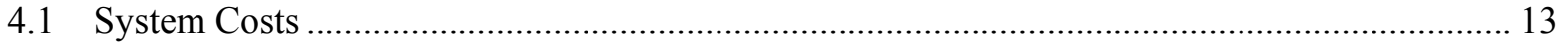

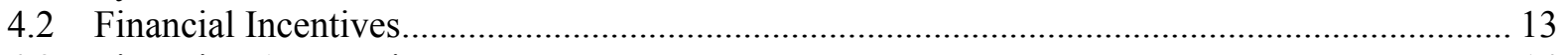

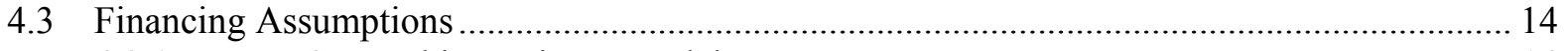

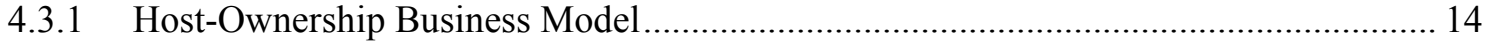

4.3.2 Third-Party Ownership Business Model .................................................... 14

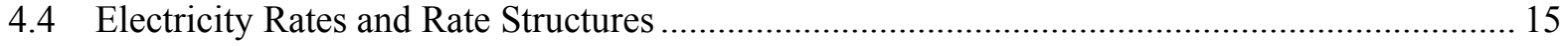

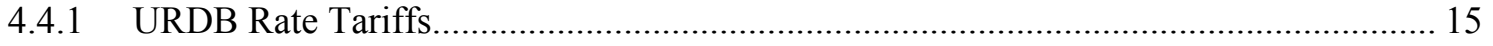

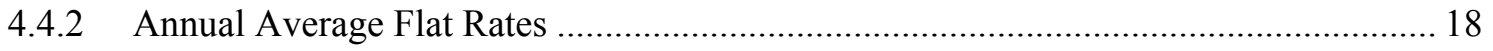

4.4.3 User-Defined Flat Rates .............................................................................. 19

4.5 Excess Generation Value (Net Metering) .............................................................. 19

4.6 Bill Savings Calculator........................................................................................... 20

4.7 Value of Avoided Carbon Emissions ...................................................................... 20

4.8 Cash Flow Analysis......................................................................................... 20

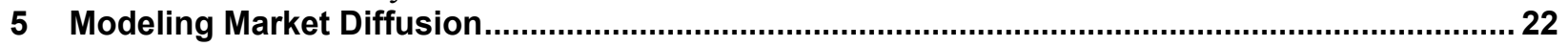

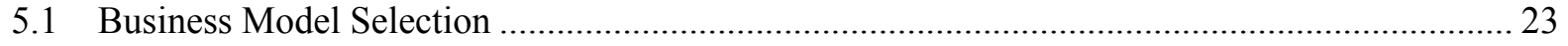

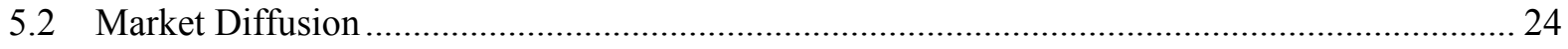

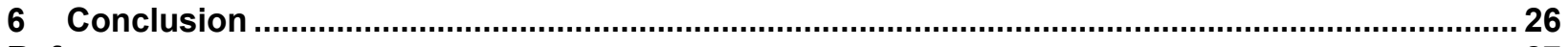

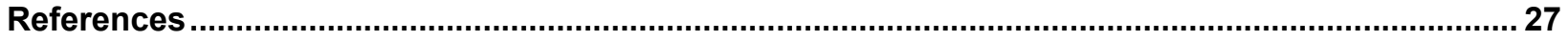

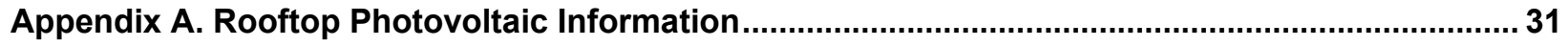

A1. Solar Resource .................................................................................................. 31

A2. Rooftop Technical Potential ................................................................................... 32

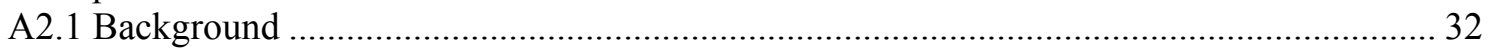

A2.2 Technical Potential Caps ................................................................................. 33

A2.3 Regional Variation in Rooftop Configuration .................................................. 33

Appendix B. Distributed Wind Information ............................................................................... 41

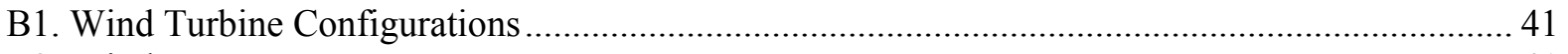

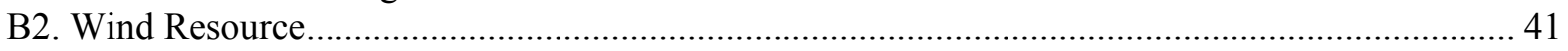

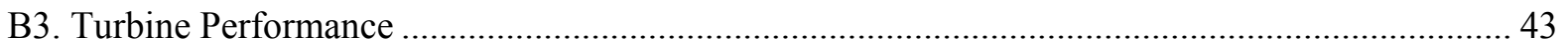

B4. Turbine Height and Size Restrictions ....................................................................... 46

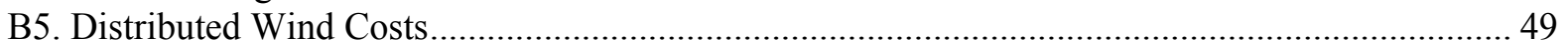

Procedure Summary for Current Installed Costs....................................................... 49 


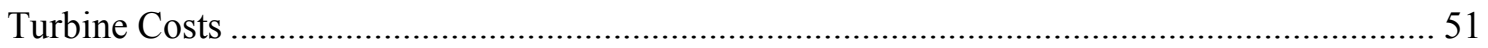

Height as a Function of Rated Power........................................................................ 51

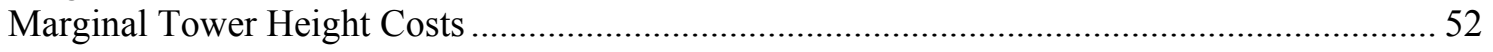

Final Cost Data for Model Input ............................................................................. 52

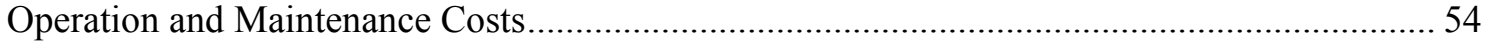

Appendix C. Linkage with ReEDS Capacity Expansion Model .......................................................56

Appendix D. Calibrated Bass Parameters ..................................................................................6 60 


\section{List of Figures}

Figure ES-1. Residential sector annual average electric rates by county $(2012)$...................................... Figure 1. Comparison of dGen residential customer locations to land legally zoned for residential use in Boulder, Colorado....

Figure 2. Summary of optimal wind turbine sizes and hub heights for each market segment................... 12

Figure 3. Geographic coverage of rates from the URDB used in dGen................................................ 16

Figure 4. Annual average electricity rates for residential customers by county ..................................... 19

Figure 5. Annual and cumulative adoption rates simulated using the diffusion of innovations

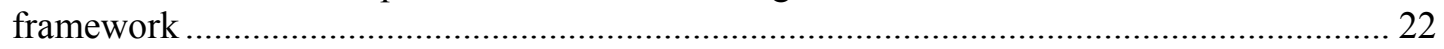

Figure 6. Maximum market share as a function of payback period based on different sources ................ 23

Figure A-1. Map of PV resource derived from NSRDB 10-km Gridded Hourly Solar Radiation Database .......................................................................................... 31

Figure A-2. Distance to the nearest residential, commercial, and industrial presence cells ...................... 34

Figure A-3. Daytime and nighttime population in Boulder, CO....................................................... 35

Figure A-4. Example of building footprint size in an area of Boulder, $\mathrm{CO}$........................................... 35

Figure A-5. Map illustrating the accuracy of classifying residential and non-residential buildings in

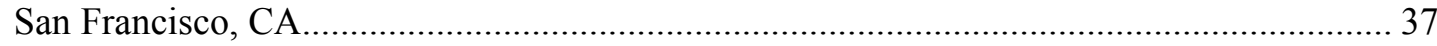

Figure B-1. Annual average gross capacity factor for a modeled International Electrotechnical Commission Class II turbine at an 80-m hub height and $200 \mathrm{~m}$ horizontal resolution ........... 42

Figure B-2. Normalized wind turbine power curves used to calculate power production based on size and technology evolution.....

Figure B-3. Workflow illustrating the analysis used to develop and combine each of the factors that affects the range of developed turbine hub heights at each customer location ...................... 46

Figure B-4. Procedure for determining installed cost values used for wind in dGen ............................. 50

Figure B-5. Wind turbine operation and maintenance cost assumptions by size used in dGen................. 55

Figure C-1. ReEDS map showing the ReEDS regional structure ...................................................... 57

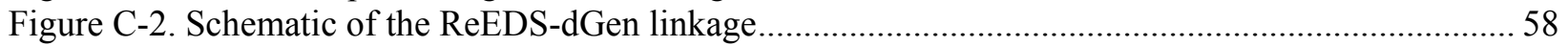




\section{List of Tables}

Table ES-1. Key Differences between the dGen and SolarDS (Deprecated) Models ............................... vi

Table 1. Key Data Sets used to Characterize dGen Model Agents......................................................... 4

Table 2. Default Financing Assumptions for Host-Owned Systems by Sector ........................................ 14

Table 3. Financing Assumptions for Third-Party-Owned Systems by Sector .......................................... 15

Table 4. User Input for Defining the Relative Prevalence of Different Rate Structures, by Sector ........... 17

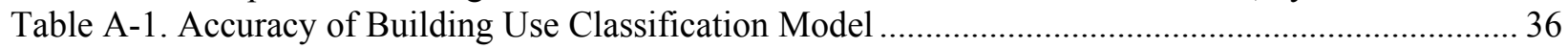

Table B-1. Wind Turbine Configurations included in in the dGen Model ............................................ 41

Table B-2. Baseline 2015 Distributed Wind Turbine Performance ........................................................ 44

Table B-3. Future Performance Characteristics for the Turbines used in dGen ................................... 45

Table B-4. User Input Defining Minimum Parcel Size Required for Each Turbine Hub Height, Populated with Current Default Values ..................................................................................................... 47

Table B-5. User Input Defining the Maximum Allowable Percent of Heavily Developed Land at Each Agent Location for Each Turbine Hub Height, Populated with Current Default Values....... 48

Table B-6. User Input Defining the Canopy Clearance Required for Each Turbine Size (i.e., Rated Capacity), Populated with Current Default Values .............................................................. 48

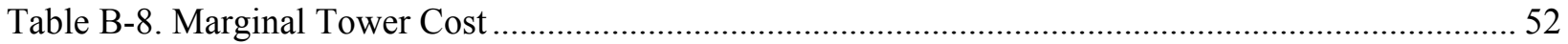

Table B-9. Comparison of Actual Tower Height Ranges to the Ranges used in the Model...................... 53

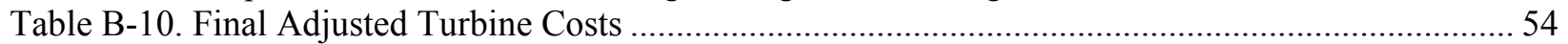

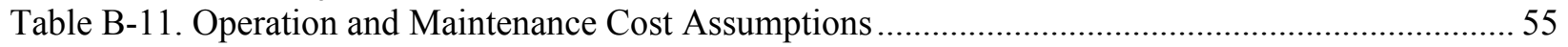

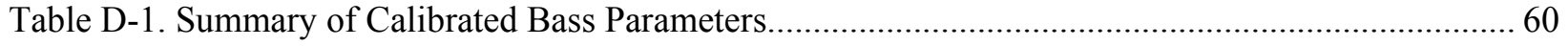

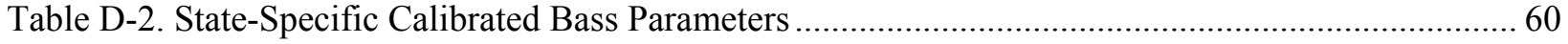




\section{Introduction}

The Distributed Generation Market Demand model (dGen) was developed by the National Renewable Energy Laboratory (NREL) as a tool to analyze the key factors that will affect future market demand for distributed energy resource (DER) technologies in the United States. The model is capable of simulating the adoption of distributed solar (via its dSolar module) and distributed wind (via its dWind module), and it has been designed explicitly to facilitate incorporation of additional technologies. It can analyze the impact of several market drivers on DER market potential, including research and development (R\&D) driven price and performance improvements, financial rebates, net energy metering (or other methods of valuing DER energy exports to the grid), retail electricity rates and rate structures, and other factors.

Behind-the-meter DER demand is simulated by dGen at two-year increments from 2014 through 2050 for residential, commercial, and industrial customers. It builds on, extends, and provides significant advances over NREL's Solar Deployment Systems (SolarDS) model (Denholm et al. 2009; Drury et al. 2013). SolarDS was developed to explore rooftop photovoltaic (PV) market demand, and it has been used to inform solar market evolution for the SunShot Vision Study (DOE 2012), the Renewable Electricity Futures study (Hand et. al. 2012), and the recent Wind Vision study (DOE 2015). Though many of same parameterizations and assumptions used in SolarDS are also used in dGen, the updated model provides significant advances including: access to updated and more highly databases, new and refined algorithms for modeling DER economics, customer decisions, and diffusion of technology, and a flexible framework capable of extending to additional DER technologies (e.g., batteries, ground source heat pumps, etc.).

SolarDS stimulated development of a common modeling platform that could simulate the market demand of multiple DER technologies, with a consistent set of parameters and algorithms used to simulate customer adoption but with appropriate distinctions for individual technologies. Under the current dGen platform, users may simulate the diffusion of distributed solar or distributed wind individually, assuming no competition between the technologies. Ongoing model development, which will be documented in future work, includes the addition of a module to facilitate customer choice between wind and solar, as competing technologies. Similar to SolarDS, dGen is fundamentally geospatial, capturing regional variation in the underlying factors that affect market demand across the United States; however, the dGen model captures spatial relationships at a significantly higher level of detail than SolarDS using an updated and expanded geospatial database.

The increased spatial resolution of dGen compared to SolarDS not only permits more robust deployment forecasts but also permits more sophisticated analyses of those forecasts. Examples of analyses include correlating DER adoption forecasts with socio-demographic data and electric vehicle purchases and overlaying deployment forecasts with distribution networks to improve understanding of local impacts of high levels of DER adoption. Nearly all data in the model is mapped spatially; site-specific parameters are then linked with locally and regionally variable data sets of other market factors through the data backbone, such as electricity rates and rate structures, policy incentives, and electricity demand. These data sets are combined within a geographic information system to model market penetration at the county and parish levels, and results are aggregated to the state and national levels. 
The remainder of this report describes the methods, data, and assumptions behind each major aspect of dGen: agent identification (Section 2), technical potential (Section 3), economic calculations (Section 4), market diffusion (Section 5), and future work (Section 6). A set of appendices provides additional information on PV and wind applications of dGen as well as the linking of dGen and NREL's Regional Energy Deployment System (ReEDS) model. 


\section{Potential Customer (Agent) Identification}

Forecasting the deployment of DERs requires different approaches than forecasting the capacity expansion of utility-scale resources (e.g., PNNL 2012; Short et al. 2011), because DER investment decisions are made by individuals, not profit-maximizing firms. Other important differences are that DER value is typically determined by offsetting energy consumption at the retail (not wholesale) level, DER technologies are relatively unproven and thus have considerable scope for cost/performance improvement, and nonfinancial technology characteristics (e.g., novelty, appearance, and conferred status) can influence the DER adoption decision. For these reasons, dGen simulates the market adoption of DERs through an aggregation of individual adoption decisions made by potential residential and nonresidential customers called "agents."

To capture the variation in attributes driving DER adoption, dGen uses a statistical framework to represent the individual-level characteristics through a set of agents for every county in the United States. Each agent is assigned a set of attributes representing a likely configuration-such as location, system capacity, and annual electricity consumption-by sampling from distribution of the same parameters. Additionally, agents are assigned a weighting factor corresponding to the number of similar customers they represent within the county. This framework reflects two key principles: 1) investment decisions are made at the individual level based on the agent's attributes and 2) a sampling-based approach accurately represents the variability in the population and thus improves the determination of attributes that predict adoption.

\subsection{Methodology for Categorizing Agents}

The methodology for categorizing potential agents includes three main steps: 1) assigning attributes to possible system-installation locations, 2) sampling from possible system locations, and 3) sampling end-user annual energy demand (combination of electrical (kWh) and fuel use (MMBtu)). This process reflects our core assumption that location and end-user energy consumption are the most important and heterogeneous attributes for determining an agent's propensity for adoption. At a high-level, the model uses a $200 \mathrm{~m}$ by $200 \mathrm{~m}$ point grid to represent locations of individual agents, which are then aggregated to the county level.

\subsubsection{Assigning Attributes to Agent Locations}

The first step in characterizing agent types is to assign attributes to all potential agent locations based on land-use grids (spatial layers). Each land-use grid represents the set of potential location(s) of agents within a given market segment at the resolution of a $200 \mathrm{~m}$ by $200 \mathrm{~m}$ cell for the continental United States; the location of each cell is used to associate additional spatially dependent attributes (Table 1). Note that the data sets in Table 1 represent the initial data upon which the model is based; several of these data sets are easily updatable and may be replaced with more current versions during future model maintenance and development. 
Table 2. Key Data Sets used to Characterize dGen Model Agents

\begin{tabular}{|l|l|l|}
\hline Data Set & Source & Spatial Resolution \\
\hline $\begin{array}{l}\text { Resource Quality - Annual Energy } \\
\text { Production }\end{array}$ & $\begin{array}{l}\text { AWST 2012a, AWST } \\
\text { 2012b, Dobos 2015, } \\
\text { George et al. 2007, } \\
\text { NSRDB 2015 }\end{array}$ & 200 m by 200 m \\
\hline Potential Agent Locations & ORNL 2011, HSIP 2012 & 200 m by 200 m \\
\hline $\begin{array}{l}\text { Additional Technology-Dependent Siting } \\
\text { Criteria (e.g., roof orientation, minimum } \\
\text { and maximum turbine heights) }\end{array}$ & $\begin{array}{l}\text { ORNL 2011, HSIP 2012, } \\
\text { Gagnon et al. (2015) }\end{array}$ & 200 m by 200 m \\
\hline $\begin{array}{l}\text { Prevailing Retail Electricity Rates (2014) } \\
\text { Applicable Incentive Policies }\end{array}$ & OpenEI 2014 & $\begin{array}{l}\text { Electric Utility Service } \\
\text { Territories }\end{array}$ \\
\hline Existing Net-Metering Availability & DSIRE 2014 & $\begin{array}{l}\text { Variable: } \\
\text { Electric Service Territories, } \\
\text { County, State, Nation }\end{array}$ \\
\hline Total Annual Electric Load by County & Barnes et al. 2013 & State \\
\hline $\begin{array}{l}\text { Total Count of Electric Customers by } \\
\text { County }\end{array}$ & Ventyx 2012 & County \\
\hline $\begin{array}{l}\text { Microdata Representations of Customer- } \\
\text { Level Electric Load }\end{array}$ & EIA 2008 & County \\
\hline Load Growth Projections & EIA 2015b & $\begin{array}{l}\text { Census divisions (multistate } \\
\text { regions) }\end{array}$ \\
\hline Electricity Rate Projections & EIA 2015b & $\begin{array}{l}\text { Census divisions (multistate } \\
\text { regions) }\end{array}$ \\
\hline Financing Parameters & DOE 2012 2012 & Nation \\
\hline Capital Cost Projections & DOE 2012 & Nation \\
\hline R\&D-Based Performance Improvements & Nation \\
\hline
\end{tabular}

Because each agent is assigned an actual location, each potential agent can be associated with a number of attributes from data sets in the underlying geospatial database (or "data backbone") using a simple spatial overlay (i.e., intersection). In the agent-generation step, each customer location is attributed with annual and hourly energy production for a set of possible system configurations, ${ }^{1}$ technology-specific siting parameters governing technical feasibility (e.g., roof slope or maximum turbine height), prevailing financial incentives, electricity rates and rate structures, and existing net-metering policies or policies for valuing excess system production exported to the grid. Several other key customer attributes - such as capital costs, financing options, and other market projections - are resolved only at the state, regional, or national level. This process of spatial overlay results in a nearly complete characterization of the attributes at each $200 \mathrm{~m}$ by $200 \mathrm{~m}$ potential customer location.

\footnotetext{
${ }^{1}$ In the agent-generation stage, each agent considers a set of possible configurations, many of which are untenable. In the economics module, the agent will "choose" a single configuration that offsets a given fraction of their energy consumption while maximizing their utility (if any such configurations exist).
} 


\subsubsection{Sampling Potential Locations}

Because the land-use grids represent potential agent locations rather than known customer locations, they are interpreted in the model as the statistical pool of possible configurations of customer attributes that exist within the county, not the discrete population of every potential customer in the county. Additionally, there are likely to be relatively small differences between each $200 \mathrm{~m}$ cell $^{2}$, which permits aggregating cells to unique combinations of location-based attributes, which significantly reduces the number of distinct types of customer locations within each county. Based on this interpretation, dGen uses weighted random sampling to draw agents from the population of feasible and unique combinations of agent locations and attributes.

\subsubsection{Sampling Agent Annual Electric Load}

Energy consumption is a critical agent attribute, because the primary financial motivation of DER adoption is to reduce energy costs through reduced energy consumption. However, we know of no nationally resolved data sets of individual-level energy-consumption patterns. For this reason, dGen uses the U.S. Energy Information Administration's (EIA's) Residential Energy Consumption Survey (RECS) and Commercial Building Energy Consumption Survey (CBECS) (EIA 2008; EIA 2015b) to assemble distributions of customer-level energy consumption across the country and assign an agent's level of energy consumption.

The EIA RECS and CBECS surveys collect information on the energy consumption patterns of residential and commercial end users, respectively. ${ }^{3}$ The results are anonymized and compiled into regional microdata samples that represent the individual survey responses, including annual electric consumption at the individual household and commercial building levels. Each individual survey response also includes a survey or sample weight, which is used to reconstruct the prevalence of that type of end user in the general population. As with the location types described earlier, these microdata define the statistical pool's electrical or thermal energy consumption as well as building characteristics. The electric demand microdata- unlike the location types - are only resolved spatially to the coarse scale of large multistate regions. As a result, it is not feasible to determine the exact customer-level electric demand at each $200 \mathrm{~m}$ by $200 \mathrm{~m}$ agent location.

Because the exact customer-level electric demand cannot be determined for each location, dGen uses a statistical sampling approach, randomly drawing customer-level electric demand from the pool represented in the EIA microdata. This process is performed using a weighted random sampling with replacement, in which the weighting is based on the prevalence of each customer, as determined by EIA. The model then assigns each sampled electric-load value and its corresponding weight to one of the sample agent locations.

As a result of the sampling methodology, the aggregate sum of the customer-level electric-load values sampled to agents can differ from the total county-level electricity load for a given market segment (Ventyx 2012). To ensure county-level load constraints are maintained, the sampled

\footnotetext{
${ }^{2}$ For example, in Jefferson County, Colorado, there are 8,219 distinct residential customer locations in the land-use mask but only 220 unique combinations of attributes (as currently modeled) across those locations.

${ }^{3}$ Because of data limitations on industrial energy consumption, the Commercial Building Energy Consumption Survey is also used to categorize the energy consumption of industrial customers.
} 
electric-load values are treated as intensity measures rather than absolute values. The countylevel load is then allocated across the agents, with the amount of load in each agent being proportional to the sampled load value from the microdata. Concurrently, a similar scaling process is applied to apportion the county-level customers to individual customer bins, according to the EIA microdata weights. The resulting load and customer values preserve the county-level totals across the discrete set of agents as well as the general variability in intensity of electric demand found in the region.

To accommodate analysis of electricity rates with seasonal, time-of-use, and demand charge structures (see Sections 4.4.1 and 6), the dGen model also attributes each agent with a normalized hourly electric consumption pattern that is scaled to meet the annual consumption of the agent. We use the hourly electric consumption patterns derived by Ong et al. (2013) and Davidson et al. (2015b). These hourly consumption data are based on typical meteorological year climate data measured at 79 weather stations across the United States, and region-specific building models for 16 different building types. Agents are assigned consumption patterns based on nearest-neighbor proximity to 79 weather stations as well as matching to the most appropriate building type. The 16 building types are comprised of 15 commercial building types and one residential building type. Consequently, all residential agents in single region are assigned a single hourly consumption pattern, while commercial and industrial agents are assigned consumption patterns by mapping building types to the primary building activities of the sampled CBECS microdata.

By combining the annual and hourly electricity consumption values with the location-based characteristics assigned in the first two steps, the agents for each county are assigned all necessary parameters for subsequent calculations of technical potential (Section 3), system economics (Section 4), and diffusion modeling (Section 5)

\subsection{Advantages and Limitations of dGen Agent-Based Approach}

The stochastic process of agent categorization detailed above results in specific advantages and limitations for modeling DER market penetration. We describe some of the most important advantages and limitations in this section.

\subsubsection{Generation of Statistically Probable Representations of Agent Types}

Modeling national adoption decisions involves an inherent challenge due to data limitations: it is necessary to model the specific characteristics and decision-making of individual consumers; however, it is not feasible to accurately parameterize individual preferences and attributes due to lack of data at the level of the individual household or company. Therefore, it is critical to represent population variance, because central tendencies of a population do not represent the prototypical diffusion process in which initial adopters of a technology are themselves outliers (Rogers 2003). Therefore, using regional median values for key consumer attributes would inadequately represent the propensity for adoption - especially in the initial stages of diffusion.

Thus, the sampling process used in dGen overcomes limitations of the best available data sets by generating likely representations of customer types. By using random sampling to extract and link agent-level attributes that are based on the statistical prevalence of those attributes, the resulting customer types will tend to represent the most common configurations of consumers within each county. The component of randomness also enables the model to incorporate rare 
customer types as appropriately small components of the overall market. As a result, when a sufficient sample size is used, the customer types generated produce statistically faithful representations of the variation in types of customers likely to be present within each county and market segment.

\subsubsection{Decreased Model Bias and Quantified Model Uncertainty}

A second significant advantage of the techniques used to characterize agent types is that it facilitates quantification of uncertainty in both the input data and the model results. Data limitations ensure there will always be some uncertainty about the true attributes of the underlying population. Therefore, a deterministic approach will almost certainly be biased and, more importantly, biased in the same way for every model run. Furthermore, the degree of bias cannot be quantified, so uncertainties caused by data limitations are not transparent in model outputs.

The statistical sampling framework used by dGen acknowledges this source of model bias by treating uncertainty related to agents' actions and attributes in a more sophisticated and appropriate manner. By using random sampling, the model can generate a large number of unique, equally probable agents and associated deployment pathways, reflecting the uncertainties in data and agent decision-making ${ }^{4}$. Users of the model can produce a different sample of agents for each model run and leverage this ability to perform Monte Carlo simulations of DER market penetration where variance in model outcomes can be used to quantify the uncertainty in the model and its supporting data. For example, a user could test a given scenario using 100 different sets of sampled agents. The median output values from the 100 simulations would represent the most probable single prediction of the scenario outcome, based on the input data, whereas the $5^{\text {th }}$ and $95^{\text {th }}$ percentile values would place a $90 \%$ confidence interval around the median prediction. Although this approach does not necessarily eliminate model bias, which can enter into the model through many pathways, the statistical sampling approach seeks to minimize the likelihood of consistent bias in model results.

\subsubsection{Flexibility in Model Applications}

A third significant benefit of the framework is derived from the fact that users can specify the number of unique agents to model in each market segment and county. Increasing the number of agents increases the required run time while reducing the variance between results. The user can change the number of customer types to tune the model for different analysis requirements.

By increasing the number of agents generated, the user can decrease the variance in model results, because each region is represented by a larger and, therefore, more representative sample of the set of all potential customer configurations. At the extreme level, the number of customer types could be set to the total number of customers within each county, such that the theoretical combination of all customer attributes would be fully represented in the model; however, as more customer bins are modeled in each county, the overall run time of the model increases. This feature of the model can be leveraged to use the model for different applications. For example, it

\footnotetext{
${ }^{4}$ It is important to clarify that if repeatable results for any given single set of model scenarios are desired, users of the model can set a random generator "seed", which will ensure that the same set of agents are sampled for each scenario run.
} 
could be used to perform a tiered scenario modeling process. A user could initially set the number of customer types relatively low to perform quick comparisons of the nationwide effects of different policy, $R \& D$, or cost-improvement scenarios. Then, based on these preliminary results, the user could model specific scenarios of interest in depth at a more granular spatial resolution (e.g., at the state level) by raising the number of customer bins.

\subsubsection{Flexibility for Model Enhancement}

One final advantage of the method used for characterizing customer types in dGen is that it provides a flexible foundation for integrating additional customer attributes, particularly when the covariance structure can be established with the existing attributes. For example, survey data relating demographic or behavioral attributes to a customer's propensity for adoption could be incorporated using the probabilistic sampling framework. With this approach, the model can continue to be enhanced to account for not only additional predictive customer attributes but also important relationships and combinations of those attributes. 


\section{Establishing Technical Potential}

After it categorizes agents, dGen establishes measures of the "technical potential" of each DER technology, defined as the maximum installable capacity, where feasibility is determined by excluding system installation sites that are technically prohibited and any system configurations that are either infeasible or wholly inferior to alternative configurations. Thus, the definition of 'technical potential' is slightly different than the traditional definition, since we not only assume the system must be co-sited with the agent, but that the agent's level of energy consumption caps the installable capacity.

Establish technical potential involves assessing resource quality (i.e., translating resource assessments to estimates of system production including R\&D-related performance improvements and restrictions on siting). The output of this assessment is a set of technically feasible system configurations for each agent based on their sampled location, should any such feasible configurations exist. Each of the technically feasible configurations is then evaluated in the economics module, which retains only the most profitable configuration for each agent.

\subsection{Assessment of Distributed Energy Resource}

The availability and quality of renewable energy resources, particularly wind and sunlight, vary considerably within the United States, with important implications for DER electricity generation and value. Resource assessments have been conducted for each technology, as described in Appendix A (solar) and Appendix B (wind). Please refer to those appendices for detailed descriptions of the data sets, assumptions, and tools used to assess the spatial variability in DER resource.

\subsection{System Performance}

Like most market models, dGen uses current and estimated future technology performance, which, when combined with the geo-specific resource information, estimates energy production for each agent location over time. The model also provides a method that clarifies how potential investments in technology performance can impact deployment. Current and future performance model inputs are described in Appendix A (PV) and Appendix B (wind). System performance and model cost are both exogenous inputs to the dGen model; therefore, the model does not support the identification of technology improvement opportunities or show how improvements change performance or cost. However, it can describe the potential market impact of achieving different performance levels. 


\subsection{Siting Criteria and Land-Use Mapping}

Not every $200 \mathrm{~m}$ grid cell modeled in dGen is suitable for DER systems. To be suitable, a site must meet general and technology-specific criteria. For all technologies, a site must be located in the appropriate zoning type (i.e., residential, commercial, or industrial), and, for residential systems, the building must be owner-occupied. ${ }^{5}$ Technology-specific criteria include, for example, wind systems restricted based on factors such as high population density and tree cover and solar requirements of a minimum roof size and configuration. See the appendices for additional information on the technology-specific criteria and methodology.

The dGen model assumes that DER installation must occur on properties zoned as commercial, industrial, or residential. The model uses a national series of high-resolution land-use grids (spatial layers) for each market segment to identify whether customers from a given market segment are likely to be present in each $200 \mathrm{~m}$ by $200 \mathrm{~m}$ area. Figure 1 is an example of the residential land-use mask for Boulder, Colorado, showing the close correspondence with land zoned residential by the city. The land-use grids do not characterize land use perfectly, but they capture the general extent of land used by each customer segment, especially at the aggregate (county, state, or national) level.

Customer locations for the residential sector were developed primarily using an analysis of the LandScan ${ }^{\mathrm{TM}}$ USA geospatial grids, which provide a fine-resolution estimate of daytime and nighttime population (ORNL 2011). These population grids were overlaid and combined to determine the ratio of nighttime to daytime population. Under the assumption that residential areas tend to be more heavily populated at night (when most people are home) than during the day (when many people are at work or school), grid cells with a nighttime-to-daytime ratio above one were classified as residential. A second analysis removed grid cells coinciding with known locations of non-residential facilities with high nighttime populations, including prisons, hotels, motels, college campuses, and industrial complexes (HSIP 2012). For the commercial and industrial sectors, the customer location grids were derived using a data set of known business locations, including but not limited to the non-residential facilities dropped from the residential grid. These business locations were separated into commercial and industrial groups based on two-digit codes from the North American Industry Classification System (NAICS); each point location was expanded by a $90-\mathrm{m}$ radius, and the resulting areas were overlaid on the grid to identify cells occupied by facilities of each sector.

The residential, commercial, and industrial grids all are resolved to the same spatial resolution ( $200 \mathrm{~m}$ by $200 \mathrm{~m}$ ) as the renewable energy resource data, allowing for the seamless integration of the two data sets. Within dGen, these land-use masks are treated as the entire pool of candidate customer locations for each market segment, and thus they constrain DER diffusion. This approach helps avoid over-prediction of the market by identifying locations where siting criteria would restrict adoption despite sufficient resource quality and customer demand, and it can identify the areas suitable for different types of DER technologies.

\footnotetext{
${ }^{5}$ Although non-owner-occupied commercial and industrial buildings may adopt DERs in actual markets, they do so at a lower rate than owner-occupied structures.
} 


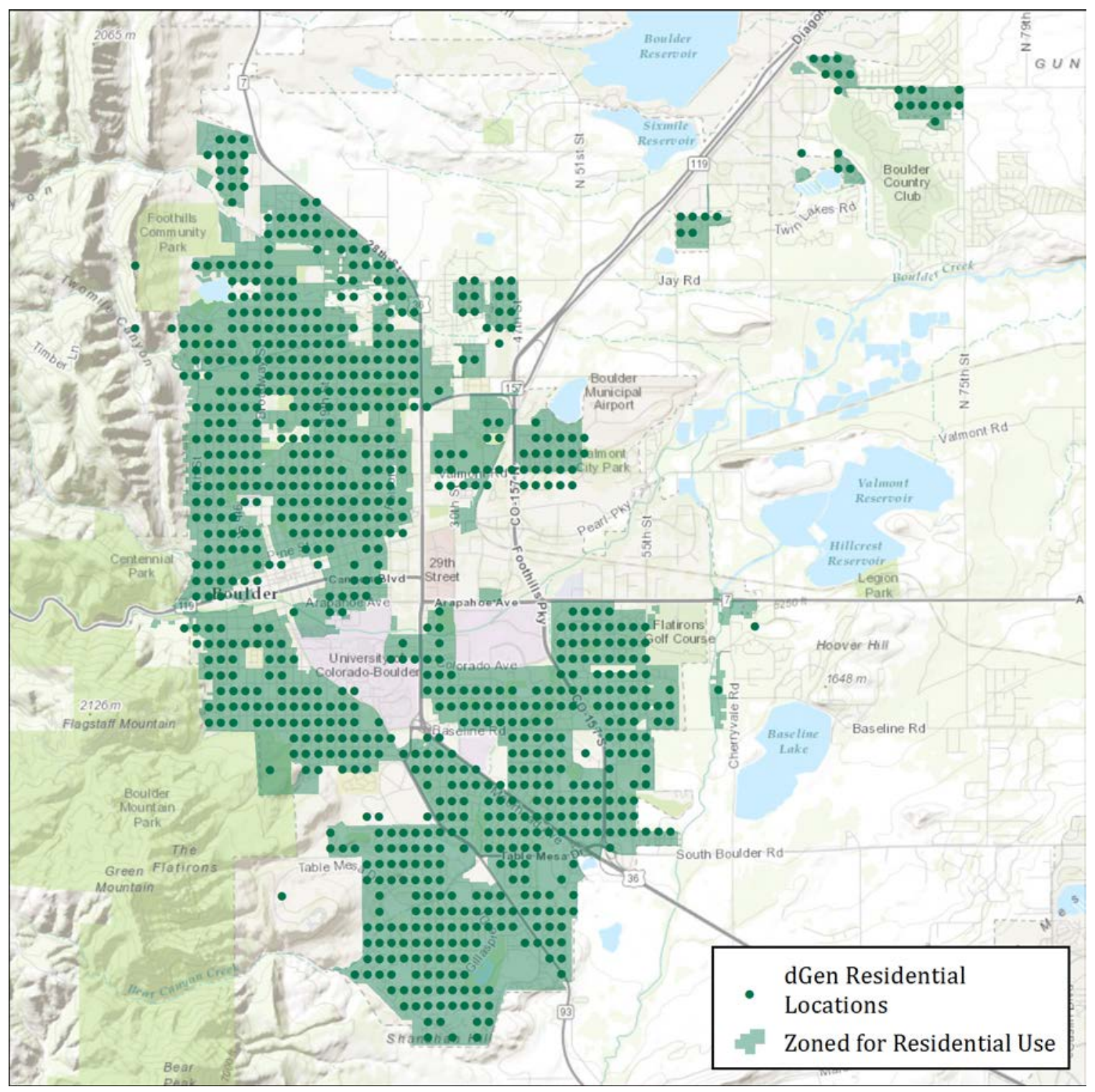

Figure 1. Comparison of dGen residential customer locations to land legally zoned for residential use in Boulder, Colorado

\subsection{Selection of Optimal System Configurations}

Even after applying generic and technology-specific restrictions on system configuration, there are likely to be multiple feasible configurations for an agent. Therefore, dGen selects the system configuration with annual system generation that meets a user-defined percentage of the customer's annual electricity consumption. The default values for offsetting consumption are 95\% for agents with net metering and 50\% for agents without net metering (Davidson and Margolis 2015a). The actual offset percentages for agents are constrained by site-specific factors (e.g., rooftop availability, turbine height limits); therefore, sizing to the specified offset targets is not always precise. This algorithm produces a simple estimate of optimum system configurations for each agent, without performing detailed economic analyses, which would be prohibitive given computation limits. Figure 2 illustrates the results of this selection process for wind 
turbines, showing the system configuration preference for the three sectors, where the area of each circle is proportional to the amount of capacity that would be installed at the selected height-capacity combination.

After this rapid screening, a more thorough cash flow analysis is conducted to determine the financial viability of the single selected system configuration.

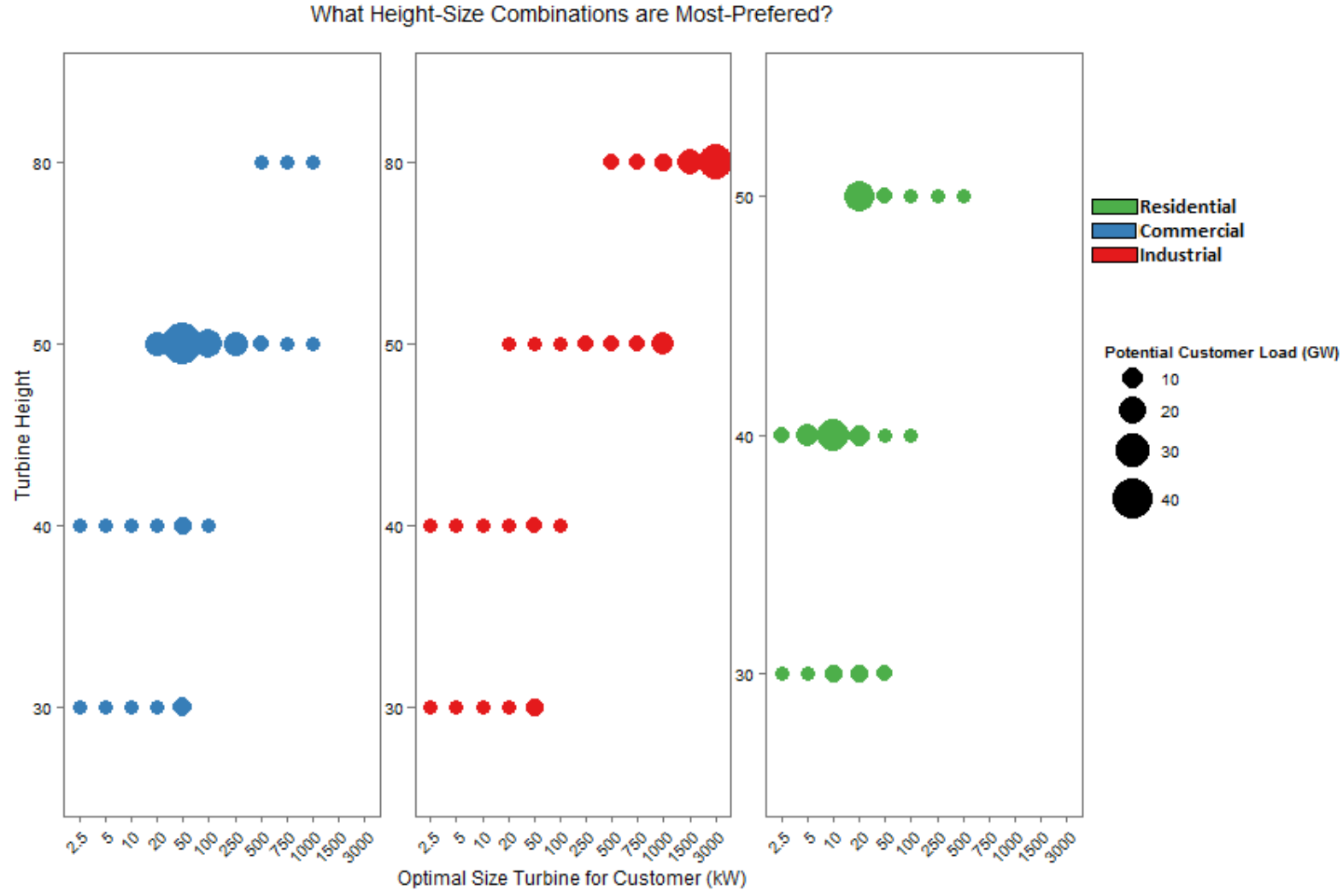

Figure 2. Summary of optimal wind turbine sizes and hub heights for each market segment 


\section{Economic Calculations}

The economics of each DER technology are determined in dGen using discounted cash flow analysis to determine the profitability (e.g., the payback period, net present value, and monthly electricity bill savings) over the system's lifetime. This approach assumes that the DER value is created by reducing the electricity or fuel bills that the agent would have paid had they not adopted. Specifically, expenses include initial capital costs, such as the down payment and monthly loan/lease payments, and annual operation and maintenance requirements. Revenue includes energy bill savings, applicable financial incentives, and tax-based credits, such as depreciation and interest rate deductions for nonresidential customers.

\subsection{System Costs}

Three components of system cost are incorporated in dGen: installation capital costs and variable $(\$ / \mathrm{kWh})$ and fixed $(\$ / \mathrm{kW} /$ year) operation and maintenance costs. Each cost component includes cost-reduction trajectories based on exogenous reductions. Assumptions for current and potential future costs are described in the appendices. Capital costs are defined for each sector (residential, commercial, and industrial) and can vary by project size to reflect economies of scale.

\subsection{Financial Incentives}

The model provides a flexible framework for modeling the full life cycle impact of a range of potential state and federal incentives. By default, users can model current incentives, based on the Database of State Incentives for Renewables \& Efficiency (DSIRE) database (DSIRE 2014). These incentives are applied across a range of geographic scales - such as electric service territories, counties, states, and nationwide - and are categorized as either production based $(\$ / \mathrm{kWh})$, a tax credit as a percentage of installed costs, or a fixed-value rebate. The DSIRE database specifies the expiration date of incentives and the maximum amount that will be dispersed to a project. An expiration of 2020 is assumed in dGen for incentives with no announced expiration date. As of this writing, the federal Investment Tax Credit, a key incentive for spurring early adoption, is scheduled to expire in 2016 for residential systems and to decrease from $30 \%$ of installed cost to $10 \%$ for non-residential systems, which is the default assumption used in dGen.

Alternatively, users may manually prescribe a variety of incentive structures - tax, production, and rebate - with various levels, caps, and expiration dates. These manual incentives can be assigned to specific states or nationally and used to either overwrite the DSIRE incentives or phase in for any future model year. Several built-in default scenarios for future incentivesincluding low, medium, and high scenarios for each incentive structure - can also be defined. Using this flexible framework, dGen permits in-depth analysis of the effects of policy incentives on DER deployment. 


\subsection{Financing Assumptions}

The economic value of a DER system is affected by the financing structure used by a potential customer. In dGen, DER systems may be adopted through either a host-ownership business model, whereby the customer directly owns the system, or a third-party model, whereby the customer leases the system, receiving all system energy generation in exchange for a fixed monthly payment. In both models, the DER systems provide no additional costs or benefits beyond their stated lifetime. Users are able to edit all default financing assumptions to investigate the effects of financing structures on market outcomes.

\subsubsection{Host-Ownership Business Model}

Under host ownership, the agent owns and operates the DER system independently, accruing all costs, revenues, and financial incentives. The agent is assumed to use financing to acquire the system, unless a down payment of $100 \%$ is selected. Table 2 lists the default financial assumptions for host ownership as used in the SunShot Vision Study (DOE 2012), where the cost of debt for a residential customer is based on a 15-year home equity loan, and for commercial and industrial customers is based on a 20-year AA corporate bond. For both sectors, calculating the cost of equity is problematic because of use of the payback period as an evaluation metric.

Table 3. Default Financing Assumptions for Host-Owned Systems by Sector

\begin{tabular}{|c|c|c|c|}
\hline Market Segment & Residential & Commercial & Industrial \\
\hline Cost of debt (real) & $5 \%$ & \multicolumn{2}{|c|}{$5.25 \%$} \\
\hline Debt term (years) & 15 & \multicolumn{2}{|c|}{20} \\
\hline Debt Fraction & $80 \%$ & \multicolumn{2}{|c|}{$80 \%$} \\
\hline Cost of Equity (real) & $10 \%$ & \multicolumn{2}{|c|}{$10.5 \%$} \\
\hline Investment horizon & \multicolumn{3}{|c|}{ Lifetime of technology } \\
\hline Combined Tax Rate & $33 \%$ & \multicolumn{2}{|c|}{$35 \%$} \\
\hline Inflation Rate & \multicolumn{3}{|c|}{$2.5 \%$} \\
\hline
\end{tabular}

\subsubsection{Third-Party Ownership Business Model}

With the third-party ownership (TPO) business model, the agent enters into an agreement to lease the system from a third party that owns the system. Under this agreement, the agent receives all energy produced by the system in exchange for paying a fixed payment over the length of the lease. Additionally, the system qualifies for commercial-sector incentives - such as the federal investment tax credit, depreciation, or interest rate tax deductions - regardless of the agent's sector. In addition, the agent is not required to make a down payment. To determine the monthly lease payment, dGen calculates the payment required by the lessor to achieve a specified hurdle rate on invested capital (i.e., the installed system cost net of any applicable incentives), where financing terms are based on Davidson (2015a; 2015b) (Table 3). Lease structures are based on a fixed, non-escalating monthly lease payments, and do not include a power purchase agreement (PPA); neither business model allows PACE financing. 
The TPO option is not available in all states, because some jurisdictions deem it in violation of regulations governing electricity sales by third parties. As of this writing, the District of Columbia and the following 21 states permitted TPO models: Arkansas, California, Colorado, Connecticut, Delaware, Indiana, Maine, Maryland, Michigan, New Jersey, New Mexico, New York, North Carolina, North Dakota, Ohio, Oregon, Pennsylvania, Rhode Island, Texas, Utah, and Virginia (DSIRE 2014). The default assumption in dGen is that the TPO option is available only in states that currently allow TPO through 2019 and that the TPO option is available in all states beginning in 2020, though this assumption is adjustable.

Table 4. Financing Assumptions for Third-Party-Owned Systems by Sector

\begin{tabular}{|l|l|c|c|}
\hline Market Segment & Residential & Commercial & Industrial \\
\hline Cost of capital (real) & \multicolumn{3}{|c|}{$7 \%$} \\
\hline Lease term (years) & \multicolumn{2}{|c|}{20} \\
\hline Debt Fraction & \multicolumn{2}{|c|}{$100 \%$} \\
\hline Cost of Equity (Lessee) & $10 \%$ & $35 \%$ \\
\hline Tax rate & $33 \%$ & \\
\hline Inflation Rate & $2.5 \%$ & \\
\hline
\end{tabular}

\subsection{Electricity Rates and Rate Structures}

To estimate the value of DER systems to agents, dGen calculates the projected electricity bills with and without a DER system over the proposed investment period, which is typically 25 years for each agent. These costs are derived from location-specific retail electric rates. In the model, users can select from three types of retail rate structures: real-world tariffs based on the Utility Rate Database (URDB) (OpenEI 2014), annual averages by state ( $\$ / \mathrm{kWh}$ ) from EIA 861 forms (EIA 2015a), and user-defined flat rate structures. These different approaches are described in the following sections.

\subsubsection{URDB Rate Tariffs}

By default, rate structures are based on data from the URDB (OpenEI 2014), which is an opensource database of actual rate data for a majority of U.S. electric utilities. Rate data stored in the database provide detailed information about various tariff parameters, including seasonal and time-of-use (TOU) rates, rate tiers, demand charges, and other energy charges. The URDB contains a large number of rates and covers most of the United States.

The first step in bill calculation involves automating the assignment of rates to an agent in the model based on its location. When an agent qualifies for multiple rates within its assigned utility, a heuristic is used to select single rate. Specifically, an agent is limited to certain rates based on its sector (residential, commercial, or industrial) and electric use requirements (e.g., allowable demand ranges). Most of the URDB rate data do not include information about electric use requirements. Therefore, dGen uses only a subset of rates from the URDB, which include a set of rates for which NREL manually reviewed and added applicable demand ranges as well as a second set of rates for which each rate is the only available rate in its utility territory and sector. In total, 2,370 rates from the URDB were curated for use in dGen, corresponding to utilities serving approximately $80 \%$ of residential and commercial load in the United States. Figure 4 
shows the geographic coverage of the two combined subsets of rates extracted from the URDB for use in the model. Most of the URDB rates used in dGen are of 2013-2014 vintage, with some slightly older (2012) and some slightly newer (2015).

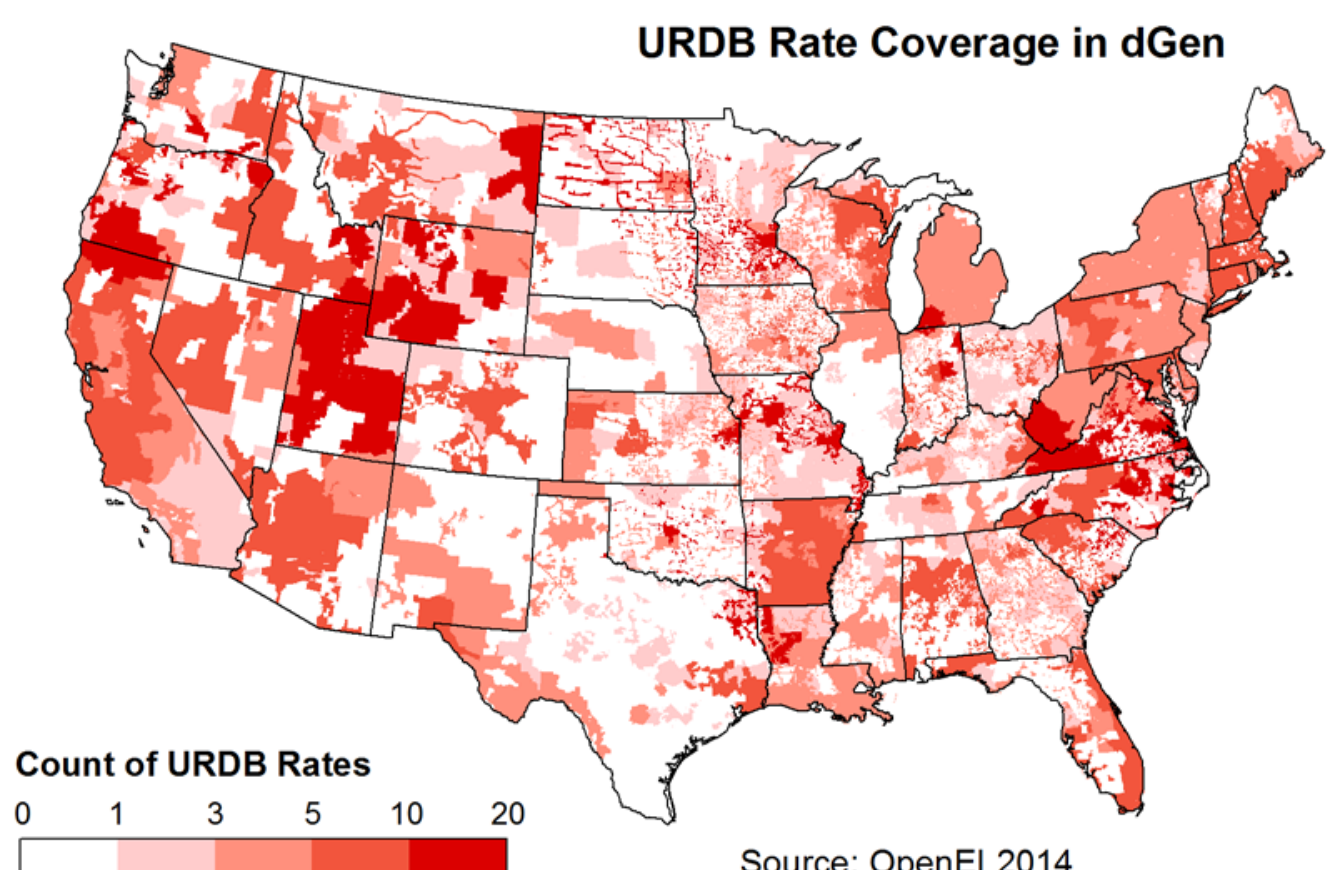

Figure 3. Geographic coverage of rates from the URDB used in dGen

For geographic regions lacking rate coverage, we developed a ranked backfilling methodology. In this ranking, priority is assigned in tiers. In the first tier, all rates associated with a utility territory within 50 miles of the agent location and matching the utility type (municipal, cooperative, investor-owned, or other) of the agent are ranked in order of distance from the agent location. For agents located in utility territories with rate coverage (as shown in Figure 3), these criteria automatically result in prioritizing the rates from the customer's own utility territory; for customer locations without rate coverage, these criteria limit the influence of location-based drivers of differences in rates, such as differing climate and utility company structure. The remaining set of rates (i.e., rates that do not meet the two criteria) constitutes the second tier of rates and are ranked using only their proximity to the customer location. The two tiers of rate rankings are then consolidated, in order, into a single seamless set of rankings of potential rates for each customer location.

The rate rankings often include ties between rates from the same utility territory. Breaking of ties is dealt with dynamically within dGen. As described in Section 2.1, during each model run, a stochastic process is used to generate a set of model agents by sampling customer locations and annual electric loads. As also noted in Section 2.1, each agent is assigned a normalized annual electric load profile to correspond to their annual electric consumption. Using this temporal profile and the annual electric load of the customer, dGen determines the maximum demand required by the customer over the course of a typical year. This maximum demand is compared 
to the demand ranges associated with each of the curated URDB rate structures to filter out inapplicable rates. The remaining rate with the highest rank is then selected as the most applicable. If there is a tie among the most highly ranked rates, a weighted random sample is computed to determine the single rate to use for the customer. This random sampling process is performed independently for each customer with a tie in its most highly ranked rates; therefore, customers from the same region with the same rates may each end up with a different selected rate. The weights for random sampling are based on user-defined inputs that give the prevalence of different rate types by sector (Table 4). Values for these weights are estimates based on the judgment of NREL staff and do not have an empirical basis. Future work will be needed to update these weights based on available empirical or modeled data.

Table 5. User Input for Defining the Relative Prevalence of Different Rate Structures, by Sector

\begin{tabular}{|l|l|l|}
\hline Elements of Rate & Residential & Commercial/Industrial \\
\hline Flat & 0.2 & 0.05 \\
\hline Demand & 0 & 0.2 \\
\hline Seasonal & 0.2 & 0.05 \\
\hline Tiered & 0.2 & 0.05 \\
\hline Time of use & 0.15 & 0.1 \\
\hline Demand tiered & 0 & 0.3 \\
\hline Tiered seasonal & 0.2 & 0.05 \\
\hline Demand time of use & 0 & 0.15 \\
\hline Other & 0.05 & 0.05 \\
\hline Sum & 1 & 1 \\
\hline
\end{tabular}

This random sampling approach for breaking ties is consistent with other techniques used in dGen. In the absence of better data or knowledge, we are uncertain which rate to use for certain customers. Therefore, rather than make a potentially incorrect or biased choice, the model allows users to apply a random sampling to investigate the effects of this uncertainty on model outputs. As part of ongoing model maintenance and development, we plan to improve this approach by incrementally updating the curated URDB rates with data on the actual prevalence of each rate (i.e., percentage of customers within the state and sector using each rate). These updates will be performed on a state by state basis, as funding permits, and will provide for a more empirically founded ranking of rate prevalence within each state. 
There are two important caveats to note about URDB rates used in dGen. First, the URDB rates used in dGen are currently limited to residential and commercial sector rates. Industrial rates do exist in the URDB and may be added to dGen later as a model enhancement. In place of industrial rates, the current version of the model uses commercial rates to evaluate electric bills for industrial customers. Thus, dGen will overestimate industrial DER adoption potential since industrial rates are typically than lower those of commercial entities. However, industrial adoption potential in dGen is much lower than commercial, so the error is not large. Second, the data extracted from the URDB for the model represent a snapshot of real-world rate structures as of the time they were downloaded (December 2014).

Though retail rate structures are likely to evolve over time, dGen assumes that the structure of a particular rate does not change, though tariffs escalate over time using EIA forecasts (EIA 2015b). As solar penetration increases, rate structures may adjust in response to that increased penetration, and this modeling framework does not capture that feedback. Users may evaluate the effect of alternative rate structures through manually specifying rate escalations or inputting alternative structures in the URDB format; a dynamic model of solar energy and capacity value as a function of penetration, as demonstrated by Darghouth et al (2016) is an intended future enhancement.

\subsubsection{Annual Average Flat Rates}

As an alternative to using the default URDB rates, dGen allows users to calculate bill savings assuming that all agents have flat-rates, where the flat rate is based on the average cost of electricity $(\$ / \mathrm{kWh})$ by state. Although average rates represent overall energy expenditures for customers, by definition they do not incorporate important nuances in the DER value proposition, such as offsetting energy charges at higher tiers or reducing demand charges. These flat rates are derived from average retail price data by sector and utility territory provided by EIA (EIA 2015a). The rates are then mapped to counties using the utility territory to county lookup table included in the EIA 861 forms (EIA 2015c), as shown in Figure 4 for the residential sector. For counties with multiple utility territories, a simple average rate from the overlapping utility territory rates was calculated. 


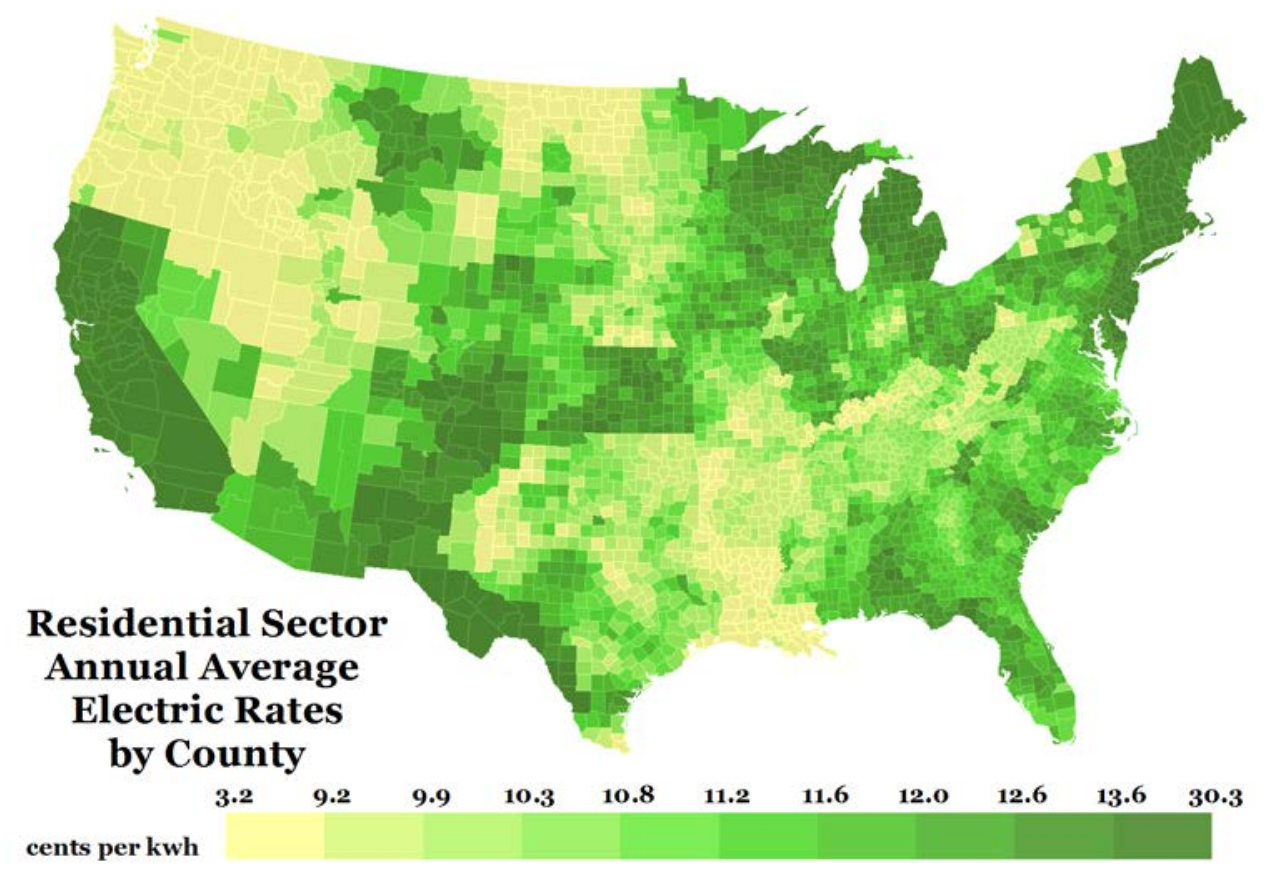

Figure 4. Annual average electricity rates for residential customers by county Source: EIA 2015a

\subsubsection{User-Defined Flat Rates}

As a final option, dGen users may also choose user-defined flat retail rates and can specify a unique rate for each state and sector. Default values in the input table for user-defined rates are based on the state annual average flat rates from 2012, as provided by EIA (EIA 2015a).

\subsection{Excess Generation Value (Net Metering)}

Depending on system configuration, local DER resource, and temporal energy consumption patterns, imbalances in the temporal profiles of an agent's system generation and energy consumption likely will result in times when generation that exceeds consumption must be exported to the electrical grid. Net metering is a billing mechanism that permits customers with grid-connected distributed generation to receive full retail credit for the energy the customers produce but do not consume. Although full-retail-credit net metering is available in multiple jurisdictions, it has provoked numerous regulatory disputes, and its future is uncertain. To reflect this uncertainty, dGen offers multiple options for valuing excess generation, such as: (1) indefinitely continuing current policy (Barnes et al. 2013); (2) valuing exported generation at the state wholesale electricity rate or avoided fuel cost of a natural gas combined-cycle generator; and (3) using a user-defined scenario.

Net metering configurations are defined by state, sector, outflow credit value (e.g., full retail rate, avoided fuel cost, none, or user-specified), and maximum system size that qualifies for the outflow credit. Users may also specify a transition period after which the "avoided cost" value will be used for all subsequent years (e.g., full credit through 2020, avoided cost credit for 2022 2050). 


\subsection{Bill Savings Calculator}

Agents receive value from DER system generation through two streams: value from offsetting energy consumption and value from selling excess generation back to the electrical grid. Both value streams are automatically calculated using the utilityrate 3 module of the NREL System Advisor Model (SAM) (Blair et al. 2014), using the rates and excess generation values determined in Sections 4.4 and 4.5. Savings from offsetting energy consumption are based on a bottom-up calculation of the potential bill savings including, where applicable, fixed charges, seasonal rates, tiered rates, TOU rates, and demand charges. Value from excess generation is based on the credit received for energy exported to the grid during hours when system generation exceeds consumption. The credit used for excess generation ranges from zero, when "No Net Metering" is selected, to full retail credit under the "Full Net Metering" option.

Including these two value streams, SAM calculates the agent's annual electricity costs (\$/year) with and without the proposed system. The difference of the costs is the cost savings (revenue) the agent would receive in the first year of system ownership. First-year bill savings are used as the basis for estimating bill savings over the system lifetime, subject to rate escalation forecasts (EIA 2014b) and system degradation. That is, rate changes and degradation are assumed to proportionally increase or decrease bill savings, which avoids recalculating exact bill savings for the entire system lifetime. Two assumptions implicit in the calculations are that (1) retail rates and rate structures will not dramatically change over the system lifetime and (2) the agent's adoption decision is based on their expectations in the year they adopt. In each year, nonadopters update their expectations based on changing conditions.

\subsection{Value of Avoided Carbon Emissions}

The potential impact of a carbon constraint and a corresponding increase in the price of retail electricity can be considered in dGen. The dGen default settings do not include a price for carbon emissions. However, users can specify a national price of carbon emissions - in dollars per metric ton of carbon dioxide $\left(\mathrm{CO}_{2}\right)$ - for each two-year model time step. Setting a carbon price increases the assumed offset retail rate $(\$ / \mathrm{kWh})$ as the product of the assumed regional carbon intensity $\left(\mathrm{t} \mathrm{CO}_{2} / \mathrm{kWh}\right)$ and price $\left(\$ / \mathrm{t} \mathrm{CO}_{2}\right)$, thereby increasing the potential financial attractiveness of adopting.

Users have two options for estimating the carbon intensity of displaced electricity. They can use state-specific carbon intensity based on the local mix of fuels used to generate electricity or they can select a carbon intensity based on natural gas generation, which is frequently the marginal fuel in most electrical systems. Assuming the second approach, the retail adder for a carbon price range of $\$ 10-\$ 50 / \mathrm{t} \mathrm{CO}_{2}$ would be $0.4-2.1$ cents $/ \mathrm{kWh}$, respectively. These options allow users to quantify the sensitivity of distributed generation adoption to multiple carbon price scenarios.

\subsection{Cash Flow Analysis}

Combining the processes described above, dGen performs a detailed assessment of economic value using a formal cash flow analysis over the system lifetime for each remaining feasible system configuration. From the cash flows, a number of standard metrics are outputted, including net present value, internal rate of return, and payback period. These values are then used to calculate customer likelihood of adopting the technology, as described in Section 5. 
The following six components determine annual cash flows:

1. System Payment: For host-owned systems, the annual costs of servicing loans (principal repayment and interest) are based on the amount borrowed, loan term, and annual percentage rate; for TPO systems, the annual lease payments are used ${ }^{6}$

2. Operation and Maintenance Costs: These costs consist of variable $(\$ / \mathrm{kWh})$ and fixed (\$/kW/year) components.

3. Revenue from Generation: The primary source of revenue is from generation, which offsets electricity costs, calculated as the sum of avoided consumption multiplied by the marginal avoided cost. Bill savings are calculated using the SAM utilityrate 3 calculator, reflecting rate structure and excess generation credits as described in Sections 4.6 and 4.7. Revenue from generation is exactly calculated for the first year of system ownership and projected forward using assumptions about rate escalation and system degradation.

4. Revenue from Depreciation: Commercial, industrial, and TPO systems ${ }^{7}$ may deduct asset depreciation over the system's lifetime, which helps lower the agent's tax burden. The depreciable basis is calculated as the installed cost of the system less half of any tax credits received. The depreciation schedule is selected by the model user. The available options include straight-line depreciation, the Modified Accelerated Cost Recovery System schedule, or a user-defined schedule.

5. Revenue from Interest deductions: All agents are allowed to deduct the interest paid on systems from their taxable burden ${ }^{8}$. Thus, interest deductions are a source of revenue at the specified taxable rate. The model assumes that the agent has a sufficient taxable burden to monetize interest deductions fully.

6. Revenue from other incentives: Agents can receive revenue from a variety of other incentive sources, including production-based incentives, production tax credits, investment tax credits, and rebates.

\footnotetext{
${ }^{6}$ See section 4.3 for a description of financial differences between the business models

${ }^{7}$ While the homeowner is the primary agent/adopter of the technology, since it is owned by a commercial entity we assume tax benefits from depreciation are passed through to the homeowner in the form of lower lease payments.

${ }^{8}$ Residential customers may not deduct interest from an unsecured loan, but may do so when financing via home equity line of credit
} 


\section{Modeling Market Diffusion}

The diffusion of DER for each customer type is calculated in dGen by combining the economic attractiveness of potential adoption, as determined by the cash flow analysis (Section 4), with insights from the "diffusion of innovations" framework popularized by Bass (1969) and Rogers (2003). The framework posits that the diffusion of a novel technology occurs in an epidemic-like fashion, whereby the adoption pattern follows a logistic "S-curve" form (Figure 6). Furthermore, the rate of diffusion is initially slow, accelerating as additional customers consider the new technology.

A "market diffusion" or "S-curve" model is used in dGen to determine both the rate of technology uptake for different agent types as well as the maximum market size. Two outputs of this formulation are the market share (the cumulative fraction of eligible technologies that have already been adopted) and the maximum market share (the maximum fraction of eligible agents who would eventually adopt if economics remained unchanged). The general characteristics of the S-curve model are shown in Figure 5.

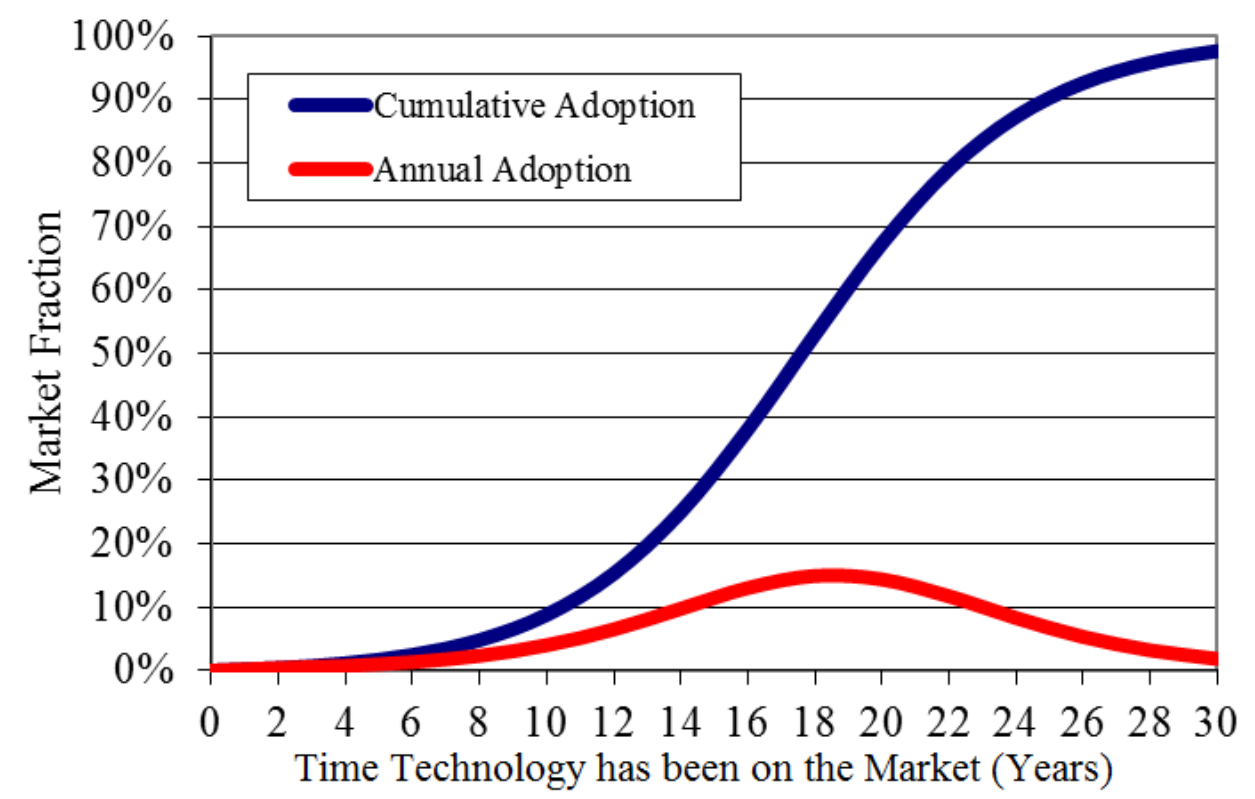

Figure 5. Annual and cumulative adoption rates simulated using the diffusion of innovations framework

Each agent in the model represents a subset of customers in the overall DER market, and the specific attributes of that subset dictate how the technology diffuses into their subpopulation over time. This means that, although the adoption of DER technologies in dGen follows an S-shaped trajectory for the set of customers represented by an agent, the specific shape (e.g., maximum market and pace of adoption) of the adoption curve varies across customer types. The maximum market share is determined by the level of economic attractiveness for each agent (Figure 7). The pace of adoption is controlled by year-to-year changes in economics, with adoption accelerating if economics substantially improve. 
The relationship between economic attractiveness and maximum market share has been quantified by several different sources, including NREL (Sigrin and Drury 2014), Navigant (Paidipati et al. 2008), EIA (2004), R.W. Beck (2009), and Kastovich et al. (1982) (Figure6). Users of the model can select from these alternative estimates of maximum market share to investigate the effects on market diffusion. Current parameterization of the maximum market share assumes that, for host-owned systems, residential agents evaluate the economic attractiveness based on the system payback period (time to recoup the initial investment) whereas commercial and industrial customers use the internal rate of return. For leased systems with no upfront cost, agents evaluate adoption using their monthly net bill savings (i.e., bill savings minus lease payment) as a fraction of their summer bills prior to adoption using the market share curves published by Sigrin and Drury (2014) (not included in Figure 6).

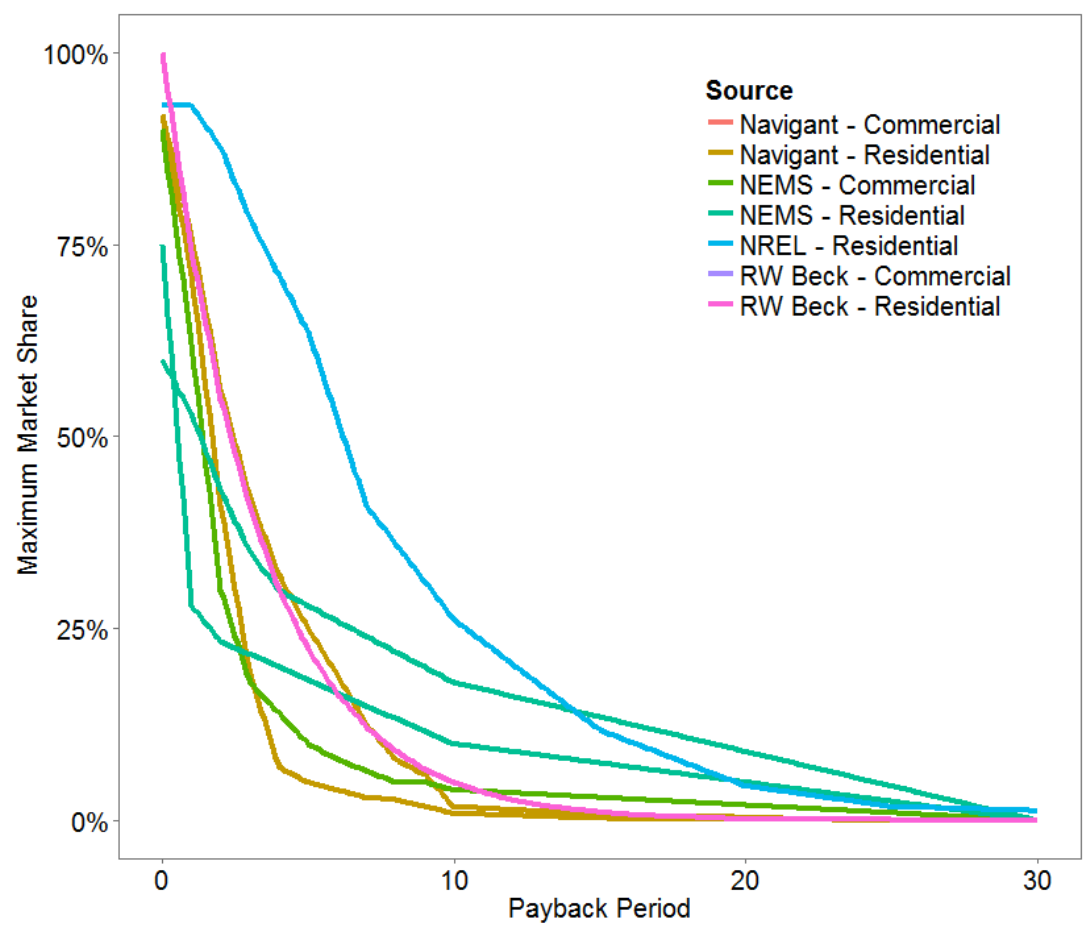

Figure 6. Maximum market share as a function of payback period based on different sources

Sources: R.W. Beck 2009; EIA 2004; Paidipati et al. 2008; Sigrin and Drury 2014 (NEMS = National Energy Modeling System)

\subsection{Business Model Selection}

For agents able to adopt via host or third-party ownership, dGen can evaluate both options and select the business model that is more economically attractive as measured by the maximum market share. Users of dGen can further define the decision-making criteria using the "ranking" method, whereby agents select the business model with the larger maximum market share, or the "probabilistic" method, which assumes some fraction of agents will select the economically inferior business model. In the probabilistic method, the probability of an agent selecting the leasing model $\left(P_{l}\right)$ is defined using a standard logit equation: 


$$
P_{l}=\frac{M_{l}^{\alpha}}{M_{l}^{\alpha}+M_{b}^{\alpha}}(1)
$$

where $M_{l}$ and $M_{b}$ are the maximum market shares of the leasing and buying models, respectively, and $\alpha$ is a segregation parameter with a default value of two. In this formulation, the agent is indifferent to either model when both models provide equal economic benefits, but it is likely to prefer the business model with superior economics.

\subsection{Market Diffusion}

The model is initialized with historical diffusion levels consistent with 2013 market conditions. At each subsequent time step, historical diffusion levels are updated to reflect the incremental diffusion during the previous time step, and financial calculations are updated to reflect changing market and technology factors. Basic exemption handling ensures that previously installed systems are not removed if the market conditions deteriorate and that growth in population and load does not distort historical diffusion levels. The model tracks adoption levels-including new customers, installed capacity, and overall DER market value - over all model years to capture the cumulative adoption for each from 2014 through 2050. In a post-processing step agents are aggregated together to report aggregate diffusion of each DER technology in the state and national markets.

To determine the amount of annual technology, the following specific formulation is used. Let $S$ and $M$ be the market share and maximum market share calculated for year $t$ for agent $i$. Parameter estimates for the Bass model can be determined in one of two ways. First, the $p \& q$ parameters may be estimated independently for each state by fitting a Bass model to a time series of penetration rate of the technology (Appendix D). Alternatively, one can use locationindependent values for $p \& q$ based on values from previous studies of technology diffusion, with a default value for $p=0.0015$ and q defined as:

$$
\begin{aligned}
& q=0.5 \text { if payback period } \leq 3 \text { years, or percentage of monthly bill savings } \geq 180 \% \\
& q=0.4 \text { if } 3<\text { payback period } \leq 10, \text { or } 133 \% \leq \text { percentage of monthly bill savings }<180 \% \\
& q=0.3 \text { if } 10<\text { payback period } \leq 30 \text { or } 0 \% \leq \text { percentage of monthly bill savings }<133 \%
\end{aligned}
$$

A complication of using multiple S-curves occurs when transitioning from one curve to another when DER economics change with cost reductions, electricity rate changes, or other factors. Because the market-penetration fraction scales the total deployment, this transition would lead to a step increase in adoption in the year that the model switched from one curve to another. To smooth this transition, we calculate the position on the new S-curve by solving for the "equivalent year" $\left(t_{e q}\right)$ the technology has been in the market, which as calculated as:

$$
t_{e q}=\frac{\ln \frac{(1-\text { ratio })}{1+(\text { ratio }) *\left(\frac{q}{p}\right)}}{-(p+q)}
$$


where ratio is shorthand for $\frac{M_{t-1}}{M_{t}}$.

Then, stepping forward two years from the equivalent time, dGen calculates the new adoption fraction in time $\mathrm{t}\left(A_{t}\right)$ using the classic Bass diffusion as:

$$
A_{t}=\frac{1-e^{-(p+q) * t e q+2}}{1+\left(\frac{q}{p}\right) e^{-(p+q) * t e q+2}}
$$

Finally, calculate the market share rate $(\mathrm{S})$ as:

$$
S_{t}=M_{t} * A_{t}(4)
$$

where market share cannot decline from the previous year's level (which would imply systems are uninstalled):

$$
S_{t}=\operatorname{Max}\left(S_{t-1}, S_{t}\right)
$$




\section{Conclusion}

In 2009 when NREL first developed the SolarDS model, our expectations of the tool were relatively modest. Over time, however, the model has grown to be used in a number of prominent analyses and influenced the design of other new tools ${ }^{9}$. Furthermore, we hardly have expected the phenomenal growth of the distributed solar market and, with this growth, increasing expectations that distributed energy resources will play an important role in a modern, flexible, and low-carbon grid. With the growth of DERs come a number of new policy and regulatory issues (future of net metering/value of solar, revenue-neutral retail electricity rates, interconnection policies) as well as grid operation ones (contribution of DERs to VRRE-based curtailments, impacts of DER growth on new generation and transmission builds, impacts of DER on local distribution networks). It is exactly this new round of analysis opportunities that motivated our overhaul of the SolarDS model to dGen.

Expecting an evolution in the nature of analysis opportunities, NREL began overhaul of SolarDS model into a Python and PostgreSQL framework in 2013, completing revision in 2014. The primary areas of improvement considered (Table ES-1) were overhaul of the representation of customer types from a 'binned' approach to an agent-based one, integrating additional sources of geospatial data (aka data backbone), and more explicit consideration of complex retail rate structures. The combination of these features results in highly scalable tool, which can analyze national, state, and sub-state regions with ease, integrate new sources of data, and that explicitly recognizes uncertainty in input and output metrics. In publishing this documentation, our aim was to summarize improvements to the core model, and thus explicitly excluded scenario analysis, which will be documented in future analysis-focused publications.

Developing the dGen model remains an ongoing project, where new features are added as needed by project, and underlying datasets updated regularly. Anticipated updates are to complete a behind-the-meter storage module (dStorage) and heat pump and direct use geothermal module (dGeo) in FY16. Our vision is to add additional DER technologies to directly weigh the costs and benefits of competing DER technologies against each other. Additionally, high levels of DER penetration can create integration issues, both at the transmission and distribution-level, and this is an ongoing line of research.

\footnotetext{
${ }^{9}$ See $h$ ttps://scholar.google.com/scholar? safe $=$ active \&um=1\&ie=UTF-8\&lr\&cites $=576210604085479837$ for a full list of publications that have cited the 2009 model documentation.
} 


\section{References}

AWST (AWS Truepower, LLC). 2012a. "3\% Gross Capacity Factor TMY Profile at $20 \mathrm{~km}$ Locations."

—. 2012b. "IEC Class II Annual Gross Capacity Factor at 80 m."

Barnes, Justin, Culley, Thad, Haynes, Rusty, Passera, Laurel, Wiedman, Joseph, and Jackson, Rosalind. 2013. Freeing the Grid 2013: Best Practices in State Net Metering Policies and Interconnection Procedures. Interstate Renewable Energy Council. Accessed July 7, 2014: http://freeingthegrid.org/wp-content/uploads/2013/11/FTG_2013.pdf.

Bass, Frank M. 1969. “A New Product Growth for Model Consumer Durables," Management Science 18: 215-227.

Blair, Nate, Aron P. Dobos, Janine Freeman, Ty Neises, Michael Wagner, Tom Ferguson, Paul Gilman, and Steven Janzou. 2014. System Advisor Model, SAM 2014.1.14: General Description. Golden, CO: National Renewable Energy Laboratory. NREL/TP-6A2061019. http://www.nrel.gov/docs/fy14osti/61019.pdf.

Cole, Wesley, Haley Lewis, Benjamin Sigrin, and Robert Margolis. Forthcoming. Interactions of Rooftop PV Deployment with the Evolution of the Bulk Power System.

Darghouth, N; Wiser, R; Barbose, G; Mills, A. (2016). Net metering and market feedback loops: Exploring the impact of retail rate design on distributed PV deployment. Applied Energy, 162.

Davidson, Carolyn, Pieter Gagnon, Paul Denholm, and Robert Margolis. 2015. Nationwide Analysis of U.S. Commercial Building Solar Photovoltaic (PV) Breakeven Conditions. Golden, CO: National Renewable Energy Laboratory. NREL/TP-6A2064793. http://www.nrel.gov/docs/fy16osti/64793.pdf.

Davidson, Carolyn, and Robert Margolis. (2015a). PV Quote Data: New Insights into PV Product Variation. Golden, CO: National Renewable Energy Laboratory. NREL/TP-6A2064792.

Davidson, C; Steinberg, D; Margolis, R. (2015b). Exploring the market for third-party-owned residential photovoltaic systems: insights from lease and power-purchase agreement contract structures and costs in California. Environ. Res. Lett. 10024006

Denholm, Paul, Easan Drury, and Robert Margolis. 2009. The Solar Deployment System (SolarDS) Model: Documentation and Sample Results. Golden, CO: National Renewable Energy Laboratory. NREL/TP-6A2-45832. http://www.nrel.gov/docs/fy10osti/45832.pdf.

Dobos, Aron P. 2015. PVWatts Version 5 Manual. Golden, CO: National Renewable Energy Laboratory. NREL/TP-6A20-62641. http://www.nrel.gov/docs/fy14osti/62641.pdf.

DOE (U.S. Department of Energy). 2012. The SunShot Vision Study. DOE/GO-102012-3037. Washington, DC. 
-2015. Wind Vision: A New Era for Wind Power in the United States. DOE/GO-1020154557. Washington, DC.

Dragoon, K., and Dvortsov, V. 2006. "Z-Method for Power System Resource Adequacy Applications.” IEEE Transactions on Power Systems 21 (2): 982-88. doi:10.1109/

TPWRS.2006.873417.

Drury, Easan, Mackay Miller, Charles M. Macal, Diane J. Graziano, Donna Heimiller, Jonathan Ozik, and Thomas D. Perry IV. 2012. The Transformation of Southern California's Residential Photovoltaics Market through Third-Party Ownership. Energy Policy. Volume 42, March 2012, Pages 681-690.

Drury, Easan; Denholm, Paul; and Margolis, Robert. 2013. Sensitivity of Rooftop PV Projections in the SunShot Vision Study to Market Assumptions. Golden, CO: National Renewable Energy Laboratory. NREL/TP-6A20-54620. http://www.nrel.gov/docs/fy13osti/54620.pdf.

DSIRE (Database of State Incentives for Renewables \& Efficiency). 2014. "Database of State Incentives for Renewables \& Efficiency.” Accessed January 15, 2014: http://www.dsireusa.org/.

EIA (U.S. Energy Information Administration). 2004. The Electricity Market Module of the National Energy Modeling Systems: Model Documentation Report. DOE/EIA-M068.

Washington, DC: DOE.

- 2008. 2003 Commercial Building Energy Consumption Survey (CBECS) Public Use Microdata. Accessed March 2, 2014: http://www.eia.gov/consumption/commercial/data/2003/index.cfm?view=microdata.

- 2014a. 2009 Residential Energy Consumption Survey Data, accessed March 2, 2014: http://www.eia.gov/consumption/residential/data/2009/ index.cfm? view=microdata.

—. 2014b. Annual Energy Outlook 2014 with Projections to 2040. Washington, DC: DOE.

- 2015a. Detailed State Data: Average Price by State by Provider (EIA-861). Accessed January 2, 2015: http://www.eia.gov/electricity/data/ eia861/.

- 2015b. Electric Power Sales, Revenue, and Energy Efficiency Form EIA-861 Detailed Data Files. Accessed December 15, 2013: http://www.eia.gov/electricity/data/eia861/.

Elliott, D.L., C.G. Holladay, W.R. Barchet, H.P. Foote, and W.F. Sandusky. 1986. Wind Energy Resource Atlas of the United States. http://rredc.nrel.gov/wind/pubs/atlas/.

Funkhouser, Erik, Griselda Blackburn, Clare Magee, and Varun Rai. 2015. Business Model Innovations for Deploying Distributed Generation: The Emerging Landscape of Community Solar in the U.S. Energy Research \& Social Science 10 (November): 90-101. doi:10.1016/j.erss.2015.07.004. 
Pieter Gagnon, Robert Margolis, Jennifer Melius, Caleb Phillips, and Ryan Elmore. 2015. Rooftop Photovoltaic Technical Potential in the United States: A Detailed Assessment. Golden, CO: National Renewable Energy Laboratory.

George, R., Wilcox, S.; Anderberg, M.; and Perez, R. 2007. "National Solar Radiation Database (NSRDB) - 10 km Gridded Hourly Solar Database." Proceedings of Solar 2007, Cleveland, OH, Published by the American Solar Energy Society.

Hand, M.M., Baldwin, S., DeMeo, E., Reilly, J.M., Mai, T., Arent, D., Porro, G., Meshek, M., Sandor, D. 2012. Renewable Electricity Futures Study. Golden, CO: National Renewable Energy Laboratory. NREL/TP-6A20-52409. http://www.nrel.gov/analysis/re futures/.

HSIP (Homeland Security Infrastructure Program). 2012. "HSIP Gold 2012 Infrastructure ArcGIS 9.3 Filebase Geodatabases"

Jin, Suming, Limin Yang, Patrick Danielson, Collin Homer, Joyce Fry, and George Xian. 2013. "A Comprehensive Change Detection Method for Updating the National Land Cover Database to Circa 2011." Remote Sensing of Environment, 132: 159175.

Kastovich, J.C., Lawrence, R.R., Hoffmann, Pavlak, C. 1982. Advanced Electric Heat Pump Market and Business Analysis. ORNL/Sub/79-2471/1. Prepared under subcontract for Oak Ridge National Laboratory by Westinghouse Electric Corp. Oak Ridge, TN: Oak Ridge National Laboratory.

Kellndorfer, J., Walker, W., LaPoint, E., Bishop, J., Cormier, T., Fiske, G., Hoppus, M., Kirsch, K., and Westfall, J. 2012. "NACP Aboveground Biomass and Carbon Baseline Data (NBCD 2000), U.S.A., 2000.” Oak Ridge, TN: ORNL DAAC.

Mills, Andrew D., and Ryan Wiser. 2012. An Evaluation of Solar Valuation Methods Used in Utility Planning and Procurement Processes. Berkeley, CA: Lawrence Berkeley National Laboratory. LBNL-5933E.

MRLC (Multi-Resolution Land Characteristics Consortium) (2001). "National Land Cover Database 2001.” Accessed December 15, 2013: http://www.mrlc.gov/nlcd01 data.php.

NSRDB (National Solar Radiation Database). 2015. Accessed July 15, 2015: http://rredc.nrel.gov/solar/old data/nsrdb/.

Ong, Sean, Nathan Clark, Paul Denholm, and Robert Margolis. 2013. Breakeven Prices for Photovoltaics on Super in the United States. Golden, CO: National Renewable Energy Laboratory. NREL/TP-6A20-57276. http://www.nrel.gov/docs/fy13osti/57276.pdf.

OpenEI. 2014. U.S. Utility Rate Database. Accessed December 15, 2014: http://en.openei.org/wiki/Utility Rate Database.

ORNL (Oak Ridge National Laboratory). 2011. "Landscan USA'TM Raster Data sets (2011-Prerelease).” 
Paidipati, J., Frantzis, L., Sawyer, H., Kurrasch, A. 2008. Rooftop Photovoltaics Market Penetration Scenarios. Burlington, MA: Navigant Consulting. NREL/SR-58142306. http://www.nrel.gov/docs/fy08osti/42306.pdf.

PNNL (Pacific Northwest National Laboratory). 2012. GCAM Documentation Wiki. PNNL/20809. Accessed January 2013: http://wiki.umd.edu/gcam/index.php/Main_Page.

Rai, Varun, and Benjamin Sigrin. 2013. Diffusion of Environmentally-Friendly Energy Technologies: Buy versus Lease Differences in Residential PV Markets. Environ. Res. Lett. 8014022

Rogers, Everett M. 2003. Diffusion of Innovations. 5th edition. (New York: Free Press, 2003).

R.W. Beck Inc. 2009. Distributed Renewable Energy Operating Impacts and Valuation Study. Prepared for Arizona Public Service

Satchwell, A; Mills, A.; Barbose, G. 2015a. Quantifying the Financial Impacts of Net-Metered PV on Utilities and Ratepayers. Energy Policy 80 (May): 133-44.

doi:10.1016/j.enpol.2015.01.043.

Satchwell, Andrew, Andrew Mills, and Galen Barbose. 2015b. Regulatory and Ratemaking Approaches to Mitigate Financial Impacts of Net-Metered PV on Utilities and Ratepayers. Energy Policy 85 (October): 115-25. doi:10.1016/j.enpol.2015.05.019.

Short, Walter, Patrick Sullivan, Trieu Mai, Matthew Mowers, Caroline Uriarte, Nate Blair, Donna Heimiller, and Andrew Martinez, A. 2011. Regional Energy Deployment System (ReEDS). Golden, CO: National Renewable Energy Laboratory. NREL/TP-6A20-46534. http://www.nrel.gov/docs/fy12osti/46534.pdf.

Sigrin, Ben, and Easan Drury. 2014. Diffusion into New Markets: Economic Returns Required by Households to Adopt Rooftop Photovoltaics. AAAI Energy Market Prediction Symposium. Washington, November 13-15, 2014.

Sigrin, B.; Sullivan, P.; Ibanez, E.; Margolis, R. 2014. Representation of Solar Capacity Value in the ReEDS Capacity Expansion Model. Golden, CO: National Renewable Energy Laboratory. NREL/TP-6A20-61182. http://www.nrel.gov/docs/fy14osti/61182.pdf.

Patrick Sullivan, Wesley Cole, Nate Blair, Eric Lantz, Venkat Krishnan, Trieu Mai, David Mulcahy, and Gian Porro. 2015. 2015 Standard Scenarios Annual Report: U.S. Electric Sector Scenario Exploration. Golden, CO: National Renewable Energy Laboratory. NREL/TP-6A2064072. http://www.nrel.gov/docs/fy15osti/64072.pdf.

U.S. Bureau of the Census. 1994. Geographic Areas Reference Manual. U.S. Dept. of Commerce, Economics and Statistics Administration, Bureau of the Census. Accessed May 1, 2015: https://www.census.gov/geo/reference/garm.html.

Ventyx. 2012. "Velocity Suite: Electric Company Retail Sales Data Combined by Company." 


\section{Appendix A. Rooftop Photovoltaic Information}

\section{A1. Solar Resource}

The solar resource in dGen is based on the National Solar Radiation Database (NSRDB) $10 \mathrm{~km}$ Gridded Hourly Solar Database (George et al. 2007). This database consists of hourly solar radiation estimates for approximately 91,500 grid cells covering the 48 contiguous states and Hawaii at a spatial resolution of roughly $10 \mathrm{~km}$ (Figure A-1). The hourly radiation values for each grid cell in this database are representative of a typical meteorological year, derived from satellite modeled data from 1998 through 2005.

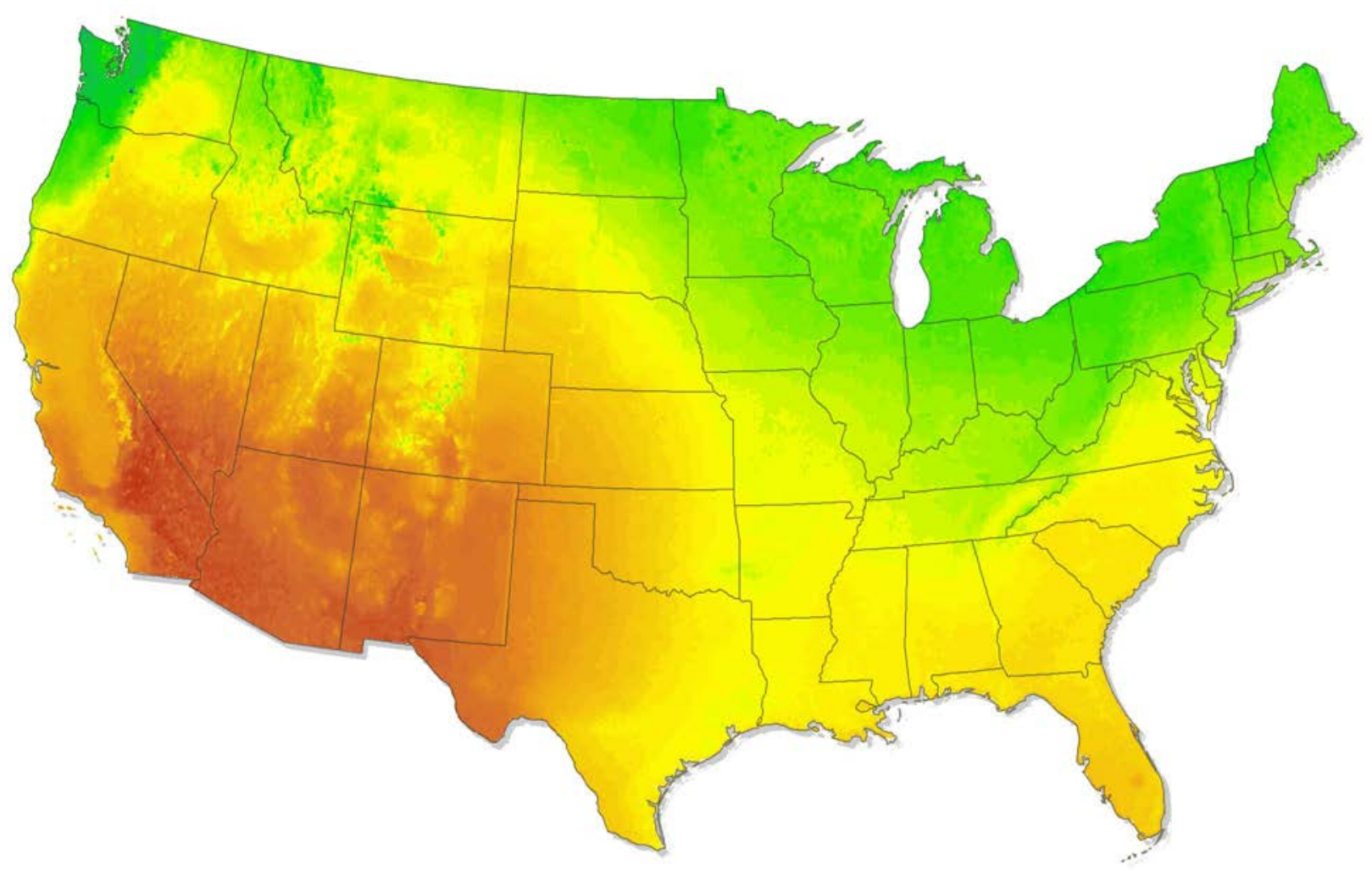

Photovoltaic Solar Resource: Flat Plate Tilted at Latitude $\left(\mathrm{kWh} / \mathrm{m}^{2} /\right.$ day)

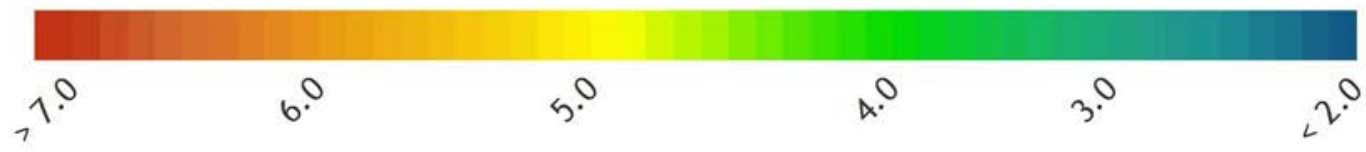

Figure A-1. Map of PV resource derived from NSRDB 10-km Gridded Hourly Solar Radiation Database

To simulate U.S. PV energy production, we applied the SAM PVWatts (Version 5) module (Dobos 2015) to the hourly solar radiation data for each $10 \mathrm{~km}$ grid cell. At each location, we modeled a 1-kW capacity, rooftop PV system for a wide variety of rooftop orientations (tilt and azimuth), including a combination of six tilts $(5,15,25,35,45$, and 55 degrees) and five azimuths (west, southwest, south, southeast, and east) as well as south-facing and tilted at latitude. Using this combination of 31 distinct orientations for each of the 91,500 NSRDB grid cells gives dGen access to annual and hourly electricity generation simulations for more than 2.8 million distinct rooftop PV system configurations across the United States, where agents at the 
$200 \mathrm{~m}$ level are mapped to one of these simulations based on location and likely system configuration.

\section{A2. Rooftop Technical Potential}

To capture regional variation in the configuration of rooftop orientations and their availability and suitability for PV development in dGen, we draw upon and extend work by Gagnon et al. (2015). This section provides a brief background of Gagnon et al. (2015) and then an in-depth description of the methods we used to build on their work to integrate the following components of rooftop PV technical potential into dGen:

1. Top-down constraints on the rooftop area suitable for PV development by region

2. Bottom-up representations of the variation in rooftop configurations (azimuth, tilt, area), also by region.

\section{A2.1 Background}

Gagnon et al. (2015) present methods used to characterize the configuration of rooftops for 128 U.S. cities based on light detection and ranging (LiDAR) data and then apply the results within a modeling framework to predict the total technical potential for rooftop PV. The LiDAR data used in their work included high-resolution (1-m by 1-m) digital surface models (DSMs) and building footprint polygons derived from aerial LiDAR surveys performed by the U.S. Department of Homeland Security (DHS) Homeland Security Infrastructure Program (HSIP) between 2006 and 2014. The full data set covers 1.5\% of mainland U.S. land area, 33\% of the U.S. population, 26.9 million buildings, and 7.7 billion square meters $\left(\mathrm{m}^{2}\right)$ of rooftop area.

Using these data sets, the authors performed a series of geographic information system (GIS) analyses to isolate individual roof planes and determine their suitability for PV development based on size, tilt, azimuth, and shading during different times of year. Suitability is treated by the authors as a Boolean variable of either developable or undevelopable. Using the outputs of this analysis, along with ancillary geospatial data sets, the authors then build, train, and apply predictive models to estimate the rooftop suitability and total technical potential for areas beyond the 128 cities. These predictive models are performed separately for three different building size classes defined by the authors: small ( $<5,000$ sq. $\mathrm{ft}$.), medium (5,000 to 25,000 sq. $\mathrm{ft}$.), and large ( $\geq 25,000$ sq. ft.). The authors provide the resulting PV technical potential estimates by zip code (for small buildings) and census region or state (for medium and large buildings).

For dGen, we applied and extended the work by Gagnon et al. (2015) for two distinct purposes. First, we applied their regional predictions of developable rooftop area as an overall, top-down cap on the allowable deployment of PV systems over time. Second, we performed additional analysis on the subset of developable rooftop planes for the 128 LiDAR cities to determine regional variation in the frequency of various rooftop configurations and sizes across the United States. These regional differences in rooftop characteristics are applied in dGen to stochastically parameterize model agents with system orientations and sizes. Compared with the top-down technical potential caps, these frequencies of rooftop configurations provide more of a bottom-up integration of regional rooftop variation into the model. 


\section{A2.2 Technical Potential Caps}

As noted in the previous section, dGen incorporates the predictions of total developable rooftop area from Gagnon et al. (2015) as caps on PV deployment. These caps constrain the cumulative PV deployment that can occur in a dGen simulation over time but will generally only effect deployment levels when the model scenario is highly favorable for growth in the PV market. The technical potential limits are initialized during the first model year (2014), equal to the developable rooftop area predicted by Gagnon et al. (2015) and scaled linearly over time in equal proportion to load and customer growth. Area is used, rather than capacity, to accommodate improvements in PV panel performance over time.

The caps are applied in the model separately for each building footprint size class. Each agent in the model is parameterized with annual electric consumption data from the RECS and CBECS microdata (EIA 2008; EIA 2014a). Although neither of these microdata sets provides information on building footprint area, we calculate an estimate of building footprint area for each building in the microdata by dividing the building's total square footage by its number of floors. We then classify these estimates into the same building size classes used by Gagnon et al. (2015) and track deployment of PV over all agents in each region by each building size class, ensuring that deployment does not exceed the total developable area estimated by Gagnon et al. (2015).

For simplicity, dGen tracks cumulative deployment and technical potential limits for all building size classes at the state-level resolution. We therefore aggregate zip code level results for small buildings from Gagnon et al. (2015) to states and use population-weighted state-level estimates for medium and large buildings, also from Gagnon et al. (2015). In the former case, aggregation to states likely lowers uncertainty in the predicted technical potential limits. In the latter case, the authors predicted estimates at the census region level and then used a simple populationweighted disaggregation to calculate state-level estimates.

\section{A2.3 Regional Variation in Rooftop Configuration}

To parameterize agents in dGen with rooftop configurations appropriate for their region, customer sector, and electricity usage, we extended the analysis by Gagnon et al. (2015) to derive data sets describing the frequency of various rooftop configurations. The outcome of this analysis is a discrete multivariate distribution of optimal developable roof planes by azimuth, slope, and area class for each region, customer sector, and building size class, which we then interpolated to non-sampled regions. This analysis involved five steps:

1. Identifying building use types aligned with dGen customer sectors (i.e., residential/nonresidential)

1. Deriving the percentage of buildings with at least $10 \mathrm{~m}^{2}$ developable roof area ${ }^{10}$ by building use and size class

2. Ranking the suitability for PV of developable roof planes on each building based on the size of the plane, the size of the building footprint, and the expected annual generation of a roof-mounted PV system

\footnotetext{
${ }^{10}$ Based on currently available technology, $10 \mathrm{~m}^{2}$ is approximately enough area for a $1.3 \mathrm{~kW}$ system.
} 
3. Consolidating the developable roof planes for each building to a single orientation representing the "optimal only" or "optimal blended" plane

4. Deriving a discrete multivariate distribution of optimal roof planes by azimuth, slope, and area class for each region, customer sector, and building size class

These data are then implemented in the agent generation stage highlighted in Section 2 to represent rooftop orientation accurately at the individual agent level.

\section{A2.3.1 Identification of Building Use}

The model simulates PV deployment for three customer sectors: residential, commercial, and industrial. Because the structural design of buildings used by these sectors can vary significantly, our first step in characterizing regional variation in rooftop configurations was to classify the use type for each of the LiDAR buildings analyzed by Gagnon et al. (2015). In preliminary analyses, we found that distinguishing between commercial and industrial use types proved intractable; therefore, our analysis resulted in classification of buildings as either residential or nonresidential.

The methodology we developed to classify building use (residential or non-residential) for each building in the LiDAR data incorporated three predictive variables: building footprint size, estimates of the daytime to nighttime population ratio near the building (ORNL 2011), and distances from known residential/non-residential point sources (HSIP 2012). The three variables were combined in a weighted index that predicted the building use based on the overall score (Figure A-2, Figure A-3, and Figure A-4).
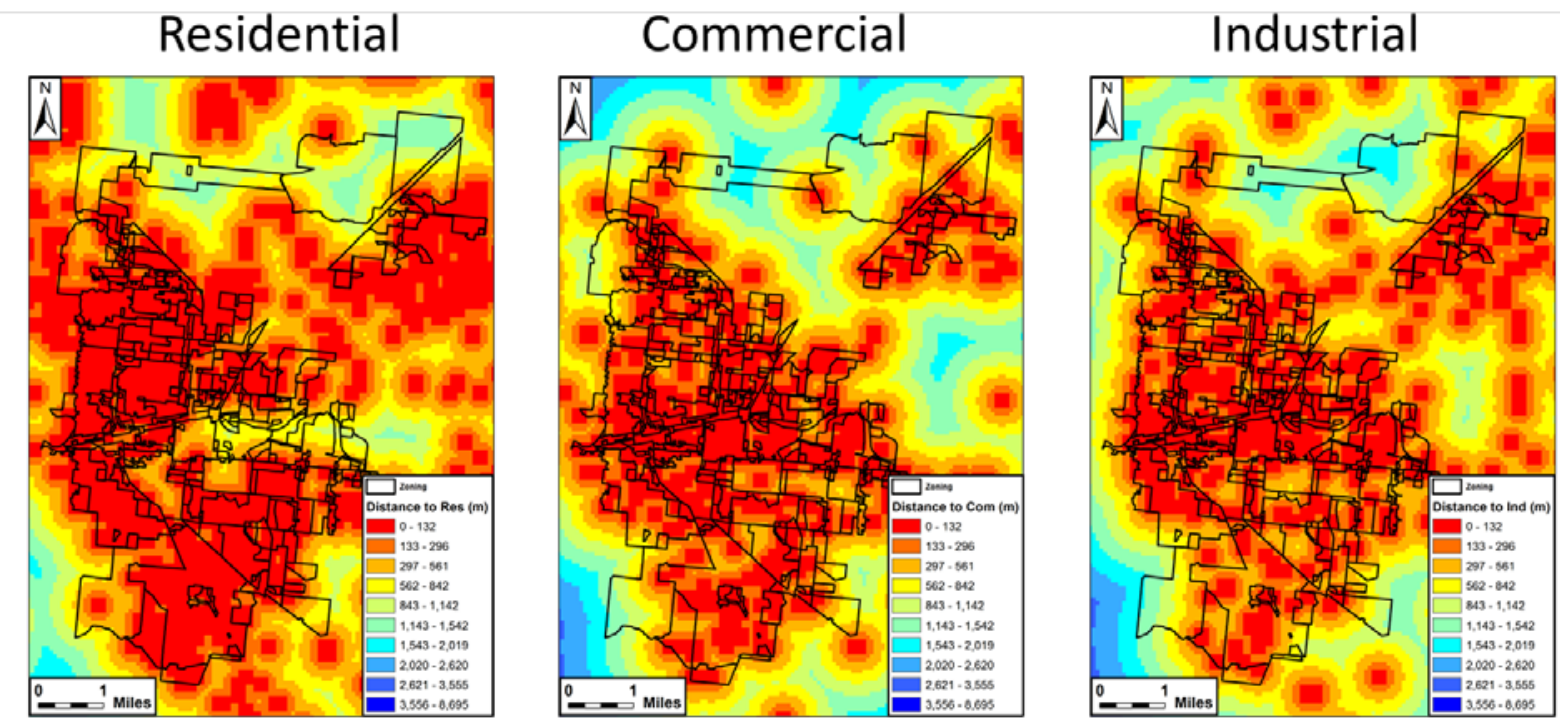

Figure A-2. Distance to the nearest residential, commercial, and industrial presence cells

Each building received a score of 1 for either residential or 1 for non-residential (commercial/industrial), based on whichever building use had the smaller distance. 


\section{Day Population}

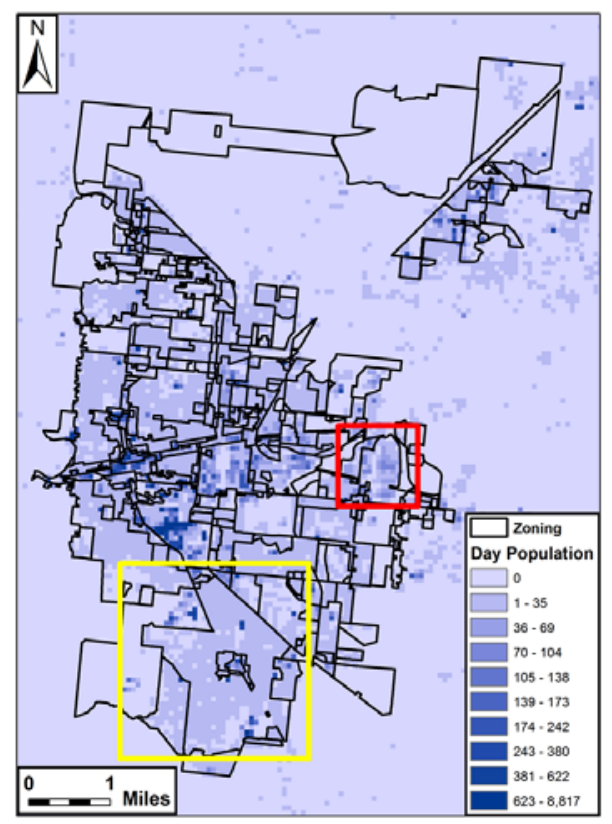

Night Population

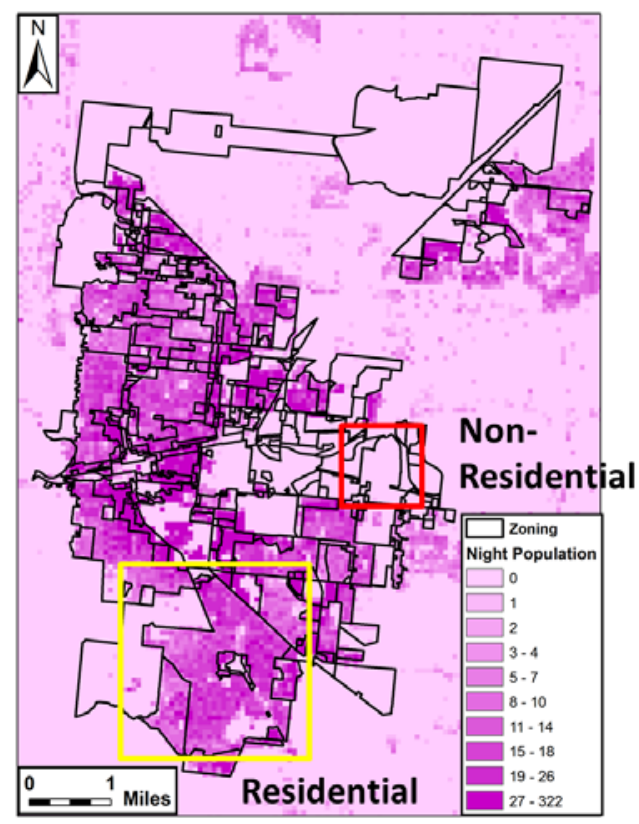

Figure A-3. Daytime and nighttime population in Boulder, CO

Buildings were given a score of 1 for residential where the nighttime population was greater than the daytime population and a score of 1 for non-residential where the daytime population was greater than the nighttime population.

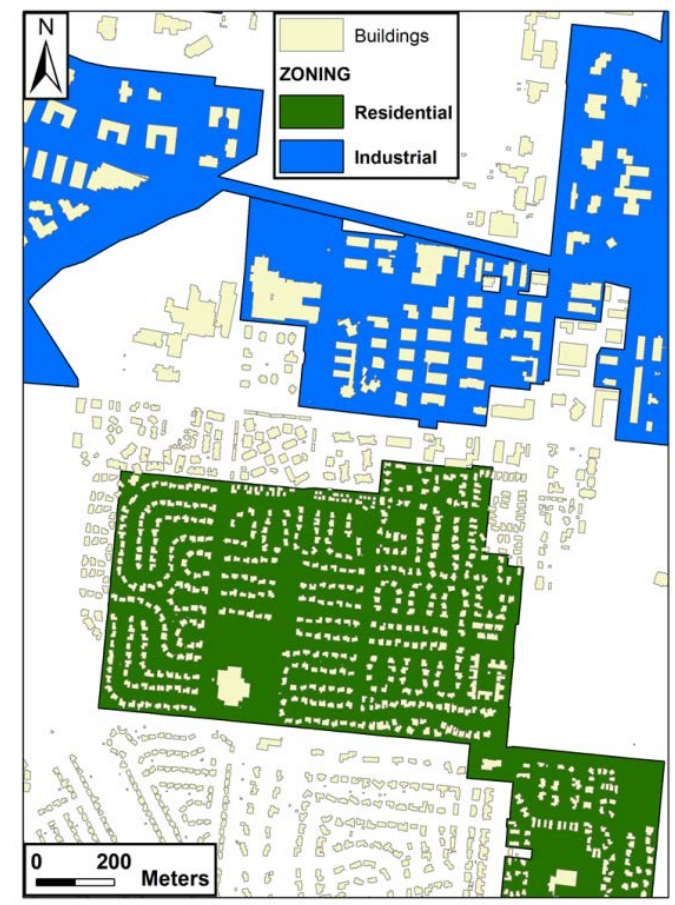

Figure A-4. Example of building footprint size in an area of Boulder, $\mathrm{CO}$

Building footprint size can be used as a predictor of building use, as smaller buildings tend to be residential (green area), and larger buildings tend to be non-residential (blue area). 
The building use classification model was trained using a cross-validation method for three cities of varying population and urban characteristics (Baltimore, Maryland; Minneapolis, Minnesota; and Boulder, Colorado). For each city, true building use was extracted from zoning polygon shapefiles downloaded from each of the city's websites, for each building location. The classification model was trained to determine the breakpoints in the building footprint size classification as well as the relative importance of each contributing data set (footprint size, daytime ratio, and distance to known establishments) to the overall classification. The final model specification was based on minimizing the error between modeled and actual classification, averaged over the three cities to avoid overfitting. Specifically, average accuracy is determined from user accuracy (Equation A1) and producer accuracy (Equation A2) for both residential and non-residential classes for each training city as described in Equation A3.

$$
\begin{aligned}
& \text { User Accuracy }=\frac{\# \text { Correct Residential }}{\# \text { Classified as Residential }} \text { X } 100 \\
& \text { Producer Accuracy }=\frac{\# \text { Correct Residential }}{\text { Total } \# \text { of Residential }} \text { X } 100 \\
& \text { Average Accuracy }=\frac{\text { Res User }+ \text { Res Producer }+ \text { Non Res User }+ \text { Non Res Producer }}{4}
\end{aligned}
$$

Finally, we validated the classification model against zoning data for three additional cities (Charlotte, North Carolina; Helena, Montana; and San Francisco, California) to assess the overall accuracy of the model. Only buildings in areas zoned for purely residential or purely nonresidential purposes were used in the accuracy assessment, and the accuracy of mixed zones was not assessed. Overall accuracy of the model was high, at 84.99\% (Table A-1, Figure A-5). Buildings that were classified incorrectly were generally located in small zones because of the coarse cell size of the input data sets. In all three cities, the lowest accuracy was the producer accuracy of non-residential buildings, suggesting that the model predicts non-residential buildings too conservatively.

Table A-1. Accuracy of Building Use Classification Model

\begin{tabular}{|l|l|l|}
\hline $\begin{array}{l}\text { Average Non-Residential } \\
\text { Building Use Accuracy }\end{array}$ & $\begin{array}{l}\text { Average Residential } \\
\text { Building Use Accuracy }\end{array}$ & Overall Average Accuracy \\
\hline $83.65 \%$ & $86.33 \%$ & $84.99 \%$ \\
\hline
\end{tabular}




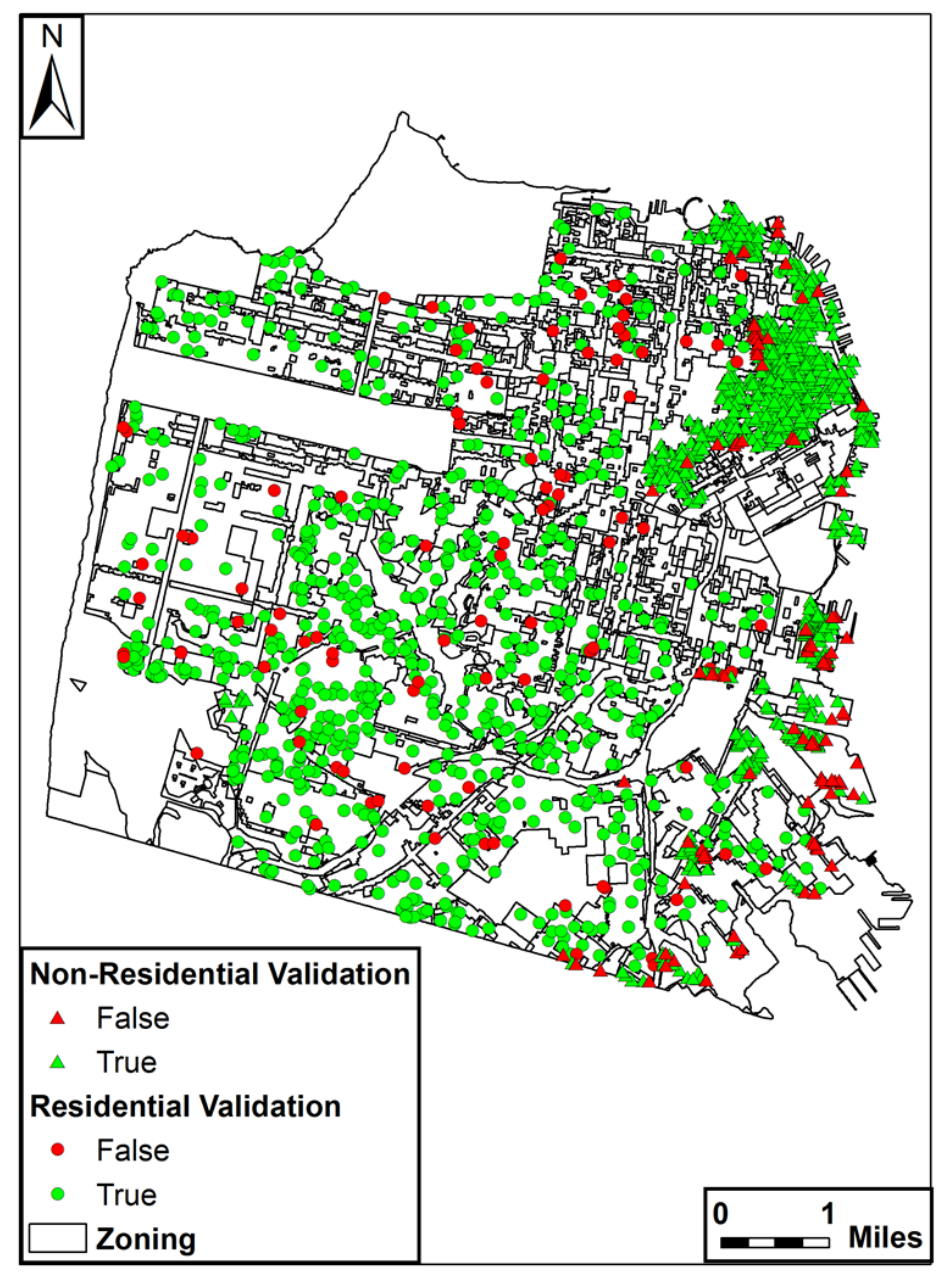

Figure A-5. Map illustrating the accuracy of classifying residential and non-residential buildings in San Francisco, CA

We applied the trained classification model to every building in the LiDAR data set, resulting in a classification of building use type for the 128 cities in the LiDAR data. The classification was applied to buildings in non-sampled areas based on locales using the nearest city.

\section{A2.3.2 Identifying Percentage of Undevelopable Buildings}

For each of the 128 cities in the LiDAR data set, we calculated the percentage of buildings with at least one developable roof plane by building use type and footprint size class (small, medium, or large). A "developable" roof plane is defined in Gagnon et al. (2015) as having at least $10 \mathrm{~m}^{2}$ of roof area which is: (1) at least $80 \%$ unshaded, and (2) not oriented to the northwest, north, or northeast. This area is roughly equivalent to a $1.5-\mathrm{kW}$ crystalline silicon (c-Si) system using currently available technology. These estimates of the percentage of undevelopable buildings are applied to each agent in dGen, according to their sector and building size class, to determine the portion of customers who are entirely restricted from rooftop PV adoption. 


\section{A2.3.3 Ranking Rooftop Suitability}

For each building in the LiDAR data set, we ranked the suitability of its roof planes for PV development. These rankings are based on the area and expected annual generation of each plane and the size of the building footprint, which is used as a proxy for electricity demand.

To rank the roof planes, we performed the following preprocessing steps:

- Reclassify the continuous slope and azimuth values for each developable LiDAR roof plane to a discrete set of 31 combinations of slope and azimuth, corresponding to the combinations used in PV system generation modeling

- Group all planes with like orientations on the same building into a "composite plane" and calculate their aggregate area

- Link each composite plane to the most appropriate estimate of PVWatts simulated annual energy production for a 1-kW PV system based on location, azimuth, and tilt.

Using the expected energy production and aggregate area, we ranked the set of eligible planes for each building to determine the optimal developable composite plane for the building. Our ranking method assumed that building owners would prioritize efficiency of energy production on large roof planes (to get the most production per unit cost) and that they would secondarily prioritize absolute energy production on small planes (to maximize production).

To match this heuristic, rankings were calculated in a stepwise fashion. First, all composite planes occupying greater than $10 \%$ of the building's footprint were ranked in descending order by PV efficiency (kWh per $\mathrm{kW}$ ). Second, all remaining small planes were ranked in descending order based on the product of PV efficiency and roof plane area. The two sets of ranks were then merged, in order, to create one seamless set of rankings.

\section{A2.3.4 Consolidating to "Optimal" Roof Planes}

Due to computational limits and performance considerations, agents in dGen are constrained such that each agent can only consider the economics for a PV system where all panels share a single uniform orientation (i.e., one tilt and one azimuth). As a result, to parameterize agents based on rooftop configurations derived from the LiDAR data set, each LiDAR building with multiple developable roof planes needs to be simplified to a representation of a single roof plane. Because there is no straightforward way to perform this simplification without inherently losing some fidelity and introducing bias into the model, we performed two different approaches and we allow users of dGen to choose between them to perform sensitivity analyses.

The two approaches we used are:

1. Optimal Only: Select only the single "optimal" developable roof plane for each building and ignore all other roof planes.

2. Optimal Blended: Treat all developable roof planes as if they shared the orientation of the "optimal" roof plane, discounting their areas in proportion to their capacity factors.

For each approach, we first used the suitability rankings, described in Section A2.3.3, to select the highest-ranked composite plane for each building as the optimal developable plane. For the Optimal Only approach, we simply filtered out all other roof planes, as if the developable area of 
each building only consists of its optimal plane. For the Optimal Blended approach, we calculated the ratio of the modeled energy production for each suboptimal composite plane to that of the optimal composite plane, applied that ratio to discount the area of each suboptimal plane, and then summed all areas. For each approach, we then proceeded to derive (separate) regional frequencies of rooftop configurations.

The two approaches - Optimal Only and Optimal Blended-likely introduce opposite biases into the parameterization of agents in dGen. In the case of the Optimal Only approach, it is possible that, because each customer is limited to only a single roof plane, some fraction of model agents will not have sufficient rooftop area to offset their targeted percentage of load. For example, analysis of the California Solar Initiative Working Data Set, ${ }^{11}$ which provides information on PV installations that received incentives through the California Solar Initiative incentive program, reveals that approximately $20 \%$ of residential customers and $27 \%$ of nonresidential customers installed systems on multiple roof planes. Therefore, the Optimal Only approach could potentially under-predict overall deployment simulated in dGen compared to the regional technical potential limits.

On the other hand, the Optimal Blended approach will slightly over-predict the amount of solar generation available, because, by blending suboptimal planes into optimal planes, some agents have more generation than they could if they actually had to install additional panels at a less efficient orientation. Therefore, whereas the Optimal Only approach could negatively bias dGen results, the Optimal Blended approach could positively bias model results. By exposing both options in the scenario inputs, users are able to perform sensitivity analyses to evaluate the impact of these potential biases on model results.

\section{A2.3.5 Deriving Regional Frequencies of Rooftop Configurations}

For each of the Optimal Only and Optimal Blended roof planes described above, we determined frequency distributions (counts) of the number of optimal roof planes binned by unique combinations of plane azimuth, tilt, and area and building use (residential and non-residential use), size class (small, medium, large), city, and locale type (e.g., urban, suburban, rural). These distributions in turn permit interpolation to non-sampled areas and are congruent with the stochastic approach used in dGen. Specifically, an agent in a given location will sample its rooftop configuration from the most proximal city's frequency distribution, limiting to those buildings that match the agent's building use (i.e., sector), building size class, and locale type.

Tilt and azimuth classes used in these frequencies are aligned with those previously described as are classes for building use and size class. Locale type is one of the predictive variables used by Gagnon et al. (2015) and provides designations that allow for distinguishing between areas such as: Small Town, Large City, Suburb Small, and Rural Remote (MRLC 2001). The area classes used for roof planes are detailed below and are based on the distribution of system sizes observed in the California Solar Initiative Working Data Set:

Slope Area for Residential Buildings Breakpoints $\left(\mathrm{m}^{2}\right)=[<0.4,12,15,18,20,22,24,26,28,30$, $32,34,37,39,42,46,50,56,67,>1278]$

\footnotetext{
${ }^{11}$ https://www.californiasolarstatistics.ca.gov/data_downloads/
} 
Slope Area for Non-Residential Buildings Breakpoints $\left(\mathrm{m}^{2}\right)=[<1,15,22,30,38,50,61,73,89$, $112,139,173,208,274,349,505,751,1202,2061,>7710]$

The end result is a count of optimal roof planes for PV development in each combination of the variables listed above. These counts represent the "distributions" of optimal roof planes across these variables and are used to parameterize agent roofs in dGen. The frequency tables of roof plane characteristics are too large to list here in a meaningful way but are available upon request. 


\section{Appendix B. Distributed Wind Information}

This appendix details the data sets, algorithms, and assumptions used to develop the distributed wind module of the dGen model.

\section{B1. Wind Turbine Configurations}

The distributed wind module of the dGen model represents the range of real-world distributed turbines using a simplified set of turbine sizes (i.e., rated capacities) and hub heights. Table B-1 below shows the combinations of turbine sizes and hub heights included in the model.

Subsequent sections in this appendix discuss turbines using four generic size classes: small residential, small commercial, mid-size, and large. These terms are not necessarily industry standard; therefore, for clarity, Table B-1 also specifies the specific turbine sizes associated with each size class.

Table B-1. Wind Turbine Configurations included in in the dGen Model

\begin{tabular}{|c|c|c|c|c|c|c|}
\hline \multirow[b]{2}{*}{ Turbine Size Class } & \multirow[b]{2}{*}{ Turbine Size (kW) } & \multicolumn{5}{|c|}{ Hub Height (m) } \\
\hline & & 20 & 30 & 40 & 50 & 80 \\
\hline Small (Residential) & 2.5 & & & & & \\
\hline Small (Residential) & 5 & & & & & \\
\hline Small (Residential) & 10 & & & & & \\
\hline Small (Residential) & 20 & & & & & \\
\hline Small (Commercial) & 50 & & & & & \\
\hline Small (Commercial) & 100 & & & & & \\
\hline Midsize & 250 & & & & & \\
\hline Midsize & 500 & & & & & \\
\hline Midsize & 750 & & & & & \\
\hline Large & 1000 & & & & & \\
\hline Large & 1500 & & & & & \\
\hline
\end{tabular}

\section{B2. Wind Resource}

Wind resource in dGen is derived from a gridded data set of hourly wind speed data licensed by NREL from AWS TruePower. These data consist of hourly average wind speeds for the typical meteorological year (TMY) at each location (AWST 2012a). These TMY hourly profiles represent typical historical conditions at each grid cell based on 14 years of wind speed data. This data product is used in several other models and studies, including the Regional Energy Deployment System (ReEDS) model (Short et al. 2011) and the DOE Wind Vision report (DOE 2015). 
The gridded AWS TruePower wind speed profiles are available at a $20-\mathrm{km}$ spatial resolution across the continental United States. To represent the variation in wind resource within each 20$\mathrm{km}$ grid cell, AWS TruePower subdivides each cell into several subsets of locations associated with different levels of annual average wind resource and provides a separate TMY profile for each one (AWST 2012a). AWS TruePower also provides a finer resolution (200 m) annual gross capacity factor grid for a modeled International Electrotechnical Commission Class II turbine (Figure B-1), which can be used to identify the subsets of locations associated with the various profiles within each 20-km grid cell (AWST 2012b). Using this $200 \mathrm{~m}$ grid, the various TMY wind speed profiles can be resolved to approximate the wind resource at various heights for each $200 \mathrm{~m}$ by $200 \mathrm{~m}$ grid cell across the country.

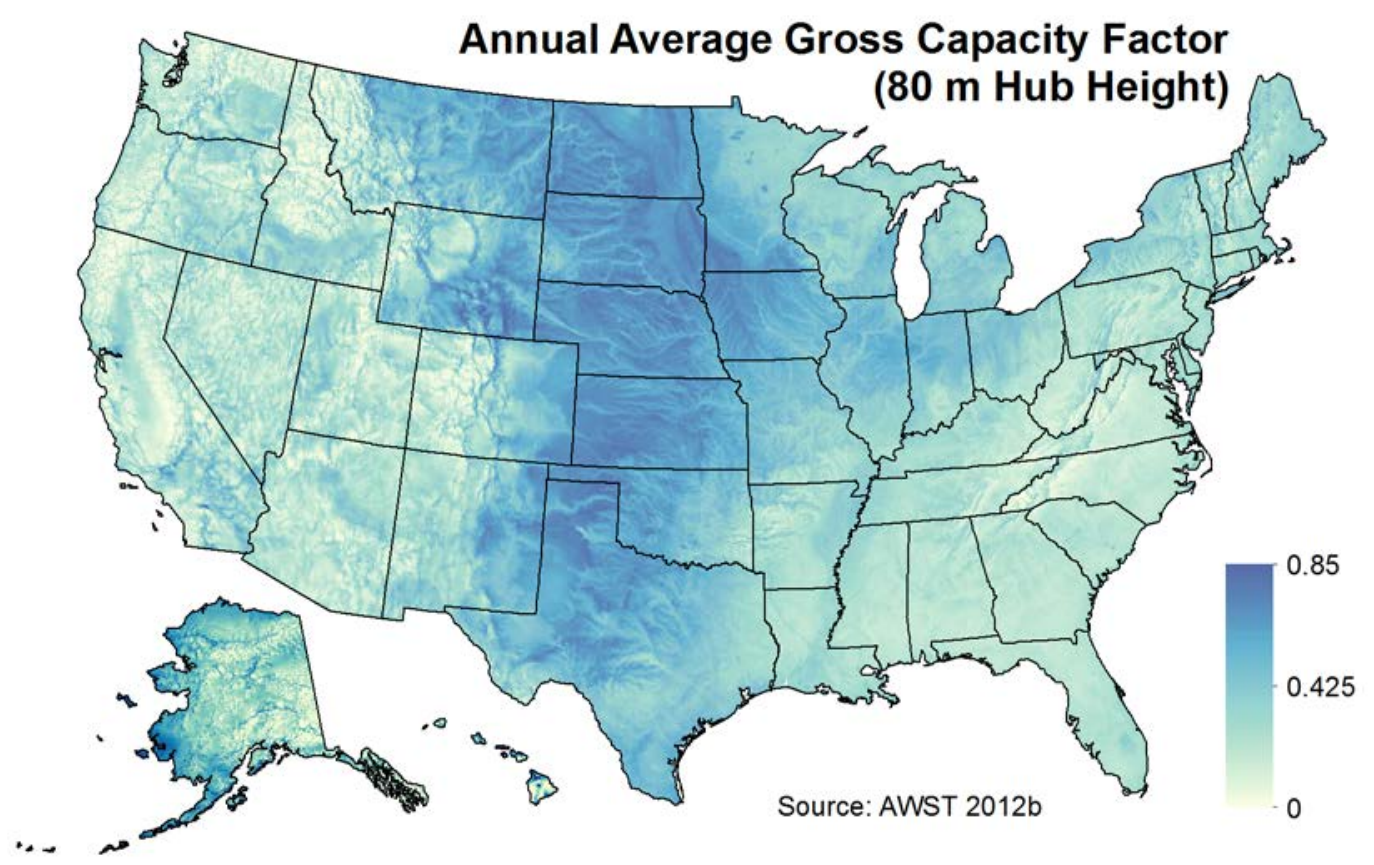

Figure B-1. Annual average gross capacity factor for a modeled International Electrotechnical

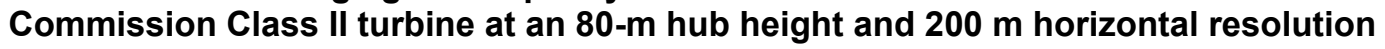

As noted in Table B-1, dGen model agents can install turbines at hub heights of 20, 30, 40, 50, and $80 \mathrm{~m}$ above ground to facilitate access to various levels of wind resource. The wind speed profiles from AWS TruePower are currently available at heights of 30,50 , and $80 \mathrm{~m}$. To model wind generation at 20 and $40 \mathrm{~m}$, NREL has applied a vertical wind shear adjustment to the $30-\mathrm{m}$ TMY profiles. The wind shear adjustment is derived from Elliott et al. (1986):

$$
V_{d}=V *\left(\frac{H_{d}}{H}\right)^{\propto}
$$

where $V$ is the known wind speed at a given height $H$, and $V_{d}$ is the derived wind speed at a given height $H_{d}$. The value for $\alpha$ (alpha) can be derived empirically by comparing wind speeds at two different heights above ground. Using the 30- and 50-m height TMY profiles, NREL has derived alpha values on an hourly basis and applied them to derive estimates of wind speed at 20- and 40-m hub heights for each location. 
To convert the wind speed profiles into wind generation profiles, we applied each of the eight normalized turbine power curves described below to the hourly wind speed data profiles, adjusting for site-specific performance factors such as elevation. The result is an estimate of normalized annual energy production for each turbine power curve at five hub heights $(20,30$, 40,50 , and $80 \mathrm{~m}$ ) for every $200 \mathrm{~m}$ by $200 \mathrm{~m}$ grid cell across the United States.

Normalized annual energy production is derated in the model based on a default value of 0.85 , which assumes $15 \%$ energy loss as a result of various factors (e.g., turbine downtime for maintenance and repair). This value is consistent with the Wind Vision study (DOE 2015); however, model users are able to alter this assumption for each turbine size class and model year.

\section{B3. Turbine Performance}

After a detailed review of power curves across the whole spectrum of sizes from $2 \mathrm{~kW}$ to 1.5 MW, we selected four power curves to represent the current and best available technology in its size range. The size ranges included small residential ( $2.5 \mathrm{~kW}$ to $20 \mathrm{~kW})$, small commercial $(50 \mathrm{~kW}$ to $100 \mathrm{~kW})$, midsize $(250 \mathrm{~kW}$ to $750 \mathrm{~kW})$, and large $(1,000 \mathrm{~kW}$ and $1,500 \mathrm{~kW})$. These curves were normalized by the rated power of the turbine. In each case, the inverse of the power density was calculated. Then, the annual energy of the normalized power curve was calculated for a five meter per second average wind speed with a Rayleigh distribution. The output is in kilowatt-hours per kilowatt per year $(\mathrm{kWh} / \mathrm{kWp} / \mathrm{yr})$. Peak power $(\mathrm{kWp})$ was used because there is no standard rated wind speed for turbines larger than $200 \mathrm{~m}^{2}$ of swept area.

NREL constructed four generic power curves that were comparable to the four normalized power curves. These generic power curves used the same swept area per kilowatt rating as the normalized curves and assumed a fixed efficiency that produced the same annual energy. Although this approach gives a slightly different power curve shape, it creates an easy format to compare across size ranges and avoids the confusion and complexity of trying to represent pitchregulated versus stall-regulated and variable-speed versus fixed-speed power curves. The results for the current performance are summarized in Table B-2. 
Table B-2. Baseline 2015 Distributed Wind Turbine Performance

\begin{tabular}{|l|c|c|c|}
\hline Turbine Size & $\begin{array}{l}\text { Rotor Efficiency } \\
\text { (m2/kW) }\end{array}$ & $\begin{array}{l}\text { Turbine Efficiency } \\
\text { (\%) }\end{array}$ & Power Curve) \\
\hline Residential & 3.07 & 29.0 & 1 \\
\hline Small & 4.9 & 37.5 & 2 \\
\hline Midsize & 3.1 & 42.0 & 3 \\
\hline Large & 4.9 & 38.5 & 4 \\
\hline
\end{tabular}

With the premise that the current large turbine is fairly mature technology and not going to make dramatic increases in performance, we adjusted the large generic power curve in the far future case to $5.2 \mathrm{~m}^{2} / \mathrm{kWp}$ and $44 \%$ efficiency, which represents less than a $16 \%$ improvement in annual energy at a five meter per second average wind speed.

The midsized turbine selected is on the large end of the scale and incorporates active pitch and variable speed. Even though it has a small swept area for its rating, it is very efficient. As a result, we considered it to be a mature technology for efficiency. Therefore, although the swept area to rating is increased from its current low point in two steps to the same high value as the far future large turbine, the efficiency is only increased 1\% at each step. The far future normalized power curve for the midsized turbine is the same as the curve for the far future large turbine. There does not appear to be any technical reason for a difference in performance between the large and midsize turbines. The question is whether there will be a sufficient investment in this size range to achieve these results.

Originally, the small turbine category included what is now referred to as residential; however, there was such a large difference between the small end of the category and the large end $(100 \mathrm{~kW})$ that we could not represent it accurately as one segment. There are turbines at the 50 $\mathrm{kW}$ and $100 \mathrm{~kW}$ scales that perform levels similar to those of the larger turbines; in other words, these turbines are fairly mature in the area of performance. However we assume that turbines $20 \mathrm{~kW}$ or less can experience large improvements in design; though they start with different performance, $3.07 \mathrm{~m}^{2} / \mathrm{kWp}$ and $29 \%$ efficiency for residential and $4.9 \mathrm{~m}^{2} / \mathrm{kWp}$ and $37.5 \%$ efficiency for small, in two steps they both end up at $5.2 \mathrm{~m}^{2} / \mathrm{kWp}$ and $40 \%$ efficiency (Table B-3). 
Table B-3. Future Performance Characteristics for the Turbines used in dGen

\begin{tabular}{|l|l|l|l|l|}
\hline Turbine Size & $\begin{array}{l}\text { Rotor } \\
\text { Efficiency } \\
\text { (m2/kWp) }\end{array}$ & $\begin{array}{l}\text { Turbine- } \\
\text { Specific Power } \\
(\mathbf{W} / \mathbf{m} \mathbf{)})\end{array}$ & $\begin{array}{l}\text { Capacity } \\
\text { Factor }\end{array}$ & $\begin{array}{l}\text { Power } \\
\text { Curve }\end{array}$ \\
\hline Small Residential & 3.07 & 326 & 0.290 & 1 \\
\hline $\begin{array}{l}\text { Small Commercial (>20 and } \\
<=\mathbf{1 0 0 )}\end{array}$ & 4.90 & 204 & 0.375 & 2 \\
\hline Midsize (>100 and <1,000) & 3.10 & 323 & 0.420 & 3 \\
\hline Large (>1,000) & 4.90 & 204 & 0.385 & 4 \\
\hline Near Future Small Residential & 4.00 & 250 & 0.325 & 5 \\
\hline Far Future Small Residential & 5.20 & 192 & 0.400 & 6 \\
\hline Near Future Small Commercial & 4.90 & 204 & 0.385 & 4 \\
\hline Far Future Small Commercial & 5.20 & 192 & 0.400 & 6 \\
\hline Near Future Midsize & 4.20 & 238 & 0.430 & 7 \\
\hline Far Future Midsize & 5.20 & 192 & 0.440 & 8 \\
\hline Far Future Large & 5.20 & 192 & 0.440 & 8 \\
\hline
\end{tabular}

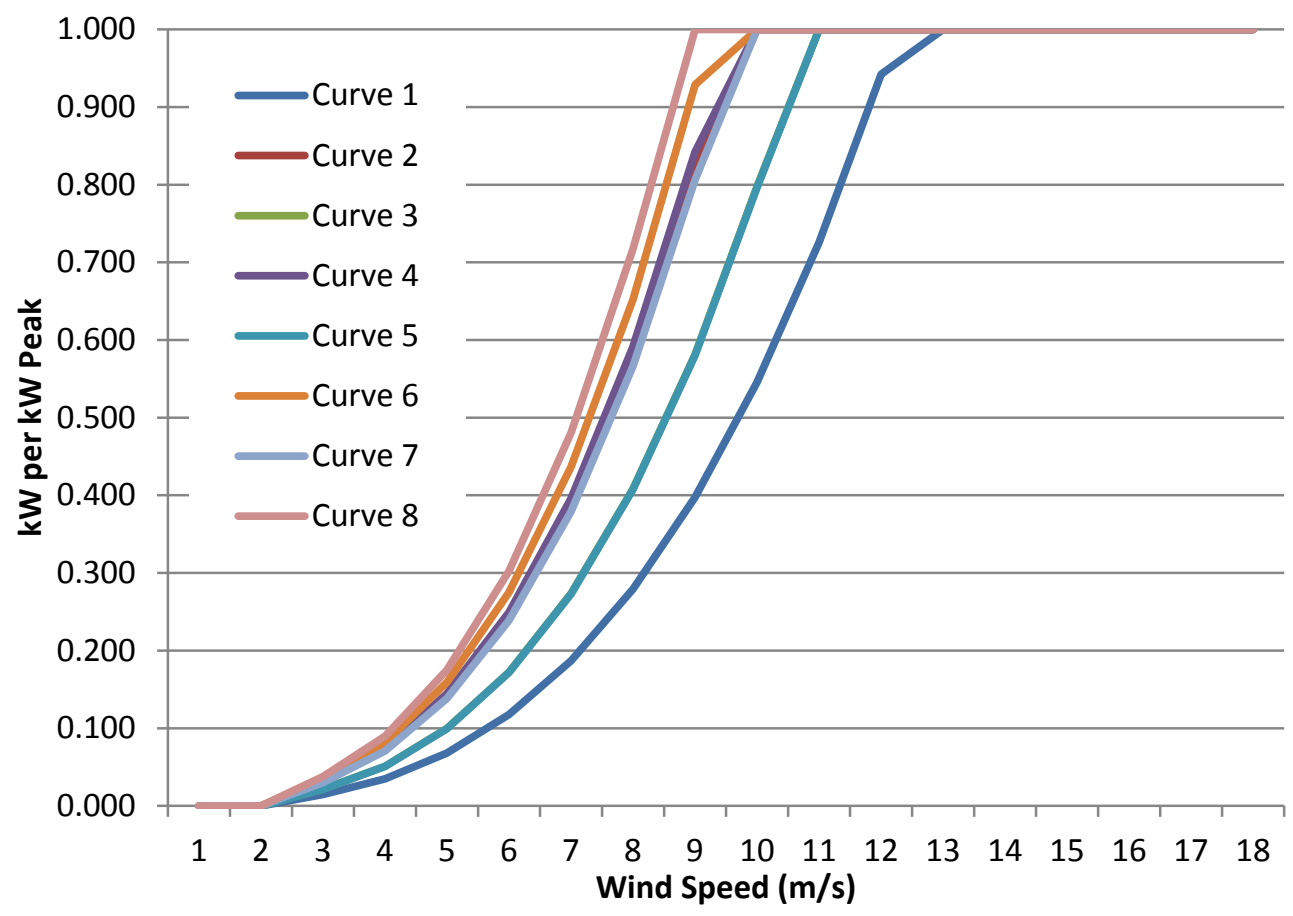

Figure B-2. Normalized wind turbine power curves used to calculate power production based on size and technology evolution 


\section{B4. Turbine Height and Size Restrictions}

As described in Section B2, dGen simulates annual and hourly wind energy production at a range of turbine hub heights for every $200 \mathrm{~m}$ by $200 \mathrm{~m}$ grid cell across the continental United States. These resource estimates are then linked to agent locations using a simple GIS spatial overlay.

Although the wind resource is modeled at several heights for every agent location, each agent may have only a limited set of allowable turbine hub heights and system sizes based on its local siting considerations. Specifically, the allowable turbine heights and sizes for each agent are constrained in the model based on three local factors: parcel size, degree of existing development, and nearby tree canopy density and height. These local factors have been set for each agent location in the model through a GIS analysis of fine-resolution, national geospatial data sets; however, the specific assumptions relating these factors to ranges of allowable turbine heights are flexible inputs that can be adjusted by users of the wind information in dGen.

Together, these three factors are used to provide a nationwide approximation of the legal (i.e., zoning, safety) and operational constraints affecting distributed wind development. Figure B-3 provides an overview of the processes used to analyze each factor and how they are combined to determine the range of allowable turbine heights at each agent location.

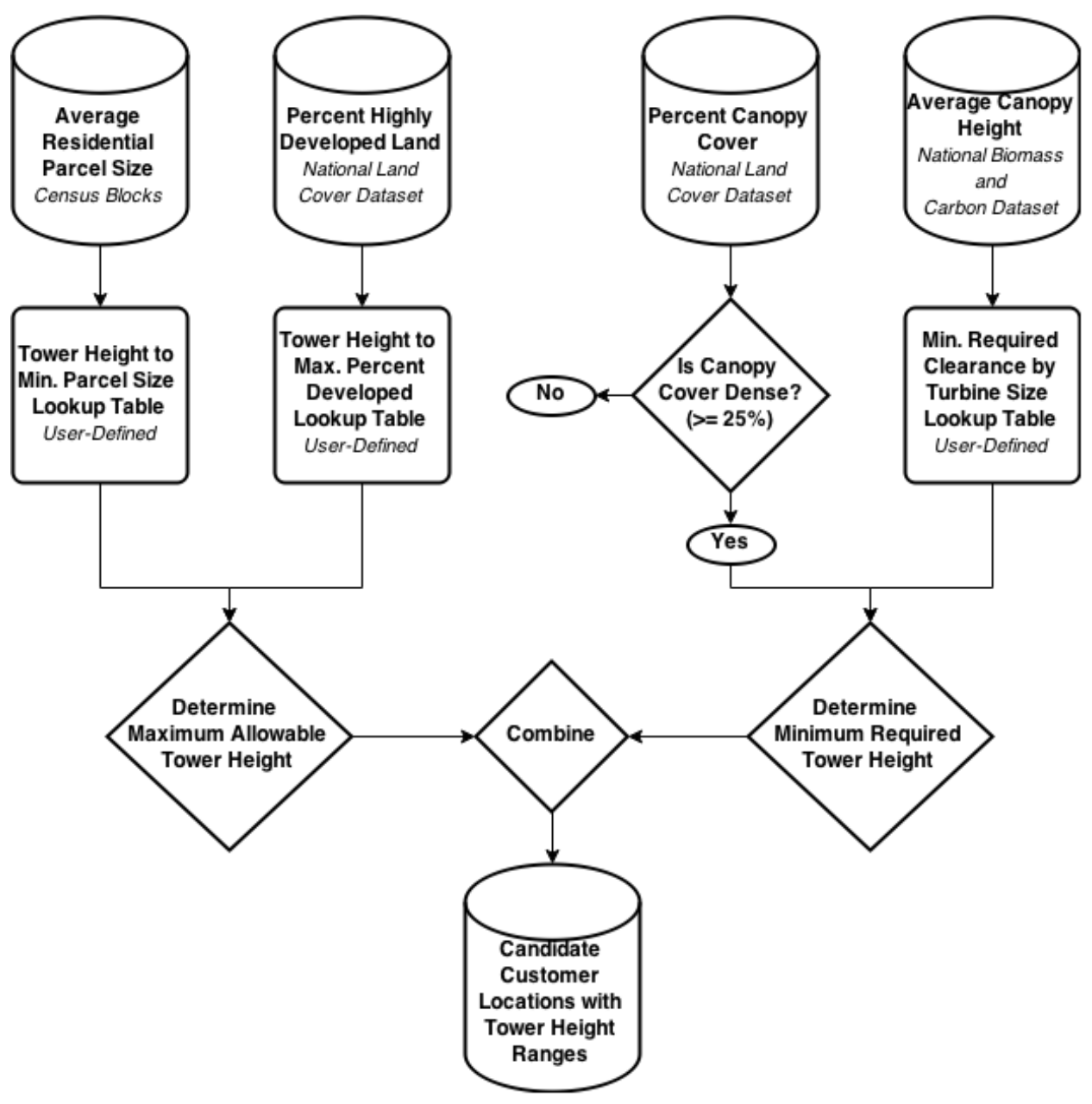

Figure B-3. Workflow illustrating the analysis used to develop and combine each of the factors that affects the range of developed turbine hub heights at each customer location 
The average residential parcel size is the first factor used in determining turbine height restrictions. This factor was selected as an important constraint because, during discussions between NREL and representatives of the Distributed Wind Energy Association, parcel size was highlighted as an important first-order indicator for the feasibility of installing different-height turbines. Nationwide parcel data sets are not freely available; therefore, dGen uses estimates of acres per housing unit derived from the Census 2010 at the block level as an alternative. Blocks are the smallest available geographic region for Census data (U.S. Bureau of the Census 1994). Due to their fine spatial resolution, blocks allow for capturing sufficient spatial heterogeneity to differentiate patterns in parcel size between agent locations. In dGen, the maximum allowable turbine height allowed at each agent location is constrained by the average residential parcel size for the intersecting block, and a user-defined table that defines minimum required parcel size for each of the turbine hub heights evaluated in the model (Table B-4). The current default values shown in Table 8 are based on preliminary feedback from Distributed Wind Energy Association representatives.

Table B-4. User Input Defining Minimum Parcel Size Required for Each Turbine Hub Height, Populated with Current Default Values

\begin{tabular}{|c|c|}
\hline $\begin{array}{l}\text { Turbine Hub Height } \\
\text { (m) }\end{array}$ & $\begin{array}{l}\text { Minimum Parcel Size } \\
\text { (acres) }\end{array}$ \\
\hline 20 & 0.50 \\
\hline 30 & 1.00 \\
\hline 40 & 2.00 \\
\hline 50 & 3.00 \\
\hline 80 & 4.00 \\
\hline
\end{tabular}

Because the Census block data only account for residential development, a secondary data set was used to assign an overall degree of all developed land to each customer location. These data were derived from the fine-resolution (30-m by 30-m) National Land Cover Data set 2011 (NLCD) (Jin et al. 2013), which includes a "High Intensity" land class that constitutes "highly developed areas where people reside or work in high numbers," including "apartment complexes, row houses, and commercial/industrial" properties (MRLC 2001). Given the intensity of development associated with this land class, dGen assumes that portions of agent locations that it occupies cannot be developed for wind. The percentage of each $200 \mathrm{~m}$ by $200 \mathrm{~m}$ agent location covered by this land class was derived from the finer resolution NLCD grid. To translate the percentage of highly developed land at each location to a turbine height constraint, dGen allows the user to define the maximum percentage of heavily developed land at an agent location for each of the turbine hub heights evaluated in the model (Table 9). The current default values shown in Table B-5 were derived by NREL analysts based on the assumption that a turbine of hub height $\mathrm{H}_{\mathrm{H}}$ requires a minimum area of undeveloped land equal to $\left(2 \mathrm{H}_{\mathrm{H}}\right)^{2}$ and that the nonhighly-developed land within each agent location is optimally configured in a contiguous square area. 
Table B-5. User Input Defining the Maximum Allowable Percent of Heavily Developed Land at Each Agent Location for Each Turbine Hub Height, Populated with Current Default Values

\begin{tabular}{|c|c|}
\hline $\begin{array}{l}\text { Turbine Hub } \\
\text { Height }(\mathbf{m})\end{array}$ & $\begin{array}{l}\text { Maximum Percentage of } \\
\text { Heavily Developed Land }\end{array}$ \\
\hline 20 & 96 \\
\hline 30 & 91 \\
\hline 40 & 84 \\
\hline 50 & 75 \\
\hline 80 & 26 \\
\hline
\end{tabular}

The third factor that contributes to the range of allowable turbine heights in dGen is the density and height of the tree canopy around each agent location. The density of the canopy cover was determined using a fine-resolution $(30-\mathrm{m}$ by $30-\mathrm{m})$ grid of percentage of canopy that is included as a component of the NLCD (2011) (Jin et al. 2013). Agent locations with an average canopy cover less than $25 \%$ are treated in the model as "low density canopy" and are not assigned any additional turbine height requirements. This threshold was selected by NREL analysts and can be adjusted in dGen if necessary. Locations with canopy coverage above this threshold are further evaluated in the model by determining the average canopy height, which was derived from the fine-resolution (30-m by 30-m) National Biomass and Carbon Data set (Kellndorfer et al. 2012). At locations with high canopy density, the canopy height is combined with a user-defined minimum required clearance above tree cover for each turbine size (e.g., $20 \mathrm{~m}$ clearance above the highest obstacle for a 10-kW turbine) (Table B-6) to constrain the range of allowable turbines. The current default values for minimum required canopy clearances shown in Table 10 were derived assuming a static clearance of $15 \mathrm{~m}$ for all turbines, plus a scalar factor of 1.1 times the approximate turbine radius.

Table B-6. User Input Defining the Canopy Clearance Required for Each Turbine Size (i.e., Rated Capacity), Populated with Current Default Values

\begin{tabular}{|c|c|c|}
\hline Turbine Size (kW) & Approx. Rotor Radius $(\mathbf{m})$ & Required Clearance $\mathbf{( m )}$ \\
\hline 2.5 & 2.2 & 17.20 \\
\hline 5 & 3.1 & 18.10 \\
\hline 10 & 4.4 & 19.40 \\
\hline 20 & 6.2 & 21.20 \\
\hline 50 & 9.8 & 24.80 \\
\hline 100 & 13.8 & 28.80 \\
\hline 250 & 21.9 & 36.90 \\
\hline 500 & 30.9 & 45.90 \\
\hline 750 & 37.8 & 52.80 \\
\hline 1,000 & 43.7 & 58.70 \\
\hline 1,500 & 53.5 & 68.50 \\
\hline
\end{tabular}




\section{B5. Distributed Wind Costs}

This section describes the process used to develop the turbine capital cost used in dGen. Our goal is to assess the current costs of distributed wind turbines and develop reasonable cost extrapolations for those areas in which we do not have sufficient data. Methods used to develop future cost expectations will be released in subsequent publications.

\section{Procedure Summary for Current Installed Costs}

NREL examined several data sets to determine the median installed cost for each size of turbine (rated power) as well as the most common hub heights for each size. We used median costs rather than mean costs to minimize bias caused by data outliers. For each size, this median cost was assumed to apply to the most common hub height for that size. The procedure used to develop the costs is summarized in Figure B-4.

Because our cost data sets do not provide sufficient resolution to determine the marginal cost of taller towers, we consulted with tower wholesalers, distributed original equipment manufacturers, and project developers for this information. We obtained sufficient data for the small and utility size ranges but collected little data for turbines of $250 \mathrm{~kW}$ to $750 \mathrm{~kW}$. The available data were then used to develop a marginal tower height cost adjustment for each turbine size provided in the model.

To maintain reasonable model run times, dGen offers only a few tower heights (in $10 \mathrm{~m}$ increments). For each turbine size, the tower height range determined from the data was adjusted to fit these increments. The marginal tower height costs were used to develop an estimated installed cost for a turbine using the shortest tower height allowed for each turbine size. We then plotted the installed cost versus the log of the rated power and determined the best fit line, and we used that result to determine the adjusted costs for each turbine size at the minimum tower height used in the model.

For each turbine size, the data used in the model consist of turbine final adjusted installed cost (i.e., the cost for the minimum tower height), the heights available in the model for that size turbine, and the marginal height cost to allow for cost estimates of installations using towers that are taller than the minimum height. 


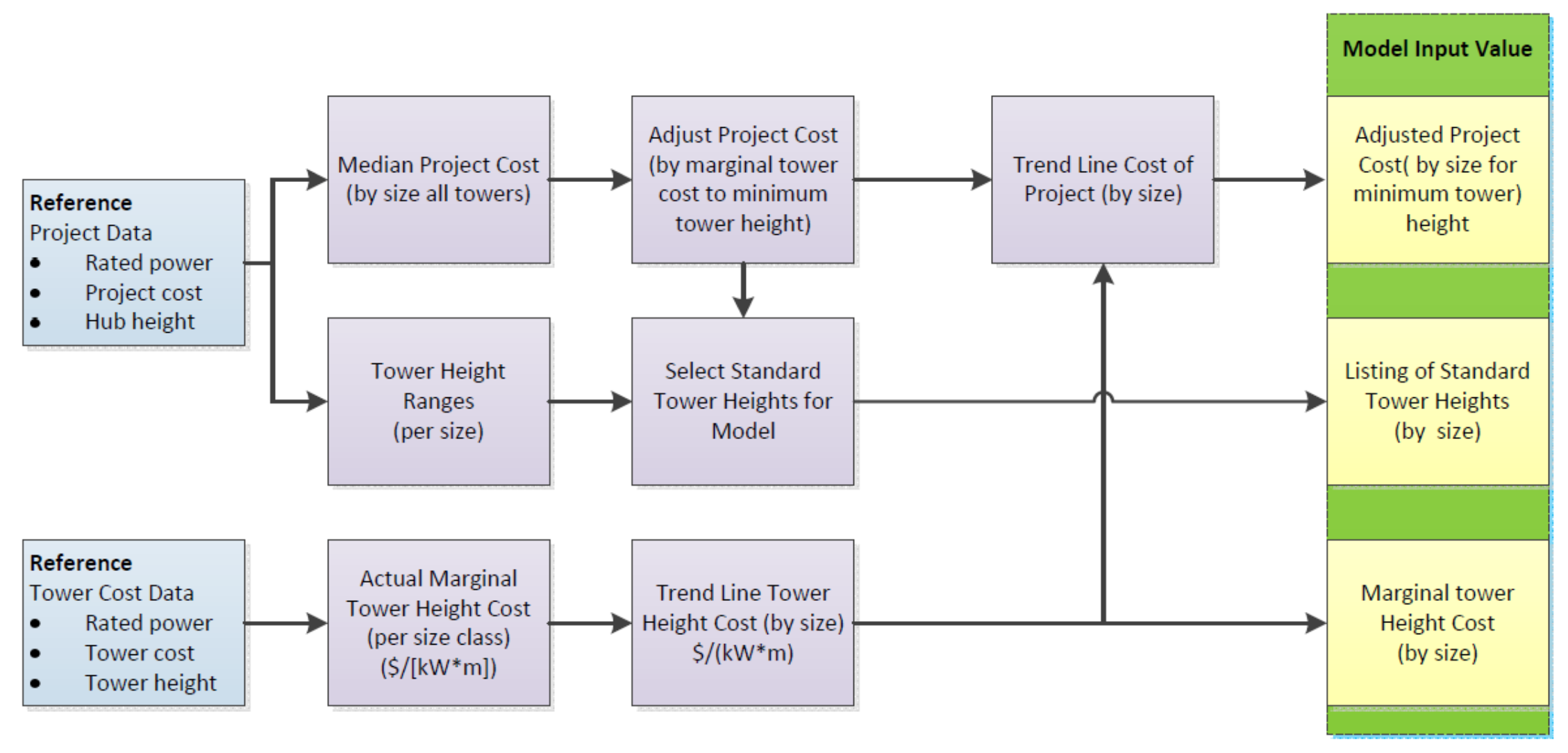

Figure B-4. Procedure for determining installed cost values used for wind in dGen 


\section{Turbine Costs}

NREL based the initial installed costs on the cost data from a non-public database of projectlevel characteristics funded under the U.S. Department of Treasury 1603 program. Though other sources of cost data exist, the 1603 database ultimately proved to be the most comprehensive source of data in a consistent format that we could locate. We used median project costs in developing data for dGen rather than the average costs because (in several cases) the average costs are somewhat skewed as a result of outliers in the respective samples. To verify the costs from the 1603 database, we also cross-validated costs from other sources.

\section{Height as a Function of Rated Power}

To determine the typical range of hub heights for each turbine size class, we analyzed turbine hub height data from the 1603 database and other sources, plotting the data on a histogram. Table B-7 shows the distribution of tower heights for projects using turbines of various rated powers. The table shows some anomalies. For example, $10-\mathrm{kW}$ turbines tend to be on taller towers than $20-\mathrm{kW}$ turbines, and $100-\mathrm{kW}$ turbines tend to be on shorter towers than $50-\mathrm{kW}$ turbines. This discrepancy is not surprising considering the limited number of manufacturers in each size and the limited data set. Because manufacturers informed us they are selling additional sizes in the midsized turbine range, we added those as well. See table B-1 for the final mapping of allowable hub heights for each turbine class.

Table B-7. Number of Projects by Hub Height and Turbine Size Class

\begin{tabular}{|c|c|c|c|c|c|c|c|c|c|c|c|c|c|c|c|c|}
\hline & \multicolumn{16}{|c|}{ Hub Height (m) } \\
\hline $\begin{array}{l}\text { Turbine } \\
\text { Size (kW) }\end{array}$ & $\begin{array}{l}9- \\
12\end{array}$ & $\begin{array}{l}14- \\
17\end{array}$ & $\begin{array}{l}18- \\
20\end{array}$ & $\begin{array}{l}21- \\
25\end{array}$ & 30 & 34 & 37 & 43 & 50 & 55 & 60 & 65 & 70 & 75 & 80 & 87 \\
\hline 2.5 & 3 & 15 & 3 & & & & 2 & & & & & & & & & \\
\hline 5 & 1 & & & 1 & 1 & & 1 & & & & & & & & & \\
\hline 10 & & 3 & 1 & 3 & 7 & 2 & 26 & 5 & & & & & & & & \\
\hline 20 & & & 4 & 14 & 11 & 12 & & & & & & & & & & \\
\hline 50 & & & & & 6 & 1 & 5 & 31 & & & & & & & & \\
\hline 100 & & & & & 3 & & 23 & & & & & & & & & \\
\hline 200 & & & & & & & & & 1 & & & & & & & \\
\hline 500 & & & & & & & & & 2 & 1 & & 1 & & & & \\
\hline $750-850$ & & & & & & & & & 1 & 1 & & 1 & & & & \\
\hline $900-1,000$ & & & & & & & & & & 1 & & & & 2 & & \\
\hline $\begin{array}{l}1,500- \\
1,700\end{array}$ & & & & & & & & & & & 2 & & 1 & & 6 & 1 \\
\hline
\end{tabular}




\section{Marginal Tower Height Costs}

In addition to typical hub heights, dGen needs estimates for the marginal cost of taller towers. The project cost data from the various data sets were too scattered or sparse to allow for an accurate determination of how the project cost changes with changes in tower height. So, we contacted various turbine and tower manufacturers to get tower prices for different turbine sizes. The data are most robust for small residential scale (up to $10 \mathrm{~kW}$ ) and large (utility) scale turbines, with limited data available for midsize turbines.

Increasing the tower height also increases other installation costs, such as foundation and erection costs; however, the bulk of the cost difference is associated with the costs of the tower and foundation; installation cost data were not readily available. To get firm numbers, we limited our data collection to tower cost data.

Because the data for the full range of sizes did not fit a log function curve, NREL used a piecewise best fit and adjusted the end points where there were good data. The $5 \mathrm{~kW}$ and $10 \mathrm{~kW}$ towers were based on lattice tower costs because they are the most common in the installed base. The $2.5-\mathrm{kW}$ and $50-\mathrm{kW}$-plus towers were based on monopole towers because they are the most common and increasing in popularity. The results of this adjustment are presented in Table B-8.

Table B-8. Marginal Tower Cost

\begin{tabular}{|c|c|}
\hline Turbine Size (kW) & $\begin{array}{l}\text { Marginal Tower Cost (Best Fit } \\
\text { Line) }\left(\$ /\left[\mathbf{k W}^{*} \mathrm{~m}\right]\right)\end{array}$ \\
\hline 2.5 & 211.0 \\
\hline 5 & 164.0 \\
\hline 10 & 118.0 \\
\hline 20 & 71.0 \\
\hline 50 & 15.7 \\
\hline 100 & 11.3 \\
\hline 250 & 10.8 \\
\hline 500 & 9.9 \\
\hline 750 & 9.0 \\
\hline 1,000 & 8.1 \\
\hline 1,500 & 6.4 \\
\hline
\end{tabular}

\section{Final Cost Data for Model Input}

NREL used the tower-height marginal cost to adjust the project cost data to the minimum tower height for each size. Table B-9 compares the tower height range in data and for use in the model. We then plotted project capital costs versus the log of the turbine size class. The data from $5 \mathrm{~kW}$ to $100 \mathrm{~kW}$ produce a reasonable log curve that smooths the discrepancy in the $20 \mathrm{~kW}$ and $50 \mathrm{~kW}$ cost. The cost per kilowatt of $50 \mathrm{~kW}$ turbines is higher than the cost of $20 \mathrm{~kW}$ turbines. The common $2 \mathrm{~kW}$ turbine models have rotors that are undersized for the given rated power, thus decreasing their cost (on a per- kilowatt basis). In contrast, the common $50 \mathrm{~kW}$ turbine model has an oversized rotor that increases its cost per kilowatt. 
Table B-9. Comparison of Actual Tower Height Ranges to the Ranges used in the Model

\begin{tabular}{|c|c|c|c|c|c|c|c|c|}
\hline \multirow[b]{2}{*}{$\begin{array}{l}\text { Turbine Size } \\
\text { (kW) }\end{array}$} & \multicolumn{3}{|c|}{$\begin{array}{l}\text { Typical Height } \\
\text { Range from Data (m) }\end{array}$} & \multicolumn{5}{|c|}{$\begin{array}{l}\text { Wind Turbine Height Range used in } \\
\text { dGen }(\mathrm{m})\end{array}$} \\
\hline & $\begin{array}{l}\text { Min. } \\
\text { Height }\end{array}$ & $\begin{array}{l}\text { Typical } \\
\text { Height }\end{array}$ & $\begin{array}{l}\text { Max. } \\
\text { Height }\end{array}$ & $\begin{array}{l}\text { Turbine } \\
\text { Height } \\
\text { Option } \\
1 \text { (H1) }\end{array}$ & $\begin{array}{l}\text { Turbine } \\
\text { Height } \\
\text { Option } \\
2 \text { (H2) }\end{array}$ & $\begin{array}{l}\text { Turbine } \\
\text { Height } \\
\text { Option } \\
3 \text { (H3) }\end{array}$ & $\begin{array}{l}\text { Turbine } \\
\text { Height } \\
\text { Option } \\
4 \text { (H4) }\end{array}$ & $\begin{array}{l}\text { Turbine } \\
\text { Height } \\
\text { Option } \\
5 \text { (H5) }\end{array}$ \\
\hline 2.5 & 9 & 14 & 18 & 20 & 30 & & & \\
\hline 5 & 24 & 24 & 37 & & 30 & 40 & & \\
\hline 10 & 30 & 37 & 43 & & 30 & 40 & 50 & \\
\hline 20 & 24 & 30 & 37 & & 30 & 40 & 50 & \\
\hline 50 & 37 & 43 & 43 & & 30 & 40 & 50 & \\
\hline 100 & 30 & 37 & 37 & & & 40 & 50 & \\
\hline 250 & & & & & & & 50 & \\
\hline 500 & & & & & & & 50 & 80 \\
\hline 750 & & & & & & & 50 & 80 \\
\hline 1,000 & & & & & & & & 80 \\
\hline 1,500 & 70 & 80 & 80 & & & & & 80 \\
\hline
\end{tabular}

On the small end of the scale, the costs by size were changing too rapidly to include the $2.5 \mathrm{~kW}$ size class in the trend line. In some cases in which we had good data, we used the actual data versus a trend line. Because the 1603 cost data for the $1,500 \mathrm{~kW}$ size class were already lower than the data from other sources, and the trend line would reduce them further, we used the actual data. The final default values for current installed cost are presented in Table B-10. 
Table B-10. Final Adjusted Turbine Costs

\begin{tabular}{|l|l|l|l|l|}
\hline $\begin{array}{l}\text { Turbine Size } \\
(\mathbf{k W})\end{array}$ & $\begin{array}{l}\text { Turbine Rated } \\
\text { Power }(\mathbf{k W})\end{array}$ & $\begin{array}{l}\text { Adjusted Cost } \\
\mathbf{( \$ / \mathbf { W } )}\end{array}$ & $\begin{array}{l}\text { Installed Cost } \\
\mathbf{( \$ )}\end{array}$ & $\begin{array}{l}\text { Min/Max Hub } \\
\text { Height }(\mathbf{m})\end{array}$ \\
\hline $2.4-2.5$ & 2.5 & 10,045 & 25,113 & $20 / 40$ \\
\hline 5 & 5 & 7,785 & 38,925 & $30 / 40$ \\
\hline 10 & 10 & 6,914 & 69,145 & $30 / 40$ \\
\hline 20 & 20 & 6,459 & 129,186 & $30 / 50$ \\
\hline 50 & 50 & 5,858 & 292,879 & $30 / 50$ \\
\hline 100 & 100 & 5,402 & 540,238 & $40 / 50$ \\
\hline 250 & 250 & 3,525 & 881,232 & $50 / 50$ \\
\hline 500 & 500 & 2,961 & $1,480,283$ & $50 / 80$ \\
\hline 750 & 750 & 2,630 & $1,972,827$ & $50 / 80$ \\
\hline 1,000 & 1,000 & 2,396 & $2,396,206$ & $80 / 80$ \\
\hline 1,500 & 1,500 & 2,185 & $3,277,628$ & $80 / 80$ \\
\hline
\end{tabular}

\section{Operation and Maintenance Costs}

Data on the cost of both scheduled (preventative) maintenance and unscheduled (repair) maintenance were gathered from a wide variety of sources, including manufacturers, leasing companies, installers, and consultants. The level of confidence that the data reflect long-term costs varies. Manufacturers have an incentive to be optimistic, and some likely were. Leasing companies and consultants that are estimating future project operating cost are motivated to estimate high. Installers who provide maintenance support are reporting their real costs, so these are likely the most reliable data, but in some cases they reflect experience of turbines that are in the first part of their life. These data may not be representative of the average cost in the later part of a turbine's design life.

Scheduled maintenance cost data are easier to obtain and more reliable because they are not likely to shift significantly over the life of the system. We obtained more scheduled maintenance cost data than unscheduled maintenance cost data, and we have used the data to develop a linear trend line for both types of costs. For each size, we added the value of the scheduled and the unscheduled maintenance costs from the linear trend line (Table B-11, Figure B-5).

Two serious weaknesses in the data may affect the results. First, there are no data for unscheduled maintenance from any source for turbines under $10 \mathrm{~kW}$. Second, the only unscheduled maintenance data for turbines over $660 \mathrm{~kW}$ are a consultant's projection for $1.5 \mathrm{MW}$ turbines. These limitations make it impossible to develop confidence in the accuracy of a linear trend line. There are not enough data points, and the confidence level in each data point varies.

In addition, two transitions could have a significant impact on the results. All turbines above $100 \mathrm{~kW}$ have gearboxes, and most are active-pitch systems. There is a transition region in the $50 \mathrm{~kW}$ to $100 \mathrm{~kW}$ class size in which there are both geared and direct-drive systems, and most turbines under $50 \mathrm{~kW}$ (at least in our samples) are direct drive and have electric brakes and passive yaw. These features reduce maintenance costs. Turbines rated at $2.5 \mathrm{~kW}$ are designed for 
no scheduled maintenance. As a result, these transitions overcome some of the scale effects on maintenance costs; however, we do not have the data required to "tease out" the impacts of these technology-scale transitions. In addition, one turbine manufacturer supplied data on unscheduled maintenance that clearly reflected some design-based reliability issues. We did not use those data and instead used trend line data for that size.

Table B-11. Operation and Maintenance Cost Assumptions

\begin{tabular}{|c|c|c|c|c|}
\hline $\begin{array}{l}\text { Rating } \\
\text { (kW) }\end{array}$ & $\begin{array}{l}\text { Total Maintenance } \\
\text { Trend Line }(\$ / \mathbf{k W})\end{array}$ & $\begin{array}{l}\text { Scheduled } \\
\text { Maintenance }(\$ / k W)\end{array}$ & $\begin{array}{l}\text { Unscheduled } \\
\text { Maintenance }(\$ / k W)\end{array}$ & $\begin{array}{l}\text { Total } \\
\text { Maintenance } \\
\text { (\$/yr) }\end{array}$ \\
\hline 2.5 & 38.94 & 27.64 & 11.30 & 97 \\
\hline 5 & 38.92 & 27.62 & 11.30 & 195 \\
\hline 10 & 38.88 & 27.58 & 11.30 & 389 \\
\hline 20 & 38.80 & 27.50 & 11.30 & 776 \\
\hline 50 & 38.56 & 27.27 & 11.29 & 1,928 \\
\hline 100 & 38.15 & 26.87 & 11.28 & 3,815 \\
\hline 250 & 36.94 & 25.69 & 11.25 & 9,234 \\
\hline 500 & 34.91 & 23.71 & 11.20 & 17,456 \\
\hline 750 & 32.89 & 21.74 & 11.15 & 24,665 \\
\hline 1,000 & 30.86 & 19.76 & 11.10 & 30,862 \\
\hline 1,500 & 26.81 & 15.81 & 11.00 & 40,218 \\
\hline
\end{tabular}

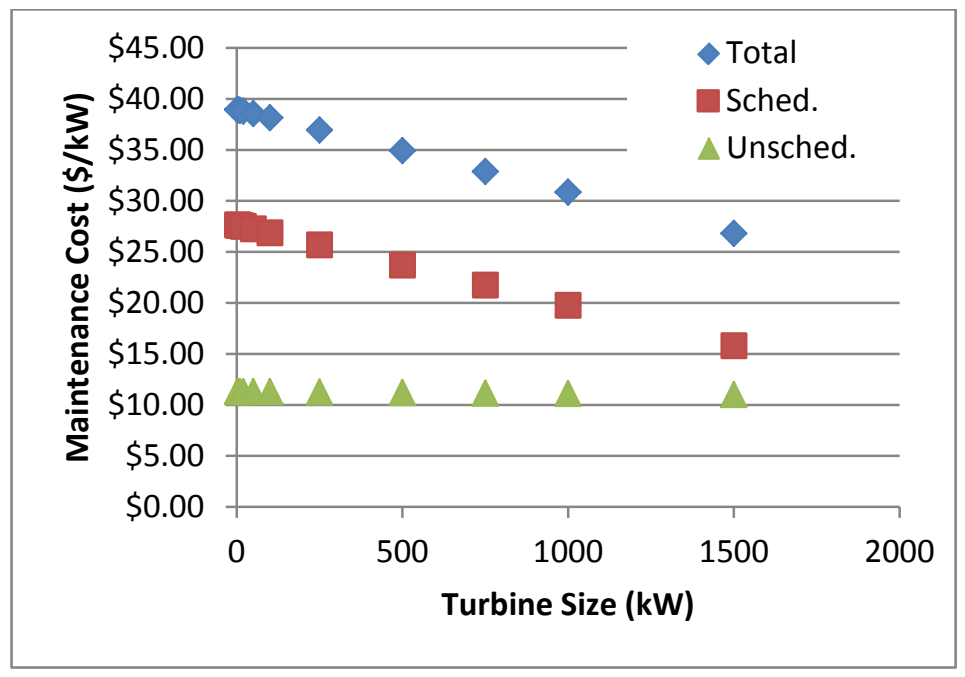

Figure B-5. Wind turbine operation and maintenance cost assumptions by size used in dGen 


\section{Appendix C. Linkage with ReEDS Capacity Expansion Model}

The economics of DERs, particularly PV, have improved rapidly, resulting in acceleration in the amount of capacity deployed. For this reason, there are important implications of increased levels of DER generation for operation of the bulk power system; notably, large-scale adoption may result in revenue loss for utility companies and additional investments in transmission and distribution infrastructure to accommodate these new variable sources of generation (Funkhouser et al. 2015; Satchwell et al. 2015a; Satchwell et al. 2015b). In addition, increased levels of distributed generation will reduce demand for competing sources of generation, such as natural gas or coal-fired generation stations, or other renewable technologies such as utility-scale solar or land-based wind. These issues, coupled with the continuing decline of PV prices and associated increase in installations, prompted us to improve the modeling capabilities to better study the interaction of deployment of rooftop PV on the U.S. electricity system and, in turn, the impacts of the U.S. electricity system on DER deployment. To examine the interaction of DER deployment and the bulk power electricity system, we completed a module that links dGen to NREL's Regional Energy Deployment System (ReEDS) model. This appendix provides a summary of the linkage between dGen and ReEDS; for a more extensive explanation, refer to Cole et al. (forthcoming).

At the time of writing, only the solar portion of dGen (the dSolar module) had been fully linked with the ReEDS model. ReEDS is a utility-side model that makes decisions as a system-wide planner for power plants nationwide based on a least-cost optimization. Because DERs are based on the decisions of individuals and businesses, the ReEDS central planning framework is inappropriate for DER adoption. On the other hand, dGen was specifically designed to model consumer adoption.

The ReEDS capacity expansion model (Short et al. 2011; Sullivan et al. 2015) is an optimization model that assesses the deployment and operation (including transmission) of the electricity sector of the contiguous United States from 2010 through 2050. It emphasizes the integration of renewable energy technologies into the grid. ReEDS represents renewable energy resources using 356 individual resource regions (for concentrating solar power (CSP) and wind resources) and 134 balancing areas (for utility PV, all other generation types, demand, and transmission) across the continental United States (Figure C-1). ReEDS includes explicit representation of key issues related to renewable energy, such as variability and uncertainty in wind and solar output, transmission costs and constraints, and ancillary services requirements. ReEDS also includes a full suite of conventional generating technologies, a reduced-form dispatch that reflects seasonal and diurnal load shapes, an aggregated transmission network, and dynamic natural gas supply curves. The major conventional thermal generating technologies in ReEDS include simple and combined cycle natural gas, several varieties of coal, oil/gas steam, and nuclear power. In addition to modeling conventional generators, ReEDS models geothermal, hydropower, biopower, wind, and solar energy resources. For solar energy technologies, it models central utility PV, distributed utility PV, and CSP with and without thermal energy storage. ReEDS does not explicitly model rooftop PV deployment; instead rooftop PV deployment is specified as an exogenous input in ReEDS. Electricity storage technologies in ReEDS include pumpedhydropower storage, compressed-air energy storage, and sodium-sulfur batteries. 


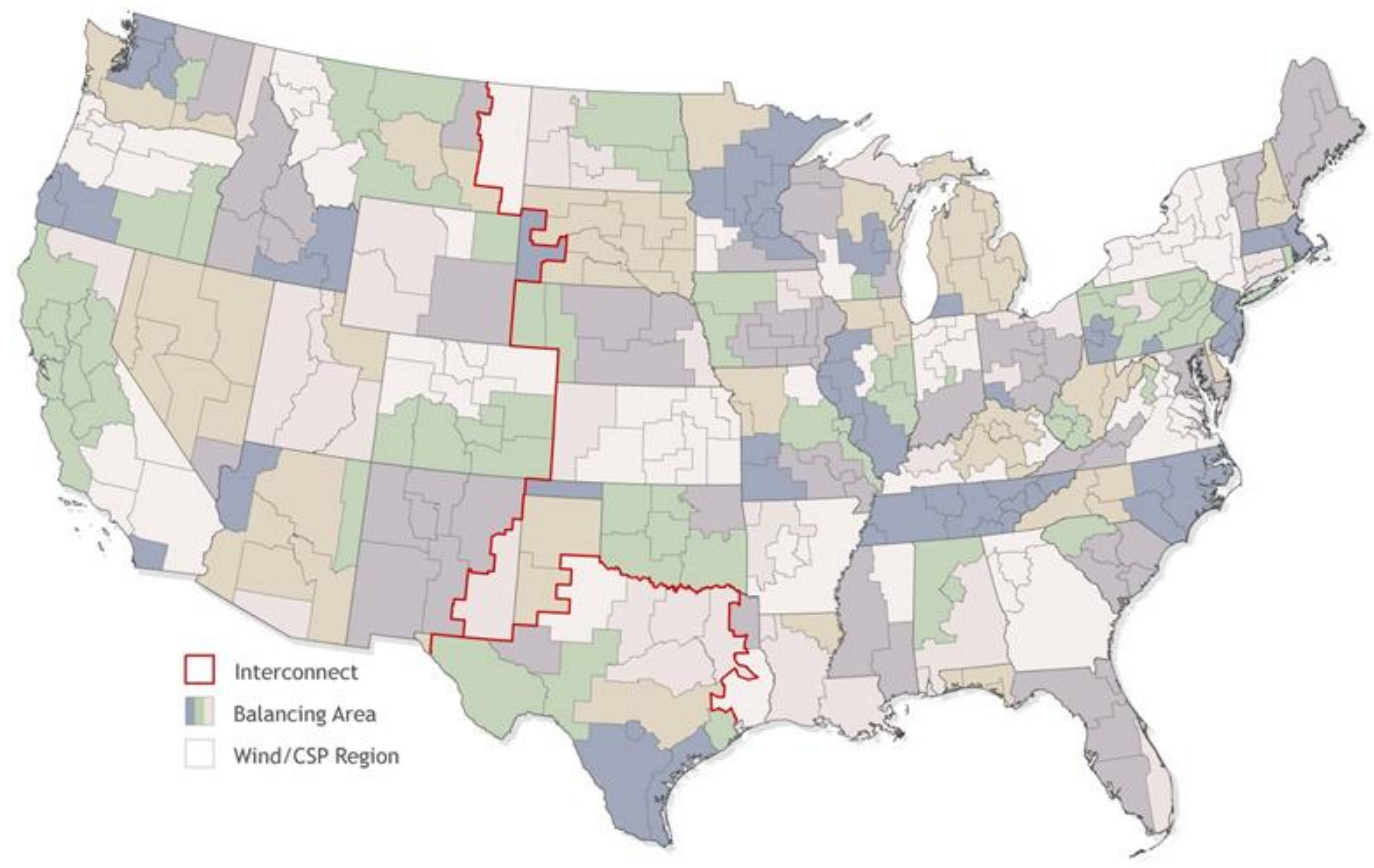

Figure C-1. ReEDS map showing the ReEDS regional structure

ReEDS includes 134 model balancing areas (shaded areas) and 356 wind and CSP resource regions (light gray lines)

The purpose of linking the two models is to harmonize assumptions between the two models so they may be run in tandem. Additionally, though each model may be run independently, the quality of outputs is improved by sharing data and results. ReEDS and dGen are linked as shown in Figure C-2. ${ }^{12}$ In the linked mode, dGen runs before ReEDS in a given year and passes the quantities of installed capacity, capacity factor, and assumed retail electricity prices of adopters to ReEDS. ReEDS uses the installed capacity and capacity factors to determine the amount of generation supplied for each DER technology.

A number of assumptions are harmonized between the models, most prominently, trends in electricity prices. When run independently, both models generate internal estimates of changes in electricity prices. In ReEDS, electricity prices are an output of the cost of building and operating the electrical grid; for dGen, price changes are exogenously set at model launch. When run in tandem, year-to-year changes in electricity prices from ReEDS are fed to dGen. Once ReEDS receives the dGen inputs, it solves the capacity expansion and dispatch problem for the year and returns several parameters to dGen to inform subsequent simulation in dGen. While the number of parameters exchanged between the models is relatively modest, the nature and complexity of linkage will expand over time with increased use.

\footnotetext{
${ }^{12}$ ReEDS solves from 2010 to 2050, while dGen operates from 2014 to 2050; both models function for only the even years. For years prior to 2014, ReEDS uses historical DER deployment in lieu of inputs from dGen.
} 

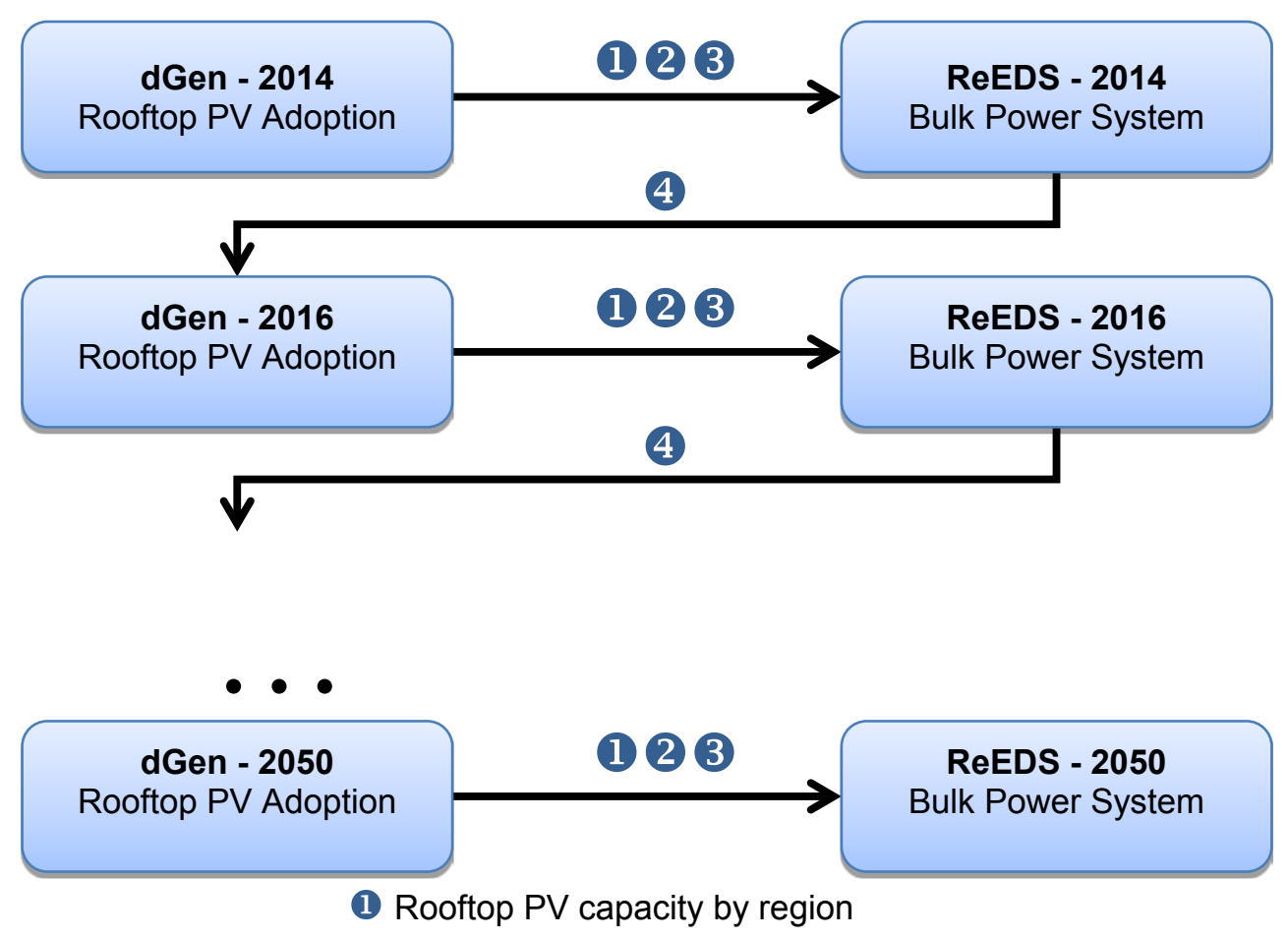

2 Capacity factor by time slice

Figure 3C-2. Schematic of the ReEDS-dGen linkage

dGen passes rooftop PV capacity, capacity factors, and retail electricity prices to ReEDS before each ReEDS solve, and ReEDS returns the rooftop PV marginal curtailment rate for the next dGen year.

A fundamental challenge in modeling PV and other variable renewable resource energy (VRRE) technologies is accurately representing the impact of increasing levels of VRRE sources on bulk power operation. Generally, VRRE sources have been shown to have decreasing value at higher levels of penetration, primarily because of erosion in capacity value (Sigrin et al. 2014; Mills and Wiser 2012). An additional nuance for DERs is that incentives, rate structures, and other market factors specific to the valuation of DER technologies will likely experience changes to accommodate utility revenue loss. We use the marginal curtailment ReEDS calculates as a proxy mechanism for incorporating both types of feedback where, as the penetration of all VRRE (utility scale or distributed-scale) increases, the increasing curtailment levels reduce the attractiveness of subsequent deployment. 
The marginal curtailment rate from ReEDS is calculated for each VRRE technology by determining the amount of additional curtailment induced when adding an (imaginary) $100 \mathrm{MW}$ block; based on the marginal rate for each technology, the gross amount of curtailment is allocated to each technology proportional to the amount of generation in the region. ${ }^{13}$ Thus, ReEDS includes a unique marginal curtailment rate for each VRRE technology in each region. There are currently three methods in dGen for applying the marginal curtailment rate of rooftop PV from ReEDS: ${ }^{14}$ (1) ignore the curtailment rate (no curtailment), (2) apply the curtailment rate only to electricity that is exported to the grid (net curtailment), or (3) apply the curtailment rate to total generated electricity (full curtailment). ${ }^{15}$ The linked model is referred to as the ReEDSdGen model.

\footnotetext{
${ }^{13}$ The methodology used for these marginal curtailment rate calculations is described by Dragoon and Dvortsov (2006), with details on the ReEDS implementation described by Short et al. (2011).

${ }^{14}$ The method is set by the user.

${ }^{15}$ Because of how dGen is structured, the curtailment rate is applied to the bill savings induced from the rooftop $\mathrm{PV}$ system. If the adopter has flat electricity rates, this is equivalent to applying the curtailment rate to the actual electricity production. In the case of other rate structures, this method approximates what would happen if actual electricity production were curtailed.
} 


\section{Appendix D. Calibrated Bass Parameters}

Diffusion in dGen is simulated using a modified Bass model, which is governed by four parameters: $P$ - the coefficient of innovation, $Q$ - the coefficient of imitation, $T$ - the number of years the technology has existed on market, and $M$ - the maximum market share (penetration). Previously, the model has relied on Bass parameters that don't vary by state and were sourced from literature i.e. Paidipati et al 2008, NEMS 2004, etc. An alternative approach is to estimate parameters directly from market data based on a time series of technology deployment to determine the market penetration. Table D-1 summarizes the parameter estimates of the $\mathrm{p}$ and $\mathrm{q}$ parameters for the distributed PV market; Table D-2 shows parameters for each state. Data was compiled using 2015 EIA counts of DGPV interconnection records and Census records of singlefamily detached households and business counts to determine the market penetration of distributed PV (EIA 2015b, Ventyx 2012). While the data is specific to DGPV, barring better data, the values could reasonably be assumed for other technologies. The implied number of years until the technology reaches $90 \%$ of its terminal penetration (i.e. $90 \%$ of $\mathrm{M}$ ) is also shown for the reader's convenience.

Table D-1. Summary of Calibrated Bass Parameters

\begin{tabular}{|l|l|l|l|}
\hline & $\begin{array}{l}\text { P } \\
\text { (median } \pm \text { std) }\end{array}$ & $\mathbf{Q}$ & Years to 90\% penetration \\
\hline Non-Residential & $4.5 \mathrm{e}-5 \pm 9.6 \mathrm{e}-4$ & $0.24 \pm 0.19$ & $45.6 \pm 24.0$ \\
\hline Residential & $7.1 \mathrm{e}-6 \pm 1.4 \mathrm{e}-3$ & $0.36 \pm 0.19$ & $37.1 \pm 23.1$ \\
\hline
\end{tabular}

Table D-2. State-Specific Calibrated Bass Parameters

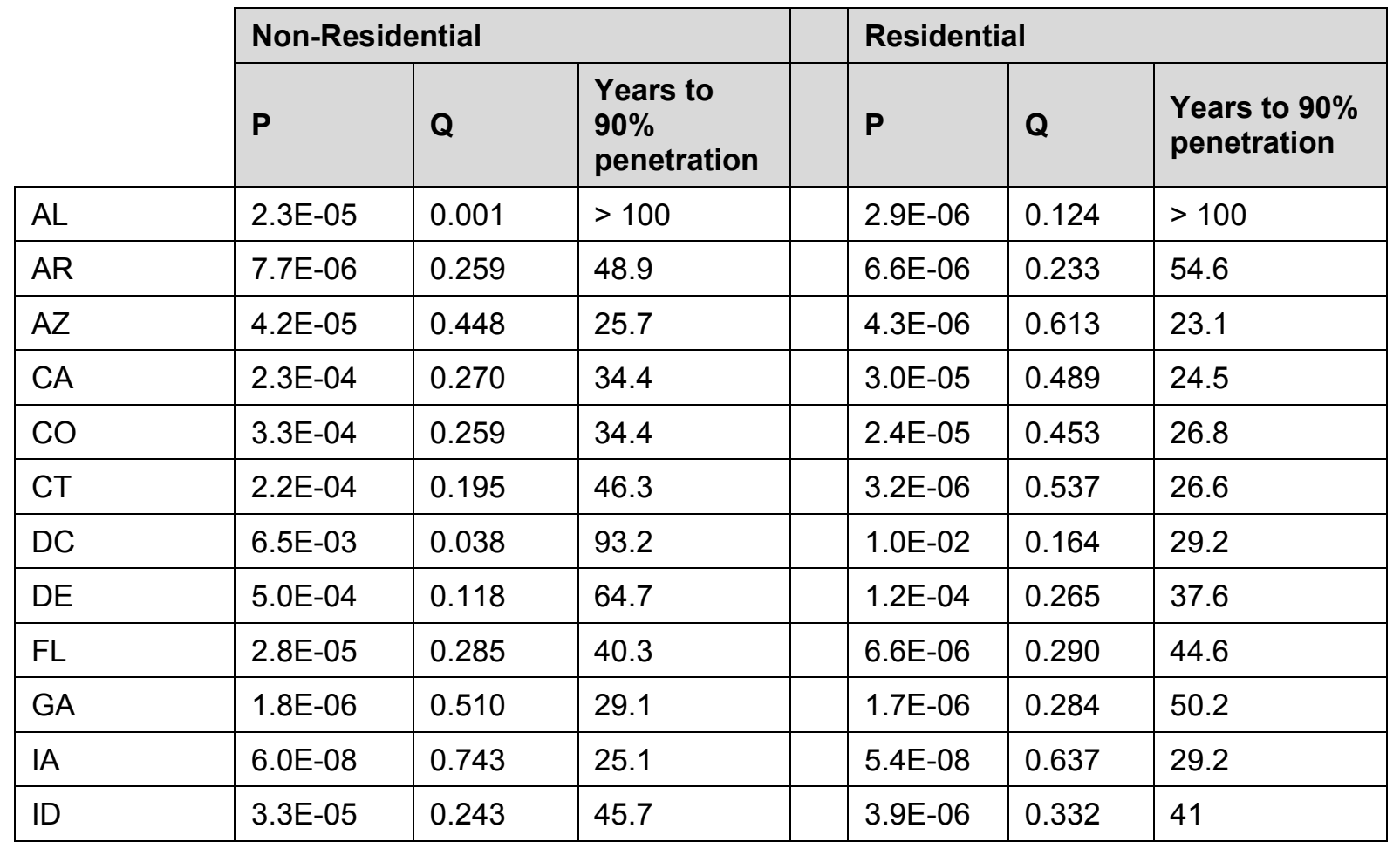




\begin{tabular}{|c|c|c|c|c|c|c|}
\hline & \multicolumn{3}{|c|}{ Non-Residential } & \multicolumn{3}{|c|}{ Residential } \\
\hline & $\mathbf{P}$ & $\mathbf{Q}$ & $\begin{array}{l}\text { Years to } \\
90 \% \\
\text { penetration }\end{array}$ & $\mathbf{P}$ & $\mathbf{Q}$ & $\begin{array}{l}\text { Years to } 90 \% \\
\text { penetration }\end{array}$ \\
\hline $\mathrm{IL}$ & 2.6E-05 & 0.185 & 60 & 8.7E-06 & 0.156 & 77 \\
\hline IN & 2.8E-05 & 0.194 & 56.9 & 7.4E-07 & 0.387 & 39.8 \\
\hline $\mathrm{KS}$ & $1.5 \mathrm{E}-04$ & 0.161 & 56.8 & 3.6E-05 & 0.540 & 22 \\
\hline $\mathrm{KY}$ & 1.1E-05 & 0.238 & 51.6 & 8.0E-06 & 0.224 & 55.7 \\
\hline LA & 7.4E-05 & 0.744 & 15.5 & 6.3E-04 & 0.608 & 15.1 \\
\hline MA & 1.6E-05 & 0.509 & 24.9 & 3.6E-07 & 0.777 & 21.8 \\
\hline MD & $9.8 \mathrm{E}-05$ & 0.330 & 31.4 & 2.4E-06 & 0.576 & 25.4 \\
\hline ME & 2.1E-03 & 0.325 & 22.3 & 5.9E-04 & 0.525 & 17.3 \\
\hline $\mathrm{Ml}$ & 4.4E-05 & 0.200 & 53.4 & 7.1E-06 & 0.239 & 53 \\
\hline $\mathrm{MN}$ & $5.5 \mathrm{E}-06$ & 0.438 & 31 & $1.4 \mathrm{E}-06$ & 0.398 & 37.2 \\
\hline MO & 1.6E-06 & 0.776 & 19.9 & 1.7E-06 & 0.661 & 22.9 \\
\hline MS & 6.0E-08 & 0.001 & $>100$ & $5.4 \mathrm{E}-08$ & 0.004 & $>100$ \\
\hline MT & 7.2E-04 & 0.095 & 74.3 & 1.4E-04 & 0.195 & 48.6 \\
\hline $\mathrm{NC}$ & 1.0E-06 & 0.512 & 30.1 & 1.2E-07 & 0.695 & 25.7 \\
\hline ND & 3.5E-05 & 0.004 & $>100$ & 8.6E-05 & 0.004 & $>100$ \\
\hline $\mathrm{NE}$ & 5.6E-05 & 0.170 & 60.1 & 3.0E-05 & 0.364 & 32 \\
\hline $\mathrm{NH}$ & 1.6E-04 & 0.299 & 32.7 & 1.3E-05 & 0.417 & 30.3 \\
\hline NJ & 3.9E-04 & 0.273 & 32.2 & 4.9E-05 & 0.403 & 28 \\
\hline NM & 1.7E-05 & 0.534 & 23.7 & 3.2E-06 & 0.533 & 26.8 \\
\hline NV & 6.0E-04 & 0.133 & 57.1 & 7.7E-07 & 0.663 & 24.1 \\
\hline NY & 2.2E-05 & 0.518 & 23.8 & 3.5E-07 & 0.739 & 22.8 \\
\hline $\mathrm{OH}$ & 1.1E-04 & 0.106 & 85.6 & 6.2E-06 & 0.251 & 51.1 \\
\hline OK & 2.4E-05 & 0.322 & 36.5 & 5.4E-05 & 0.329 & 33.3 \\
\hline OR & 1.8E-04 & 0.293 & 32.8 & 4.4E-05 & 0.344 & 32.6 \\
\hline $\mathrm{PA}$ & 5.2E-04 & 0.121 & 63.1 & 2.0E-04 & 0.123 & 69.7 \\
\hline $\mathrm{RI}$ & 1.8E-04 & 0.239 & 39.5 & 1.2E-05 & 0.297 & 41.6 \\
\hline SC & 3.9E-07 & 0.508 & 32.2 & 5.0E-07 & 0.429 & 37.1 \\
\hline SD & 7.1E-05 & 0.094 & $>100$ & 2.1E-05 & 0.267 & 43.8 \\
\hline $\mathrm{TN}$ & $6.4 \mathrm{E}-05$ & 0.214 & 48.4 & 2.9E-06 & 0.367 & 38.1 \\
\hline $\mathrm{TX}$ & 1.7E-06 & 0.505 & 29.5 & 6.2E-08 & 0.648 & 28.5 \\
\hline UT & 1.8E-05 & 0.492 & 25.3 & 3.7E-07 & 0.649 & 25.7 \\
\hline VA & 4.5E-05 & 0.197 & 53.9 & 1.1E-05 & 0.274 & 45.1 \\
\hline
\end{tabular}




\begin{tabular}{|c|c|c|c|c|c|c|}
\hline & \multicolumn{3}{|c|}{ Non-Residential } & \multicolumn{3}{|c|}{ Residential } \\
\hline & $\mathbf{P}$ & $\mathbf{Q}$ & $\begin{array}{l}\text { Years to } \\
\mathbf{9 0 \%} \\
\text { penetration }\end{array}$ & $\mathbf{P}$ & $\mathbf{Q}$ & $\begin{array}{l}\text { Years to } 90 \% \\
\text { penetration }\end{array}$ \\
\hline VT & $1.2 \mathrm{E}-04$ & 0.369 & 27.9 & 5.0E-05 & 0.418 & 27 \\
\hline WA & 4.1E-05 & 0.198 & 54.1 & 9.6E-06 & 0.330 & 38.5 \\
\hline WI & $6.5 \mathrm{E}-05$ & 0.205 & 50.1 & 1.1E-05 & 0.231 & 52.9 \\
\hline WV & 2.3E-04 & 0.001 & $>100$ & 2.7E-04 & 0.123 & 67.5 \\
\hline WY & 6.9E-04 & 0.169 & 45.6 & 5.9E-06 & 0.314 & 41.8 \\
\hline
\end{tabular}

